Florida International University FIU Digital Commons

\title{
Hazard Mitigation Element Quality in Coastal Comprehensive Plans in a State with Strong Requirements for Hazard Mitigation Plan Elements
}

Evelio E. Astray-Caneda III

Florida International University, rickyaciii@yahoo.com

DOI: $10.25148 /$ etd.FI13042214

Follow this and additional works at: https://digitalcommons.fiu.edu/etd

\section{Recommended Citation}

Astray-Caneda, Evelio E. III, "Hazard Mitigation Element Quality in Coastal Comprehensive Plans in a State with Strong Requirements for Hazard Mitigation Plan Elements" (2013). FIU Electronic Theses and Dissertations. 843.

https://digitalcommons.fiu.edu/etd/843 


\section{FLORIDA INTERNATIONAL UNIVERSITY}

Miami, Florida

\section{HAZARD MITIGATION ELEMENT QUALITY IN COASTAL COMPREHENSIVE PLANS IN A STATE WITH STRONG REQUIREMENTS FOR HAZARD MITIGATION PLAN ELEMENTS}

A dissertation submitted in partial fulfillment of the requirements for the degree of DOCTORATE OF PHILOSOPHY in PUBLIC AFFAIRS

by

Evelio Enrique Astray-Caneda III

2013 
To: Dean Kenneth G. Furton

College of Arts and Sciences

This dissertation, written by Evelio Enrique Astray-Caneda III, and entitled Hazard Mitigation Element Quality in Coastal Comprehensive Plans in a State with Strong Requirements for Hazard Mitigation Plan Elements, having been approved in respect to style and intellectual content, is referred to you for judgment.

We have read this dissertation and recommend that it be approved.

$\begin{array}{r}\text { Nazife Emel Ganapati } \\ \hline \text { Milena Neshkova } \\ \hline \text { Hugh Gladwin } \\ \hline \text { Howard Frank, Major Professor }\end{array}$

Date of Defense: March 25, 2013

The dissertation of Evelio Enrique Astray-Caneda III is approved.

Dean Kenneth G. Furton College of Arts and Sciences

Dean Lakshmi N. Reddi University Graduate School

Florida International University, 2013 
(C) Copyright 2013 by Evelio Enrique Astray-Caneda III

All rights reserved. 


\section{DEDICATION}

This dissertation is dedicated in memory of my uncle, Bill Kwalick, who always made my siblings and I support our assertions and answer the question, "Why?" Without him, I would have found neither the curiosity, nor passion, to delve so deeply into a topic. This dissertation is dedicated in honor of my parents, Vivian and Rick, who gave me the education I need to be effective in research, my career, and volunteerism. This work would not be possible without my mother's dedication to homeschooling her children among many lessons, she taught us to write well - for that, I will always be grateful. 


\section{ACKNOWLEDGMENTS}

I wish to thank those who have guided and supported me - I promise to take all that you have done to make my education and this research possible, and use both to help others. Dr. Howard Frank was especially helpful in guiding me through the process, and helping to create a research design and dissertation format that will benefit both academics and practitioners. Dr. N. Emel Ganapati's advice and guidance in navigating the fledgling hazard mitigation field was most appreciated. The guidance of Drs. Milena Neshkova and Hugh Gladwin toward an effective research design was critical. Dr. Allan Rosenbaum's support of my decision to complete this research while living away from Miami and pursuing a demanding career is much appreciated. Finally, I owe much thanks to Liga Replogle for her guidance and support in this process.

I could not have done this without my family. Many thanks to my parents, Rick and Vivian, and siblings, Vivi, Luis, Tony, and Vinnie, for patiently picking me up from airports, taking forms for signatures, and each teaching me your individual tokens of knowledge about, "...life, the universe, and everything." Much thanks to my aunt Tere your insights about human nature and interactions have helped me to work effectively with others.

I also owe a great deal of thanks to my friends. Mobruka, thank you for being by my side no matter how many miles separated us, and encouraging me to cut down any obstacles in my way. Skip, thank you for helping me laugh about others, and of course, myself - you keep me grounded. Finally, Stephanie, thank you for being my rock, and my confidant on many nights of venting over a whisky. 


\title{
ABSTRACT OF THE DISSERTATION \\ HAZARD MITIGATION ELEMENT QUALITY IN COASTAL COMPREHENSIVE PLANS IN A STATE WITH STRONG REQUIREMENTS FOR HAZARD MITIGATION PLAN ELEMENTS
}

\author{
by \\ Evelio Enrique Astray-Caneda III \\ Florida International University, 2013 \\ Miami, Florida \\ Professor Howard Frank, Major Professor
}

This dissertation examines the quality of hazard mitigation elements in a coastal, hazard prone state. I answer two questions. First, in a state with a strong mandate for hazard mitigation elements in comprehensive plans, does plan quality differ among county governments? Second, if such variation exists, what drives this variation? My research focuses primarily on Florida's 35 coastal counties, which are all at risk for hurricane and flood hazards, and all fall under Florida's mandate to have a comprehensive plan that includes a hazard mitigation element. Research methods included document review to rate the hazard mitigation elements of all 35 coastal county plans and subsequent analysis against demographic and hazard history factors. Following this, I conducted an electronic, nationwide survey of planning professionals and academics, informed by interviews of planning leaders in Florida counties.

I found that hazard mitigation element quality varied widely among the 35 Florida coastal counties, but were close to a normal distribution. No plans were of exceptionally high quality. Overall, historical hazard effects did not correlate with hazard mitigation 
element quality, but some demographic variables that are associated with urban populations did.

The variance in hazard mitigation element quality indicates that while state law may mandate, and even prescribe, hazard mitigation in local comprehensive plans, not all plans will result in equal, or even adequate, protection for people. Furthermore, the mixed correlations with demographic variables representing social and disaster vulnerability shows that, at least at the county level, vulnerability to hazards does not have a strong effect on hazard mitigation element quality.

From a theory perspective, my research is significant because it compares assumptions about vulnerability based on hazard history and demographics to plan quality. The only vulnerability-related variables that appeared to correlate, and at that mildly so, with hazard mitigation element quality, were those typically representing more urban areas. In terms of the theory of Neo-Institutionalism and theories related to learning organizations, my research shows that planning departments appear to have set norms and rules of operating that preclude both significant public involvement and learning from prior hazard events. 


\section{TABLE OF CONTENTS}

CHAPTER

PAGE

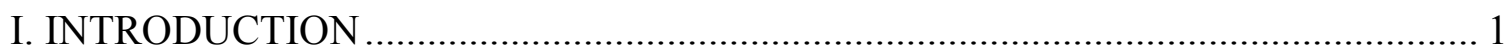

Vulnerability of the Population of the Coastal United States ........................................ 3

Flood and Hurricane Mitigation in the United States ............................................ 3

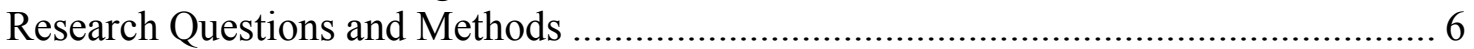

Summary of Research Findings and Contribution to Literature .................................. 8

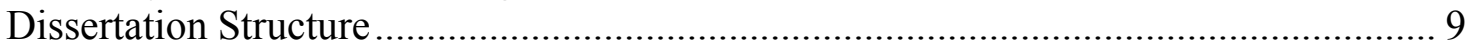

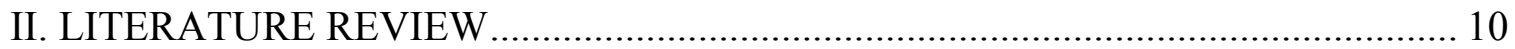

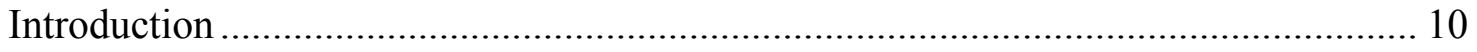

Hazard mitigation: Preventing Disasters and Reducing Their Effects......................... 11

Comprehensive Planning for Hazard Mitigation: A Form of Non-Structural

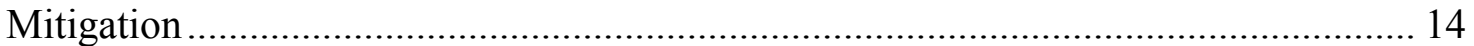

Intrastate Implementation of Hazard Mitigation Requirements in Comprehensive Plans:

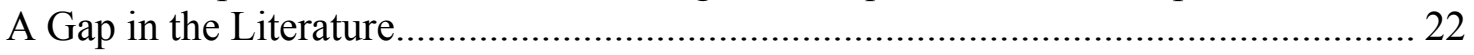

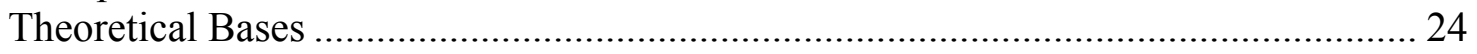

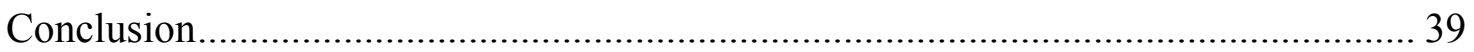

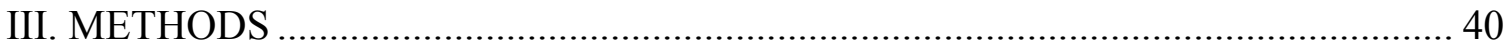

Review of Hazard Mitigation Elements and Demographic and Historical Analysis .... 40

Survey of Planning Professionals and Academics ................................................. 48

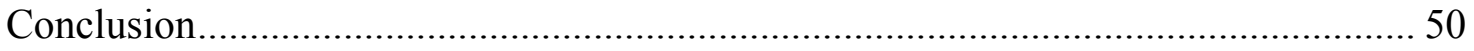

IV. QUALITY OF HAZARD-MITIGATION ELEMENTS...................................... 51

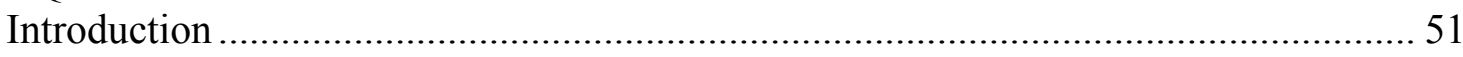

Comprehensive Plan Conceptualization............................................................. 51

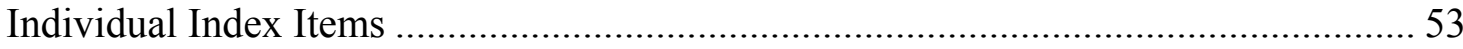

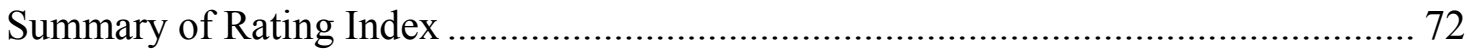

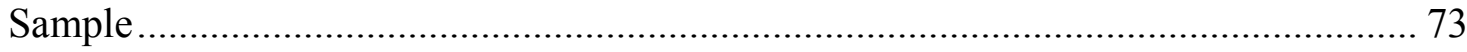

Overall Summary ............................................................................................. 77

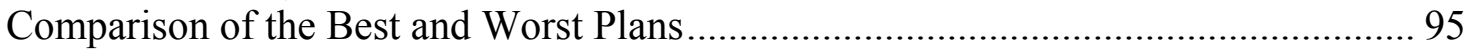

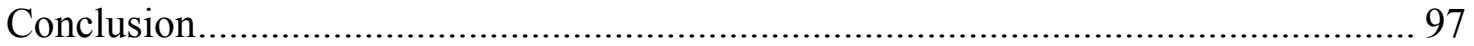

V. SURVEYS: EXPLAINING VARIATION IN QUALITY OF HAZARD

MITIGATION ELEMENTS IN LOCAL COMPREHENSIVE PLANS ...................... 101

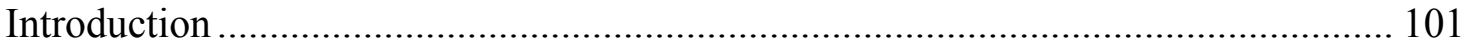

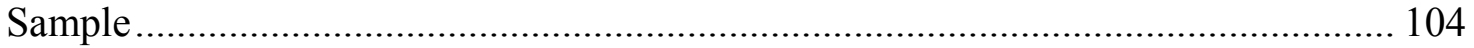

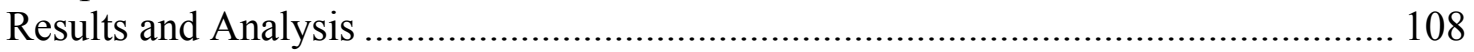

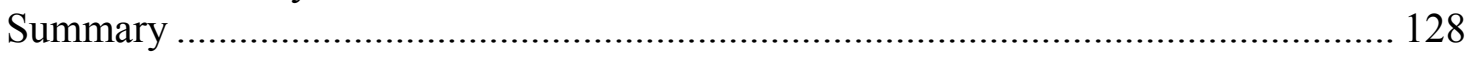

VI. FINDINGS, LIMITATIONS, IMPLICATIONS, AND FUTURE DIRECTIONS.. 130

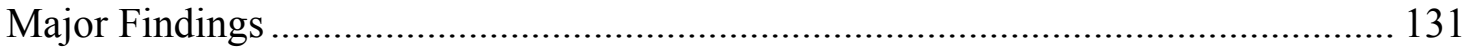




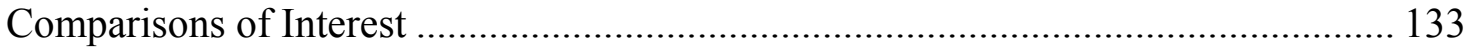

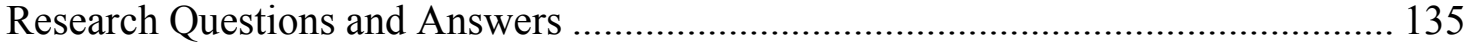

Lost Opportunities: Two Disconnects in the Process of Planning for Hazard

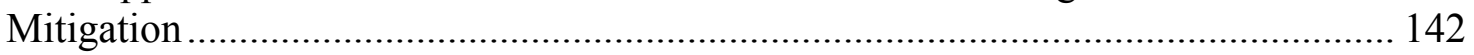

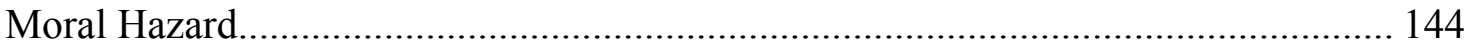

Implications for the Theories of Vulnerability and Neo-Institutionalism................. 145

Merging What Professionals Say with What Governments Do .............................. 152

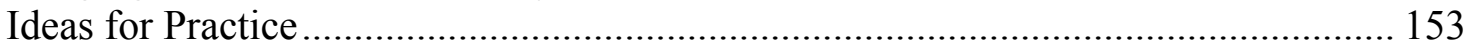

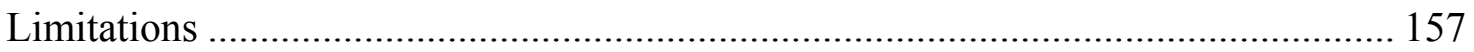

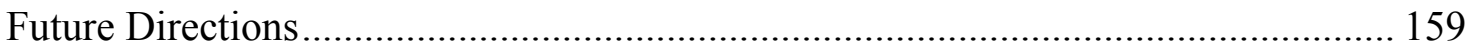

Conclusion: The Role of the Public in Planning for Hazard Mitigation ..................... 160

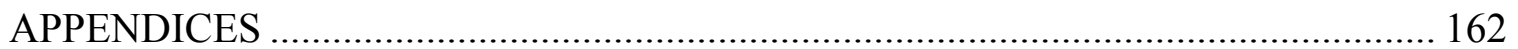

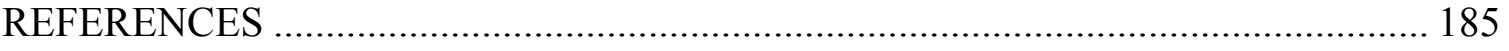

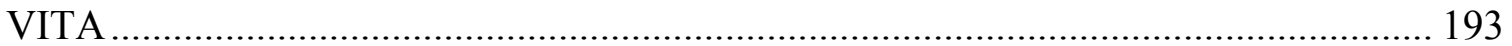




\section{LIST OF TABLES}

TABLE

PAGE

Table 1: Top three and bottom three plan rating factors as rated by professional planners 45

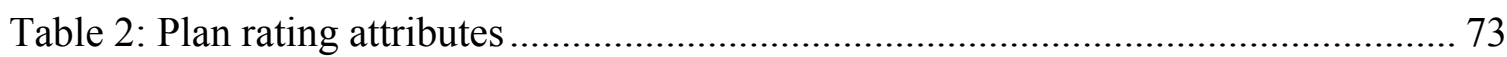

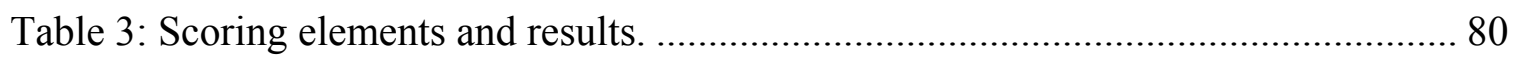

Table 4: Regions and counties used in this study ................................................... 81

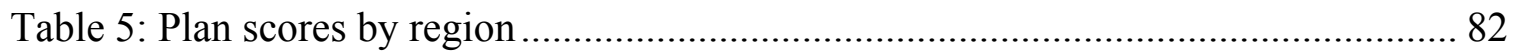

Table 6: Correlations of demographic variables and hazard mitigation element

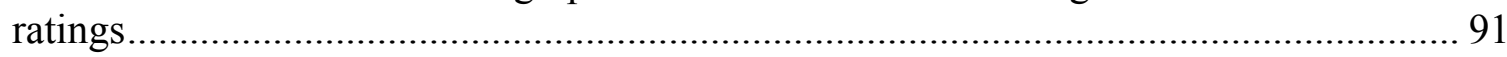

Table 7: Survey responses by contact group..................................................... 105

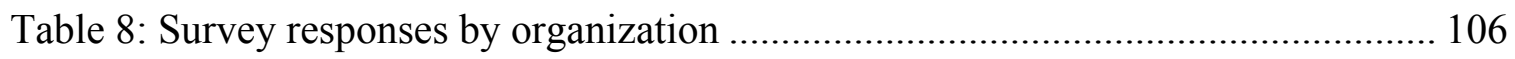

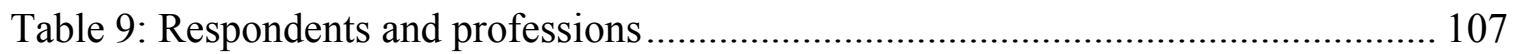

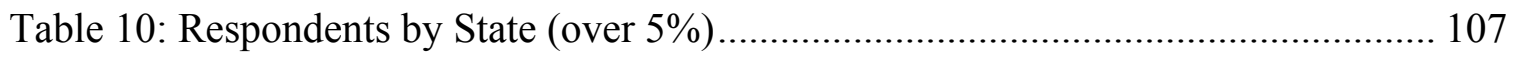

Table 11: Value of various components of hazard mitigation elements in comprehensive plans

Table 12: Differences between groups on importance of specific components in hazard mitigation elements

Table 13: Importance of using the vulnerability concept 113

Table 14: Differences between groups on use of the vulnerability concept in planning 113

Table 15: Ideas for improving hazard mitigation planning for vulnerable populations . 114

Table 16: Additional characteristics respondents said are in important in hazard mitigation elements of land use plans 115

Table 17: Importance of professional qualifications and activities 116

Table 18: How coordination is perceived to effect hazard mitigation element quality .. 118 
Table 19: Relationship between socio-economic factors and plan quality 119

Table 20: Average importance of socio-economic factors by profession 120

Table 21: Relationship between support of elected officials and plan quality 121

Table 22: Average importance of elected official involvement by profession 122

Table 23: Importance of community participation in hazard mitigation planning 123

Table 24: Perceived effect of state windstorm rates on quality of hazard mitigation elements

Table 25: Average importance of socio-economic factors by profession 125

Table 26: Additional characteristics respondents report contribute to quality of hazard mitigation elements in comprehensive plans. 126

Table 27: Perceived effect of benchmarking hazard mitigation elements..... 127

Table 28: suggested actions for governments to improve hazard mitigation elements . 156

Table 29: Summary of land use planning officials interviewed 162

Table 30: Select responses to Question 1 163

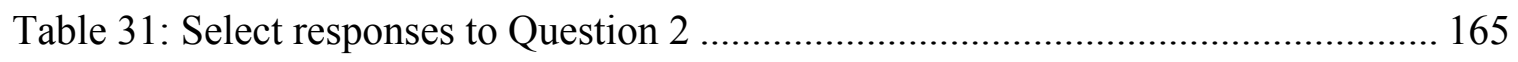

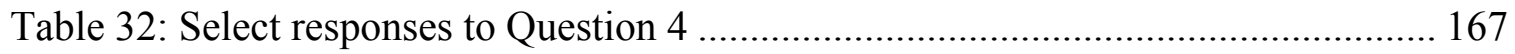

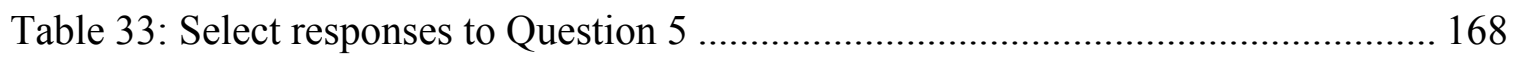

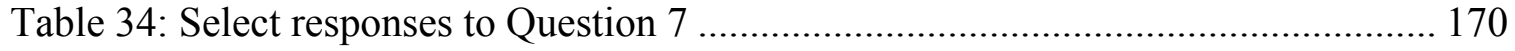

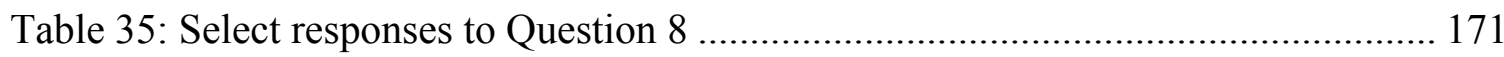

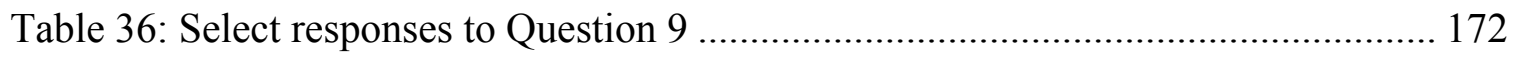

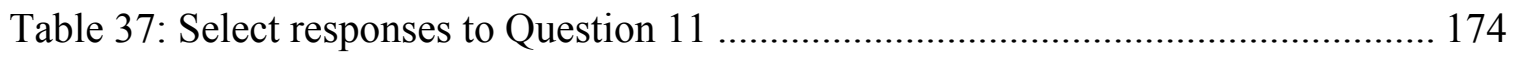

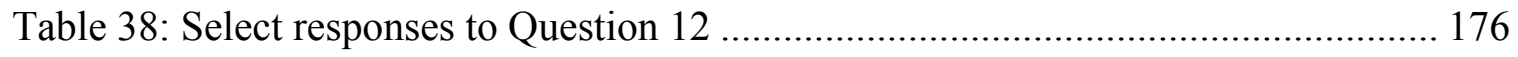

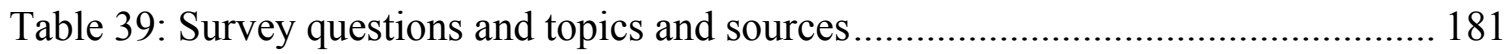

Table 40: Regression on plan quality - full model................................................ 183 


\section{INTRODUCTION}

Policymakers and public administrators are increasingly being called upon to design and implement measures for natural hazard mitigation. While structural improvements, such as building dams and wind-resistant homes, have led to a reduction in deaths attributed to natural hazards, people continue to live in places prone to natural hazards. Consequently, hundreds of thousands of people perish in disaster events every year. For example, an earthquake struck Haiti on January 12, 2010, taking an estimated 222,570 lives, injuring countless others in ways that will forever impair their ability to earn a living, and affecting an estimated 3.7 million people in total (Université Catholique de Louvain, 2010). The Indian Ocean tsunami of December 25, 2004, took the lives of 181,516 and displaced 1.6 million from their homes in countries including Indonesia, Thailand, and Sri Lanka (Jennings, 2005).

Deaths attributed to natural hazards are neither limited to less developed countries nor the distant past. For example, in 2005, Hurricane Katrina struck the Louisiana coast in the United States; the disaster took the lives of 1,464 people (Knabb, Rhome, \& Brown, 2006; Louisiana Department of Health and Hospitals, 2006). In fact, while more developed countries bear a lower proportion of disaster deaths, they tend to bear the most significant portion of disaster-related expenses. For example, examination of disasters with counts of more than 1,000 deaths and/or costs of US \$1 billion from 1977 through 1996 alone reveals that $12.6 \%$ of deaths occurred in the "developed world," but $82 \%$ of damage costs were attributed to developed regions (Alexander, 1997). Further, damages and deaths from natural disasters are increasing, not so much because more hazards are occurring, but because populations in hazard areas are growing in number and size, and 
value of property in the areas these populations occupy are increasing, as wealthier people seek homes in more "exotic" and "natural" locales (Comfort, 2006; Quarantelli, 2003; Turner, 1979). Figure 1, below, shows the growth in worldwide damage costs as measured in U.S. Dollars over time (Université Catholique de Louvain, 2011). As population continues to increase in hazard zones, mitigation through structural and policy measures must be strengthened in order to prevent disasters and stem losses of life and property when they do occur (Kapucu, 2008; Pielke Jr., et al., 2008).

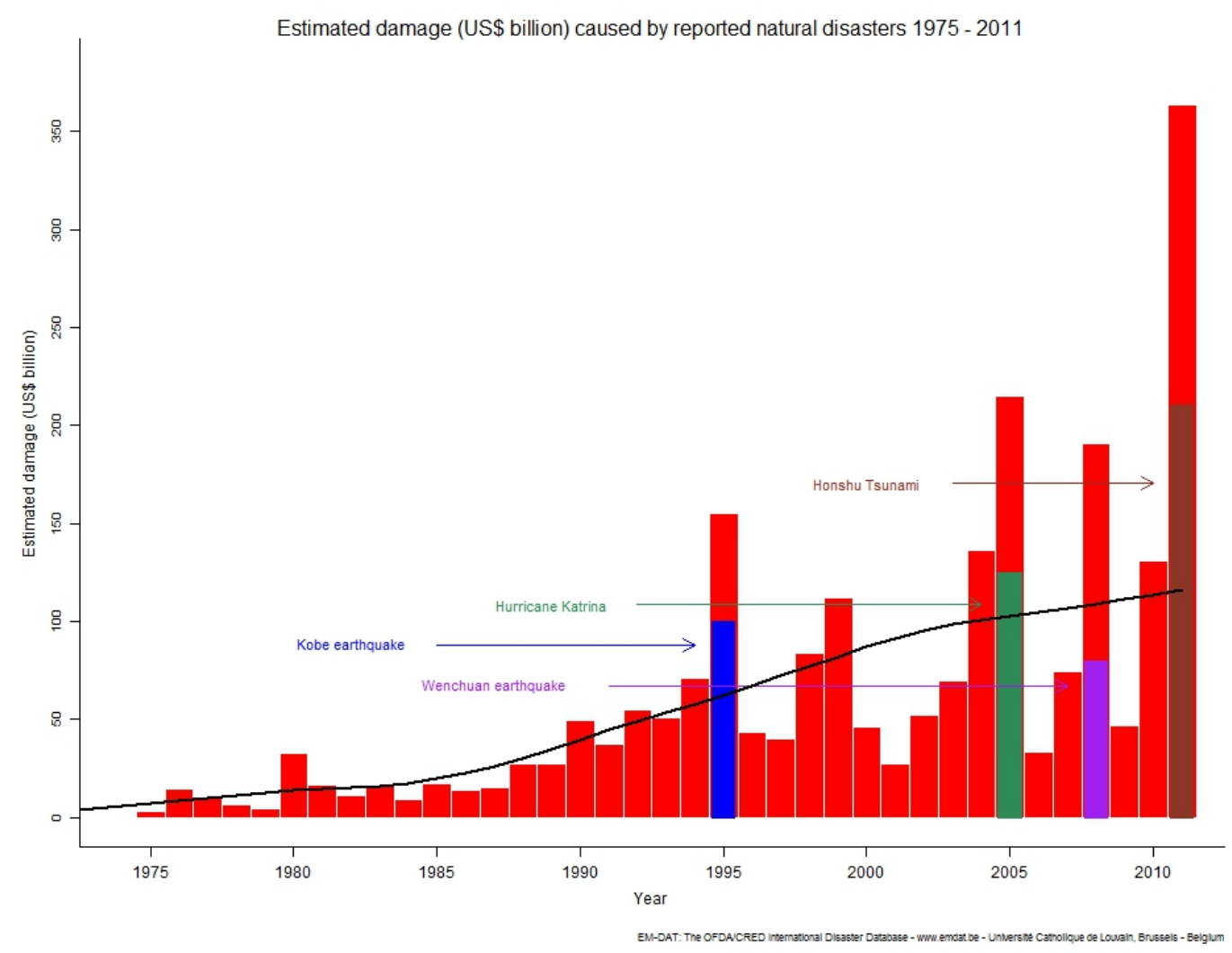

Figure 1: Natural disaster damages in billions of U.S. Dollars (courtesy of EM-DAT) 
Vulnerability of the Population of the Coastal United States

In $2007,53 \%$ of the U.S. population lived in coastal hazard zones, and the population in these areas continues to grow (Association of State Floodplain Managers, 2007). As more people move toward desirable coastal regions, increasing numbers of people and amounts of property are exposed to hazards. Significantly, hazard vulnerability increases as more people move into areas at risk for disasters and modify the environment. Activities such as paving over permeable surfaces that can absorb floodwaters, and removing mangrove forests that can buffer coasts from storms, increases hazard vulnerability (Brody, Highfield, Ryu, \& Spanel-Weber, 2007; Skertchly \& Skertchley, 2001; Wahlstrom, 2007; Wisner, Blaikie, Cannon, \& Davis, 2004). One of the first authors to remark on the conflict between development and nature was Gilbert White, who in 1937 noted that the effect of built structures such as “... bridges, highways, buildings, levees..." on existing stream channels was to increase floods. Concordant with the problem of growing population in coastal areas, homes near coasts tend to be of high value compared to others, and thus financial risk is increasing disproportionately to population.

Flood and Hurricane Mitigation in the United States

In order to prevent disasters, people engage in mitigation - both individually and in communities. Simply put, mitigation consists of policies and practices that reduce vulnerability to disaster and thus reduce disaster impacts on people and property (Gerber, 2007; Henstra \& McBean, 2005). Mitigation is a critical strategy to address natural hazards and significantly reduce disaster deaths and injuries; typically, for every $\$ 1.00$ 
invested in mitigation, an estimated $\$ 7.00$ of post-disaster spending is saved (Wahlstrom, 2007; Zahran, Brody, Peacock, Vedlitz, \& Grover, 2008). Mitigation, while historically utilized on a limited scale, is a relatively new idea for wide-scale application, especially at the local level. Until a few decades ago, the primary method of dealing with disasters was simply to respond, and then for insurers and governments to step in and help people to "recover" by rebuilding again in the path of a disaster. Today, the focus has changed to policies and practices that consider natural hazards, and try to bolster human settlement against them, or to move human settlement out of harm's way (Henstra \& McBean, 2005). However, the extent to which individual communities practice mitigation is in question. This is one of the important elements for my research.

While structural measures (engineering projects) have helped somewhat, they have generally failed to eliminate disasters (Vatsa, 2004), and can, in fact, worsen disasters (Quarantelli, 2003). Structural measures are critical to prevent disasters, but when a hazard exceeds the capacity of structural mitigation, the consequences may actually be worsened by those engineering measures. These measures connote safety and encourage people to live in dangerous areas, thereby causing more people to be vulnerable in the event of an engineering failure (Berke \& Campanella, 2006; Brody S. D., et al., 2007; Burby R. J., 2006; Burby, et al., 1999; Burby \& Dalton, 1994; Highfield \& Brody, 2006; Nelson \& French, 2002). For example, Hurricane Katrina showed that engineered structures thought to protect people can be completely overwhelmed by a disaster - and the consequences could be grave.

The failure of structural mitigation to fully address natural hazards has led to a need to also pursue non-structural measures (Vatsa, 2004). Non-structural mitigation 
addresses the threats of hazards through programs and policy, often complemented by structural mitigation (engineered measures). The National Flood Insurance Program (NFIP) is an example of non-structural mitigation (Brody S. D., et al., 2007). Communities in flood-prone areas receive a rating from the NFIP on the basis of their flood risk, and then citizens within those communities are offered flood insurance at a price commensurate with their risk level. Communities can earn higher ratings that lower insurance premiums by taking certain actions and implementing policies that reduce their exposure to flood hazards. Essentially, people are financially rewarded for taking mitigatory actions.

Comprehensive planning, the research focus of this dissertation, can incorporate non-structural measures to both enhance and, in some cases, replace structural mitigation. Comprehensive planning provides a unique opportunity to make policies that protect people and property by a) applying building and land use codes appropriate to individual areas based on hazard exposure, b) prohibiting development in areas where structural and land use measures cannot sufficiently protect the population, and c) balancing the two scenarios through risk-based decision-making.

While statistically rigorous studies are lacking, there appears to be a correlation between the use of comprehensive plans to mitigate hazards and a reduction in disaster losses. For example, recent research comparing flood insurance claims in Florida and Texas over 24 years (1978-2002) has shown that for every 1,000 persons, Florida had one insurance claim for flood damage, while in Texas the number was 21 . In monetary terms, this translated to $\$ 71$ per capita in Florida, but $\$ 325$ in Texas (Burby R. J., 2006). Essentially, not only did Florida have fewer losses per resident, but the losses were of 
lower cost. The difference between the two states is that Florida requires hazard mitigation elements in local comprehensive plans, while Texas does not.

\section{Research Questions and Methods}

Comprehensive planning offer communities many opportunities to mitigate against hazards - from addressing economic development, to bettering transit, improving education, strengthening against hazards, and employing other creative tools. My research examines the ability of comprehensive planning to improve hazard mitigation; I investigate how counties fare in terms of comprehensive planning for hazard mitigation under state laws requiring that these counties have such plans. While prior research has shown that states with these requirements have lower losses as a whole (all counties combined) to natural hazards, the unique contribution of my research is that it ascertains how individual counties within such a state fare in terms of hazard mitigation element quality. This research seeks to answer the following two questions:

1. In a state with a strong mandate for hazard mitigation elements in comprehensive plans, does plan quality differ among county governments?

2. If such variation exists, what drives this variation?

Using a combination of methods, I collected data and answered the above questions. I selected the methods based on the formative nature of my research, and these methods will help pave the way for future work to study the effects of planning mandates regarding hazard mitigation. My research employed the following methods: 
1. Document Review and Demographic and Historical Analysis - I reviewed the hazard mitigation elements of all 35 coastal Florida counties and rated each on a 24 item scale (which was created based on the literature findings). I used data from this review to answer the question regarding variation in plan quality and to provide a dependent variable for some of the analyses regarding drivers of quality. I utilized U.S. Census data and historical hurricane strike data as independent variables in regression analyses to ascertain if they correlate with hazard mitigation element quality.

2. Electronic Survey - I conducted an electronic survey of persons professionally involved with hazard mitigation and disasters. I used the survey to ascertain what factors these experts believe correspond to quality planning for hazard mitigation in comprehensive plans. I sent the survey to all of the planning staff in Florida counties, as well as to persons known to be involved in disaster practice and research. Additionally, responders could forward the survey link to others they knew might be interested in participating. I developed survey questions using extant literature, practice, and interviews of four comprehensive planning leaders in Florida county governments. I used the interviews to explore what these managers believe are good practices for incorporating hazard mitigation elements into local comprehensive plans, how they address the hazard mitigation element in their counties, and what they believe makes a quality hazard mitigation element. 


\section{Summary of Research Findings and Contribution to Literature}

Rating the plans of the 35 coastal counties revealed that there is a great degree of variation in the quality of hazard mitigation elements across counties, despite stringent state laws, regulations, and guidelines requiring and describing these elements. This variation in hazard mitigation element quality is, alone, an important research finding, because it indicates that even when a state is highly prescriptive in its instructions to local government to build hazard mitigation into local comprehensive plans, quality is not assured, and some localities will have better plans than others. This finding of variation provides a very important avenue for future research consideration.

The question of what drives variation in plan quality is answered to a degree, but further research is also warranted. Hazard mitigation element quality was not correlated with historical hazard strikes, but was correlated mildly with some social vulnerability variables that also tend to correlate with urban areas. While demographic variables representing social vulnerability were not strong drivers of hazard mitigation element quality, their effects may be mediated by the urbanity and rurality of counties.

The findings of my research are significant for state level policymakers because these findings indicate that state regulations designed to create quality hazard mitigation elements at the local level are not achieving the desired objectives in Florida, and potentially other states. My research also reveals that hazard mitigation element quality is tied neither to demographic factors (including wealth) nor hazard history. Finally, my research reveals what many professionals and researchers in the hazard mitigation and disasters fields believe contributes to higher hazard mitigation element quality. 
Governments can use this information to further improve hazard mitigation elements in comprehensive plans.

\section{Dissertation Structure}

This dissertation is structured in such a way that it supports formative exploration of topics related to hazard mitigation in Comprehensive Planning. The dissertation begins with a literature review to help define the problem and questions and create research methods. Following that, the methods section presents the research methods, including a detailed list of concepts utilized in rating the hazard mitigation elements. The subsequent chapters discuss the results of the plan review and demographic analysis and the survey results. The dissertation concludes with the major findings, limitations of the study, and future research directions. 


\title{
II. LITERATURE REVIEW
}

\author{
Introduction
}

Comprehensive planning, amongst achieving other goals, is an effective means to prepare communities for natural hazards and to mitigate against those hazards. It provides an opportunity to bring together hazard information, physical information about the community, development planning, public input, and planner technical expertise and experience to address potential effects of natural hazards in communities. Ten states require that local governments prepare comprehensive plans addressing natural hazards. Extant research has shown that in states with such a requirement, losses due to natural hazards are lower than in states without them. However, few studies, and none recently, have examined what drives the quality of hazard mitigation elements at the local level in states with a requirement to address hazard mitigation in comprehensive plans. My research fills that gap.

The research conducted for this dissertation is derived from theories of Vulnerability and Neo-Institutionalism. Under Vulnerability Theory, people are considered prone to varying levels of disaster on the basis of factors existing before a hazard strikes. To reduce disasters, these factors can be addressed to lessen hazard impacts. Neo-Institutionalism provides a framework to examine planning organizations. Under Neo-Institutionalism, planning institutions are considered to be constructed from the roles, rules, and norms that collectively influence the actions and behaviors of institutional members - in this case, planners. 
Hazard mitigation: Preventing Disasters and Reducing Their Effects

Mitigation, in terms of hazards and disasters, consists of collective policies and practices that reduce vulnerability to disasters and subsequent disaster impacts on people and property (Gerber, 2007; Henstra \& McBean, 2005). So, for example, a county facing a frequent rain hazard might install a storm drainage system to allow rainwater to flow off more readily and thus mitigate the rain hazard by preventing water from accumulating and becoming a flood disaster. For a non-structural solution, the county might offer building incentives to construct homes in less hazard-exposed areas. Overall, mitigation is a critical strategy to significantly reduce disaster deaths and injuries; research findings indicate that for every $\$ 1.00$ invested in mitigation an estimated $\$ 7.00$ in post-disaster spending is saved (Wahlstrom, 2007; Zahran, et al., 2008).

From the flood control mechanisms of the ancient Middle-East, to modern designs allowing buildings to sway in earthquakes, people have focused primarily on structural mitigation of natural hazards for millennia. Regrettably, while structural measures have helped somewhat, they have generally failed to eliminate disasters (Vatsa, 2004). Historically, structural mitigation has been problematic in the United States. While engineered structures can do well to protect an area from known disaster events, when a hazard exceeds the capacity of structural mitigation, complete catastrophe can ensue (Berke \& Campanella, 2006; Burby, et al., 1999; Burby \& Dalton, 1994; Burby R. J., 2006; Highfield \& Brody, 2006). The Hurricane Katrina example in New Orleans, discussed below, is an example of the failure of structural mitigation to prevent a disaster.

One failure of structural mitigation is that it can encourage people to live in areas not truly safe for human habitation and thus increase human exposure to hazards that may 
ensue when structural methods fail to prevent a disaster (Burby R. J., 2006; Brody S. D., et al., 2007; Wisner, et al., 2004). For example, Hurricane Katrina showed that, even in a post-industrial and technocratic society with strong capabilities in engineering, structural measures are not always effective. Since these structural means connote safety, populations increase in disaster-prone areas under a false sense of safety implied by the structural measures, and thus more people are put in the path of hazards. In the Katrina example, this problem started following the Mississippi River flood of 1927, when the U.S. government engaged in a massive program to control floods in zones around the Mississippi River (Austin, 2006). The flood protection structures were originally designed to keep the New Orleans area dry. Although they functioned well for many years, when Hurricane Katrina brought water levels exceeding design capacities, the structural system was overwhelmed, and areas previously thought to be safe because of structural measures were deluged with water. In what Burby (2006) terms the "Safe Development Paradox," the federal government's efforts to make the New Orleans area safer increased exposure to natural hazards by attracting people to the area. Although the city was safe under normal circumstances, it became a disaster-zone when flood waters exceeded capabilities of the structural mitigation measures. In summary, structural mitigation can make areas that would have otherwise remained undeveloped due to apparent risks, open to human habitation, but when these measures fail, disaster can ensue (Glavovic, Saunders, \& Becker, 2010).

Compounding the failures of engineering measures to actually keep people safe, and the aforementioned Safe Development Paradox presented by engineering measures that attract people to unsafe areas, there is the issue of "moral hazard." Often, 
governments (typically federal) provide financial assistance over and over to people who are victims of repeat disasters, without considering the more cost effective option of requiring those people to relocate (or deny more government aid following future disasters). The practice of providing aid to people who are victims of repeated losses, while not requiring them to leave hazard zones, is referred to as "moral hazard." Comprehensive planning provides an opportunity to address moral hazard by a) reducing densities in hazard zones; b) requiring stronger building codes in hazard zones; and c) putting post-disaster analysis and planning into place that will help relocate people from zones where repeat losses are occurring, or at least identify these zones so that adjustments to insurance rates and government aid policies can be made.

The failure of structural mitigation to fully address natural hazards has led to a need to also pursue non-structural measures (Vatsa, 2004). Non-structural mitigation addresses the threats of hazards without directly using engineering and built measures, but rather through programs and policy. The National Flood Insurance Program (NFIP) is an example of non-structural mitigation (Brody S. D., et al., 2007). Communities in flood-prone areas receive a rating from the NFIP based on their flood risk, and then citizens within those communities are offered flood insurance at a price based, in part, on the risk level. Communities can earn higher ratings which lower insurance premiums by taking certain actions and implementing policies that reduce their exposure to flood hazards. Essentially, people are financially rewarded for taking mitigatory actions. Note that non-structural mitigation might lead to structural measures (for example, incentive programs offering people lower insurance rates for bolstering homes against hurricanes, etc.) and can be used intentionally in conjunction with structural measures. 
Comprehensive planning, the research focus of my dissertation, can incorporate non-structural measures to both enhance and replace structural mitigation. Comprehensive planning provides a unique opportunity to make policies that protect people and property by a) creating building and land use codes appropriate to individual areas based on hazard exposure, b) prohibiting development in areas where structural and land use measures cannot sufficiently protect the population, and c) balancing the two scenarios through risk-based decision-making.

Comprehensive Planning for Hazard Mitigation: A Form of Non-Structural Mitigation Comprehensive planning, and the included component of land use planning, is an excellent means of reducing risk and vulnerability to natural hazards - especially hurricanes and floods, which can be modeled and predicted better than many other disasters, such as tornadoes and earthquakes (Burby, et al., 1999; Burby \& Dalton, 1994; Henstra \& McBean, 2005; Highfield \& Brody, 2006; Quarantelli, 2003; Sengezer \& Koc, 2005; U.S. National Committee for the Decade for Natural Disaster Reduction, 1991). Comprehensive planning is an ideal setting for hazard mitigation elements in comparison to stand alone hazard mitigation plans because the comprehensive plan weaves together multiple elements (e.g., transportation, housing, education, economic development, etc.) to address community issues (Godschalk, Brody, \& Burby, 2003). While it is a given that communities of today are faced with old, new, and changing risks, the challenge is to be aware of them and manage them to reduce vulnerability (Comfort, 2006). Comprehensive planning provides a mechanism to focus on this, and also gives the opportunity for experts (in this case, planners) to apply their knowledge to target people at risk and to 
manipulate conditions in ways that support hazard mitigation (Hewitt, 1995). It can bring together non-structural information and techniques such as hazard information, data on capacity/resilience, evacuation information, and incentive programs, in concert with structural techniques, to reduce hazard exposure.

The comprehensive plan (CP) serves not just planning needs, but is interrelated with local government activities across the disaster management cycle (Mitigation $\rightarrow$ Preparedness $\rightarrow$ Response $\rightarrow$ Recovery). While the CP is often discussed in terms of mitigation, and more specifically mitigation related to land use, there are much broader implications in terms of both inputs into the plan and outputs from it.

The CP should achieve certain mitigation objectives primarily related to land use, but it also must support other mitigation activities for the local government, and in turn cannot be an effective tool without input from government units outside of the Planning Department. Examples of the how the CP can help other government departments achieve their mitigation objectives include: regulating development so that nature is allowed to flourish as needed to protect against hazards (something that also might involve a local Department of Environmental Resources); establishing hazard zones and publishing maps of these zones, allowing Building and Zoning departments to set up and enforce effective building codes; and limiting development in hazard zones so that the Public Works department does not have to build infrastructure in risky places. Conversely, to effectively formulate the $\mathrm{CP}$, the Planning Department relies on effective information from other departments. For example, planners might need to know from the Environmental Resources Department the density of a particular foliage required to prevent soil erosion, so that the Planning Department can effectively regulate housing 
density in areas where that foliage is present. In another example, the Planning Department may need to know the maximum height a building can be safely built in a particular wind zone (from the Building Department), in order to zone for the maximum safe height in hazard areas.

From a preparedness and response perspective, the CP must both serve the response needs of various departments, and in turn integrate information from them to meet preparedness and response goals specific to comprehensive planning. In designing the $\mathrm{CP}$, planners must work with departments responsible for preparedness and response to ensure that density and transportation infrastructure are appropriately matched to the ability of these departments to evacuate people prior to the onset of a hazard (e.g., ensure that the number of people in a given area does not exceed its capacity to evacuate via planned roads prior to the onset of hurricane force winds). Matching density and transportation to abilities of preparedness and response departments requires working with response departments to discern their evacuation capacity and needs (e.g., when do they anticipate use of contra-flow lanes, what is their capacity to marshal evacuees, etc.). In turn, the $\mathrm{CP}$ should provide these departments with tools needed to effectively prepare and stage a response (density maps, infrastructure capacities, etc.). Similar give and take relationships related to preparedness and response may also be needed with local schools, environmental agencies, transportation departments, communications departments, and others in local government.

Finally, in terms of recovery, the Planning Department must work closely with other departments to analyze what happened when a hazard event occurred and how to build CPs that will rebuild a stronger community. The analysis and planning for a new 
community must often be done quickly after a disaster so that effective rebuilding can begin.

Overall, intergovernmental coordination is critical both for the success of the $\mathrm{CP}$, and the success of other government departments in their hazard mitigation endeavors. It involves all phases of the Disaster Management Cycle. That said, the CP is one of the most important ways to address vulnerability, because it bears the power to bring economic planning, iterative policymaking with public involvement, physical science (e.g., LIDAR data), history, and land use planning together to bear on the problem of reducing the impacts of natural hazards.

A small body of research has looked at both the effectiveness of CPs to mitigate hazards, and the effectiveness of state mandates requiring CPs to address hazard mitigation. While the overall research has shown that both measures are effective, a gap exists in the literature in that a) no one has examined whether or not the quality of hazard mitigation elements varies within states that have a requirement to address hazard mitigation in comprehensive plans, and, if such variation exists, b) what drives the variation is unknown. The gaps in the literature are critical because states may be able to take additional measures to improve local level hazard mitigation elements, and, if so, greater understanding of weaknesses in hazard mitigation elements is needed. My research takes a step toward understanding how to develop/implement improvements in hazard mitigation element quality by identifying drivers of quality of those elements.

Comprehensive planning is especially useful in the hazard mitigation context because it is an iterative method of policymaking with heavy public involvement; plans are generally updated in cycles and new information is considered and included every 
few years (Brody S. D., 2003). This cycle of adaption and revision based on new information is an approach that has the potential to be a highly effective tool for policymaking in a democratic environment, and can be especially useful in the context of natural hazards, in which new information routinely becomes available to planners, and environmental changes can rapidly alter the conditions for which planners must prepare. Because plans are updated in routine cycles, planners have regular opportunities to integrate new information to better serve objectives of hazard mitigation. Furthermore, because hazards tend to strike repeatedly, planners have the opportunity to learn from them and incorporate that learning in plan updates.

Comprehensive planning provides the opportunity to bring a constant focus on reduction of vulnerability to natural hazards, thus creating a routine policy-making cycle that can address natural hazards with a great deal of public input. Comprehensive planning $(\mathrm{CP})$ is a tool that has the capability to bring together the characteristics of individuals, social groups, businesses, geography, hazards, and government in one place to make informed decisions that will reduce vulnerability. The people who suffer from disasters may not even be aware of hazards as a distinct concept, and may not be able to do anything on their own even if aware. However, a $\mathrm{CP}$ factoring in hazard mitigation brings risks to the forefront of attention, and helps to find workable solutions to reduce vulnerability by coordinating actions of all parties and blending their resources to take action to reduce hazard vulnerability.

Comprehensive plans have gained status with policymakers and politicians as vehicles for participatory democracy and as important guides to policymaking - the topic of hazard mitigation is brought to further public focus by making it part of the $\mathrm{CP}$ 
process. Comprehensive plans can both prevent development from occurring in hazard zones, and set standards for site usage and building codes to ensure that construction in non-hazard zones is more resilient to hazards. Furthermore, CPs can go beyond land use and building codes to address underlying social issues (e.g., poverty, race inequity, housing disparities, etc.) that can, if left unattended, increase people's vulnerability to natural hazards (Davis, 2004). Issues can be addressed in an interdisciplinary, connected fashion, in concert with hazard information, and can be used for effective planning to mitigate against hazards. For example, in the case of the threats of coastal hurricanes and flooding, the $\mathrm{CP}$ can inform individuals and businesses of risk; prevent reduction of natural coastal resources that can act as hazard barriers by restricting development in coastal zones; open safer areas to development to satisfy business and housing needs; use planner expertise to define areas of risk and to set building standards based on geophysical risk; address social inequity (and thus contribute to increased resiliency) by improving transportation; improve economic standing of the community through an economic development element; create open space that can absorb some hazard effects, such as open parkland to absorb rainwater; and target resources to improve specific areas of the community (Burby, French, \& Nelson, 1998).

It is important to distinguish between land use plans and CPs in the context of my research. Land use plans are plans for how land is to be used in a community. They reflect current use, and a master plan for the community's growth in the long-term. Because physical location plays a significant role in hazard vulnerability, the land use component of CPs is critical; however, it is just one of many aspects of $\mathrm{CP}$ that can reduce vulnerability to natural hazards (Greenberg, Lahr, \& Mantell, 2007). 
Comprehensive planning provides more opportunities for hazard mitigation than land use planning alone (Burby, et al., 1999; Burby R. J., 2005). It can integrate broad community goals, and can connect hazard mitigation to these goals to make it an integral part of a locality's future. Furthermore, as a process, making a CP normally involves citizen engagement. The process of comprehensive planning provides governments with an opportunity to educate citizens about hazards threatening the community. Finally, comprehensive planning provides opportunities for citizen participation in planning, and may help to build community support for the plan as community members become stakeholders with a feeling of influence on the plan, and thus more likely to support implementation.

State Requirements for Comprehensive Planning in the Natural Hazard Context Historically, the communities doing the most to reduce the vulnerability of their populations to natural hazards have been located in states which require local planning for hazard mitigation (Steinberg \& Burby, 2002). The first state government to require that local CPs pay heed to natural hazards was California in 1973, following the 1971 San Fernando Earthquake (Burby R. J., 2005; Nelson \& French, 2002; Olshansky, 2001). While the state initially applied this requirement only to planning for earthquakes, the requirement was later expanded in 1986 to cover other natural hazards (Burby R. J., 2005). California's hazard mitigation legislation requires consideration of the hazard in a seismic safety element that studies the hazard, and then a response to the hazard using the findings from that element to guide land use plans (Olshansky, 2001). 
Since the 1970s, more states have added hazard mitigation planning to lists of required elements in land use plans. In 1998, the American Planning Association recommended that states require that local CPs address natural hazards. In 2002 the American Planning Association added hazard mitigation language for natural hazards to its model comprehensive plan. Currently, 26 states do not require that local governments prepare CPs, 14 require CPs but do not require a hazard mitigation element, and 10 require both $\mathrm{CPs}$ and a hazard mitigation element; Florida, the state in which my research was conducted, is among the last group (Burby R. J., 2005).

\section{Effectiveness of Planning Mandates}

Prior research has shown that state requirements for hazard mitigation elements in local plans are effective at reducing disaster losses (Deyle \& Smith, 1998). For example, Burby \& Dalton (1994) found that local governments in states with both a mandate for land use planning, and state monitoring and enforcement of the mandate, tended to incorporate limitation of development in hazard zones into their plans $(p<.10)$. Burby (2005) examined disaster losses from 1994 through 2000 in all U.S. states. He found that in the study period, mean losses per capita were $\$ 33.30$ in states with no requirement for CPs, $\$ 26.16$ in states requiring CPs, and $\$ 19.58$ in states requiring CPs with hazard mitigation elements. Notably, the differences between the groups were statistically significant $(p<.001)$.

More recently, Burby compared flood insurance claims in Florida, where hazard mitigation planning is required at the local level, and Texas, where it is not. He found that for every 1,000 persons, Florida had one insurance claim for flood damage from 1978 
through 2002, while in Texas the number was 21. In monetary terms, this translated to $\$ 71$ per capita in Florida, but $\$ 325$ in Texas (2006). Essentially, not only did Florida have fewer losses per resident, but the losses were of lower cost.

Berke \& French (1994) examined six U.S. states, three with mandates for CP with a hazard mitigation element and three without. Rather than looking at hazard impacts, they rated quality of the plans, mainly in hazard mitigation related areas. They found that having a fact base, goals, and policies for addressing natural hazards were all significantly stronger in hazard mitigation mandated states than in non-mandated states.

Intrastate Implementation of Hazard Mitigation Requirements in Comprehensive Plans: A Gap in the Literature

While a fair amount of research has been conducted which examines how states with planning mandates fare in comparison to those without, little has examined how planning mandates affect the quality of hazard mitigation elements at the local level (Deyle \& Smith, 1998). The excellent research (Deyle \& Smith, 1998) that does exist is now over a decade old, and an update is in order. The need to enhance this existing research gives rise to the following two questions, which my research answers:

1. Is there variation in the quality of hazard mitigation elements of local land use plans?

2. What are the factors that explain this variation?

In the late 1990's, Deyle and Smith (1998) examined hazard mitigation elements in 18 Florida coastal county and city CPs. They sought a more in-depth analysis of 
individual plan quality than the analyses conducted in this dissertation, and thus limited their sample to municipalities selected based on history of hurricane strikes, development of coastal areas, and population. In their analysis, they examined 60 categories of compliance with state mandates for each plan, rating each as either in compliance or not in compliance. Each community's "compliance score" consisted of the number of state planning mandates related to hazard mitigation that the community's plan met, divided by the total number of these mandates (essentially, percent complied with). At most, the mean compliance rate on any individual issue was $76.92 \%$ with a standard deviation of $22.65 \%$, indicating wide variation in the level to which plans comply with state mandate. The standard deviation of compliance scores for each individual state mandate graded ranged from a low standard deviation for one measure of 18 to a high of 31 for the most variable measure. This variation indicates that some measures tended to have compliance scores across counties closer to the mean in general, while others varied far more - thus some measures were complied with by more counties than others were. However, while making the significant finding that variation existed, Deyle and Smith did not make a thorough examination of drivers of the variation.

Other existing research has confirmed that even though the state planning mandate works well for Florida, there is significant variation in plan quality at the local level (Deyle \& Smith, 1998; Nelson \& French, 2002). No research, however, has examined what drives this variation. Theoretically, factors external to the state mandate may drive this variation. It is critical to examine what drives quality of hazard mitigation elements, or lack thereof, in order to ascertain what can be done to further improve comprehensive planning for hazard mitigation once state mandates have been put in 
place. My research fills that gap by examining hazard mitigation elements of local CPs in one state.

\section{Theoretical Bases}

Two bodies of theory guide my work. For hazard and disaster researchers, it is critical to frame the question of how people and the environment interact, and how that interaction affects people and their built environment. In order to facilitate such framing, my research is constructed on the perspective of vulnerability - essentially, the idea that a disaster is the effect of a hazard (such as a hurricane) striking a human population which has a degree of susceptibility (a degree of vulnerability) to the hazard, as mitigated by capacity. I conceptualize comprehensive planning as a tool to reduce vulnerability through policy.

Since this work deals primarily with planning institutions and their practices, a theoretical way to make sense of the information regarding these institutions is required. I chose the theory of Neo-Institutionalism, or New Institutionalism, for its recognition of the concept that institutions are growing, changing entities, which both respond to and shape the actors with whom they work.

\section{Vulnerability}

In the 1970s, 1980s, and primarily the 1990s, a new focus on human vulnerability to natural hazards emerged. The focus on vulnerability arose from researchers asking why people in different geographic locations suffered different effects from similar hazards (Alexander, 1997; St. Bernard, 2004; Furedi, 2007; Heijmans, 2004; Oliver- 
Smith, 1996; Turner, 1979; Wisner, et al., 2004; Zahran, et al., 2008). Disasters came to be perceived no longer as "Acts of God" or as events in which humans have no say, but rather, as human constructed situations. In these situations, the hazard may be an uncontrollable element, but various factors of human creation affect the severity of the disaster, including poverty, proximity to hazard-prone areas, and discrimination; the disaster is what results from the hazard strike on a human population (Parasuraman \& Acharya, 2000; Quarantelli, 2003; Turner, 1979). While this idea has gained wider acceptance only recently, it was first introduced by Gilbert White in 1937 when he wrote: Floods are natural phenomena; flood damages are products of human action. With few exceptions, major flood flows result from natural, hydrologic events; and with few exceptions the damages therefore are the price of man's encroachment upon natural floodplains.

Vulnerability is conceptualized as a set of both physical and social circumstances that interact with a naturally occurring hazard to determine the effect of that hazard on a person or group, and the severity of said effect. The effect itself is the disaster, which is aptly measured by “...damage to private property, infrastructure, economic vitality, habitat, productive ecosystems... human death, and injury" (Zahran, et al., 2008). For a given hazard, higher vulnerability will generally result in a more severe disaster, and lower vulnerability, ceterus parabus, will contribute to a less severe disaster.

In terms of natural hazards, vulnerability has been defined in a variety of ways. One simple definition is simply: “...vulnerability to environmental hazards means the potential for loss" (Cutter, Boruff, \& Shirley, 2003). In that vein, Deyle, French, 
Olshansky, and Paterson (1998) offer this broad definition of vulnerability: “...the susceptibility of human settlements to the harmful impacts of natural hazards." Social vulnerability includes both "individual characteristics of people," such as “...age, race, health, income, type of dwelling unit, employment," and "place inequalities," such as “...level of urbanization, growth rates, and economic vitality..." (Galea, Ahern, \& Karpati, 2005). Today, research often defines vulnerability in terms of both social and environmental characteristics in concert (Kusenbach, Simms, \& Tobin, 2010). Critically, researchers usually consider vulnerability in the context of a particular stimulus (e.g., disease, weather, terrorism, etc.) (Galea, et al., 2005).

In the context of comprehensive planning, it is critical to remember that the wealthy and middle class, the majority groups of social systems, and others appearing well resourced, can, in fact, be vulnerable, especially as a consequence of "vulnerability of place" (Hutton \& Haque, 2004; O'Hare \& Rivas, 2005; Vatsa, 2004). For example, regardless of wealth, a person may lack knowledge of natural hazards and may choose to build inappropriate structures in a hazard zone. Typically, vulnerability is thought to be imposed on people, although people may also choose to partake in activities that increase their risk or may be pushed into riskier situations through factors related to vulnerability. So, for example, a poor family may be vulnerable because the family must live in a mountainside favela, or shanty town, as the family can afford no other housing. The location of the favela on a crowded mountainside increases the family's risk of death in a mudslide and from diseases. In summary, it is critical to remember that all people are vulnerable to or are at risk from hazards to some extent; while some may require a greater 
focus because of increased vulnerability and reduced capacity, everyone must be considered.

Resiliency is also a critical concept in the understanding of hazards and disasters, and provides the counterbalance to vulnerability. Across the social and physical sciences, definitions of resiliency nearly unanimously incorporate "an ability to bounce back" in some form or another (Manyena, 2006). It is how individuals, communities, institutions, and systems restore normalcy or enhance themselves in the face of stressors - in the case of my research, the stressor is natural hazards. Resilience is the qualities of an individual or group that help to offset the effects of a hazard. In practical terminology, it is the "strengths" that individuals and groups have (Patterson, 2002). Resilience can often be identified by asking the question "Why did some people, given the same circumstances as others, fare better in the face of a particular hazard than did others?" The answers to this question are the clues to resilience. It is critical to go down this logical path when contemplating hazard mitigation, because the resiliency of people must be integrated into mitigation efforts if they are to be fully successful.

Ultimately, social scientists conceptualize vulnerability as part of the "disaster equation." While full discussion of this equation and its elements is beyond the scope of this dissertation, it is useful for the reader to be aware of it. The equation is as follows (Davis, 2004):

$$
\text { Disaster }=\frac{\text { Hazard } \times \text { Vulnerability }}{\text { Capacity [Resiliency }]}
$$

Essentially, the disaster is the effect of the mingling of a hazard and vulnerability, mitigated by the capacity of an affected individual or group (Glavovic, et al., 2010; 
Henstra \& McBean, 2005; Kusenbach, et al., 2010). Resiliency is included in the denominator. Increasing vulnerability or hazard severity, in the numerator, increases the severity of the disaster if the denominator is not increased as well. The disaster is not the hazard itself, but the effects that the human population suffers in terms of physical damage and disruption of routine functioning (Furedi, 2007; Hamza \& Zetter, 1998; Kreps, 1984; Yahmed, 1994). Rather, the hazard is the natural or human created phenomenon that causes harm (O'Hare \& Rivas, 2005). For example, a hurricane is, in and of itself, not a disaster, but rather a hazard. The following example illustrates this concept: A family may be vulnerable because of poverty and live in a home not built to proper building standards (vulnerability in both a social and physical sense). A hurricane strikes (hazard), and the family deals with it by using its social network to locate a person with a strong home in which the family can safely take shelter. While, thanks to the capacity the family had (i.e., ability to use its social network to find shelter), their lives are not lost, the family still loses its home and possessions - this loss is the disaster. Vulnerability, in the numerator, could have been reduced if, for example, the family had greater wealth and could have reinforced its home against hurricanes, which would have reduced the disaster.

While anyone can have a degree of vulnerability, it is generally considered to be an affliction of people with less resources in a society - those with lower levels of education, less money, less social capital, lower levels of physical ability, and less emotional capacity, than the average person are more likely to be vulnerable (Cutter, et al., 2003; Heijmans, 2004; Hutton \& Haque, 2004; O'Hare \& Rivas, 2005; Parasuraman \& Acharya, 2000; Vatsa, 2004; Wisner, et al., 2004). Having "less" in any of these areas 
requires a balancing out of having more in another in order to maintain a given level of resilience to disasters. Quality comprehensive planning is an opportunity to help level the playing field - making up for increased vulnerability. For example, if a plan defines a coastal zone (in other words, indicates that an area is vulnerable to coastal hazards such as wind and flooding), and requires a stringent building code in that zone, it helps to reduce vulnerability by increasing resistance of structures in the area to hazards. By its very nature as being "comprehensive," a comprehensive plan can also reach out to address underlying vulnerabilities. For example, Florida CPs have education and economic development elements which can be used to promote improvements in the economic situation of the community as a whole or people in targeted geographic areas and social groups. Over time, this can reduce vulnerability by creating more economically advantaged people with more knowledge - both of which can reduce vulnerability as these people can better prepare for and cope with hazards. Comprehensive planning, however, is not a panacea - it can only address some issues of vulnerability, and is only one piece of a larger puzzle of reducing vulnerability to natural hazards. Certainly, while planning can formally require that people invest in structural mitigation in hazard zones, it can only go so far. For example, in Florida, coastal zones tend to attract large populations of people working in service industry jobs; these people likely have few resources to take the mitigation actions listed in the plan. That is, they still need housing within a reasonable distance from their work, and they will still be in hazard zones when hazards strike, possibly in sub-standard housing (legal per plan mandates, or possibly not). Helping to reduce their vulnerability, for example, goes beyond just the economic development efforts of Comprehensive Plans. 
A commonly cited example of vulnerability is that of Hurricane Katrina's impact on New Orleans in 2005. While the effect of Katrina on New Orleans and the surrounding area provides only anecdotal evidence of the problems of vulnerability, it is a useful case study. As noted before, Hurricane Katrina caused the deaths of 1,464 people and displaced 15 million from their homes in Louisiana (Comfort, 2006; Louisiana Department of Health and Hospitals, 2006). New Orleans itself became a case study of physical vulnerability, and the Katrina disaster was anticipated well beforehand. While a broad swath of society, regardless of socio-economic situation in New Orleans experienced vulnerability by being in an area prone to hurricanes and living in a lowlying area prone to flooding, the poor were even more vulnerable because of their lower ability to choose their living location, purchase/rent hazard-resilient homes, and pay to rebuild/recover after a hazard strike in comparison to wealthier people. The low lying, flood-prone geography of New Orleans also put limits on the effectiveness of comprehensive planning. In the context of New Orleans, the $\mathrm{CP}$ could require hazard mitigation to an extent, but could not relocate the entire city out of the way of hazards (and has not done so even following the Katrina disaster). Since the city will continue to exist in the flood-prone location it is in, there is now a situation in which people with more money will be better able to protect themselves and rebuild following a disaster, and those with less are less able to do so. Comprehensive planning is limited in how much it can, and should, equalize these inequities.

The potential for catastrophe in New Orleans in the event of a hurricane was well known before Katrina (Gerber, 2007). For example, in 2003, in one of today's seminal texts on natural hazards, Wisner, Blakie, Cannon, and Davis wrote this of New Orleans: 
"Given its coastal situation and its location between a large lake and the Mississippi River, a direct hit on New Orleans would cost hundreds of billions of dollars and probably take thousands of lives." Certainly, there were those who tried to act on this knowledge, such as Senator David Vitter (R-La.) who just two months prior to Katrina publicized a computer model of a Category 4 hurricane flooding New Orleans under 18 feet of water and said "It's not a question of if; it's a question of when" (Grunwald \& Glasser, 2005). The fact that so many people had knowledge that a disaster could occur only highlights the importance of a quality comprehensive planning process that involves all stakeholders, engenders their support, educates them about hazards, and creates workable solutions that can be supported by all. Had such a process been in place, and supported by politicians, administrators, and citizens for the last few decades, development in New Orleans could have been more effectively channeled to keep people out of areas of high flood risk. Housing in risk areas could have been mandated to be built to standards appropriate for the risk, and populations in risky areas could have been limited to maintain a size that could be manageably evacuated.

\section{Neo-Institutionalism}

Neo-Institutionalism, or New Institutionalism, is similar to Institutionalism. Institutionalism combines classic organizational ideas focusing on "informal" aspects of institutions, such as beliefs, events, norms, habits, world-views, paradigms, codes, cultures, and knowledge, with public sector needs for results, performance, and outcomes (Alexander, 2005; Frederickson \& Smith, 2003). It also factors in management and leadership as possible components affecting outcomes of institutions. Institutions also 
have formal aspects that shape them, such as laws, rules, and regulations (Alexander, 2005). Institutionalism sees education and professions as factors affecting the behavior of institutional actors; my research pays heed to these facts, and specific questions are asked about professionalism and education in the surveys of planners. Finally, institutionalism holds that collective experience shapes people's behavior in institutions. Similarly, prior work has shown that those who have experienced natural hazards in the past tend to take more actions for hazard mitigation than those who have not. My research accounts for hazard experience and its effect on planners both by factoring in an independent variable accounting for prior hurricane experience of each county, and by asking individual planners about their hazard experiences.

Institutions themselves are built of the rules and human-created constraints that affect the behavior of participants. Examples of these are bounded rationality, information access, decision economics, and concepts such as fairness and justice (Ferris \& Tang, 1993; Healey, 1999). Institutions affect action and interaction by controlling the information people have access to and their incentive structures. The interaction between institutions and their members is critical in the hazard mitigation context, as building CPs for hazard mitigation requires balancing stakeholder concerns regarding social, political, and economic concerns (Puszkin-Chevlin \& Esnard, 2009) with technical knowledge while maintaining stakeholder support for political passage of plans and their subsequent implementation.

Institutions grow from routines, which spawn from a need to cope with uncertainty. Over their life, however, institutions also grow and adapt, as they are human creations, and humans tend to grow and adapt in response to experiences 
(Gopalakrishnan \& Okada, 2007; Healey, 1999). As people face uncertain situations, they form routines to streamline and compartmentalize these situations in a way that they can cope with; these routines form the basis of institutions (Selznick, 1996). Similarly, organizations learn as they acquire knowledge and seek to interpret it (Kapucu, 2008). Institutionalism has a focus on the rules and norms that people use to structure their approach to the world (Alexander, 2005). For institutions that deal with natural hazards to function effectively, they must be adaptable and must learn from the community around them, especially in the context of natural hazards, as these institutions need to extract local knowledge, combine that with technical knowledge, and create culturally appropriate policies that the public will follow and support (Gopalakrishnan \& Okada, 2007).

Actors in institutions are theorized to operate intentionally, but they may be unintentionally hampered or affected by lack of information, poor information, issues of perception, and transaction costs. The work of Peter Senge and his concept of the "learning organization" (1990), in part, frames my research. He theorizes that businesses (one can view the planning organization as a business) are bound by “...invisible fabrics of interrelated actions, which often take years to fully play out their effects on each other." He argued that five key elements came together to make up a learning organization, three of are important to my research.

First, Senge postulates that learning organizations engage in "Systems Thinking." Senge uses an example of a rainstorm knocking leaves around, rain falling, and streams filling with water as an example of a system of interconnected parts having an effect on each other. Similar to Systems Thinking, planning for natural hazard mitigation does not 
take place in a vacuum of individual communities. Because natural hazards know no political boundaries (except for a few that coincide with nature), and the actions of one community may have an effect on the hazard resilience of another, it is important that planning departments work beyond their individual borders, and collaborate with other communities in their "system." Further, within any given government, mitigation in land use plans is just one part of the Disaster Management Cycle. Planning departments, to achieve their goals, must not only work with other departments working on complementary mitigation goals (e.g., environmental resource departments, school boards, etc.), but also agencies involved in other parts of the cycle, such as emergency management departments. My research examines both how planning departments interact with regional agencies dealing with hazards (such as water management districts), and how they interact with other internal departments of their own governments.

Second, Senge contends that people who master their field are committed to lifelong learning in it, and the highest quality organizations will encourage that mastery and bring the mastery of their people together to benefit the organization. Based on Senge's ideas about mastery in organizations, some of the questions asked of planning organizations are not only about the qualifications of their planners, but how they support planners in professional growth.

Third, Senge states that organizations need a shared "picture of the future" that engenders genuine commitment and enrollment. Similarly, planning organizations are likely to have greater success if they do not just tell the citizens of their jurisdictions what rules to follow in land use, but develop a shared vision for their communities. Ultimately, land use planning is an iterative method of making policy, and the policies in a land use 
plan must be approved by the local governing body. To get both the political and practical support of citizens, planning organizations, just like businesses with their customers, need a shared vision with the community members for whom they plan. Thus, my research examines, in part, how land use planning organizations involve the public in the planning process.

Ostensibly, planning organizations are part of "democratic" institutions of government. In relation to "democratic" processes, Follett (1926) wrote of a difference between including people in "power" by simply taking votes and polls of opinions, versus creating a process by which people participate together to frame questions, research issues, and come up with options. Applying Follett's ideas to government, it is not sufficient for organizations (in this case, planning departments) to simply present people with options and vote on them; rather, it is critical to involve the people in the process of forming solutions.

Follett (1925) theorized that “...orders will not take the place of training." When applied to planning, this concept supports the notion that planning departments and the legislatures backing them can make plans, but people are more likely to follow plans, and see sense in them, if they understand the rationale underlying the mandates in those plans. It is not sufficient to make expert recommendations. Rather, it is necessary to help make the people themselves experts. Ultimately, Follett (1927) realized that building effective organizations with buy-in from stakeholders (in her case, employees) requires not domination, and not compromise, but rather "integration." She specifically cautioned against working groups of employers and employees (equating here to planning departments and citizens) quickly formulating a few alternatives and voting on them, but 
rather believed it important to encourage a fuller form of participation in which both sides fully understand the issues and conceive together consensus-based solutions.

Certainly, lessons from Follett's views of organization make sense in the context of planning and the interactions between planning departments and citizens. Planners cannot hope to come up with enough adequate ideas to solve issues solely on their own they need the information from the "people on the ground" who have experienced hazards, and maybe even developed their own forms of resiliency. Additionally, gathering this information engenders the approval of citizens, and can help to garner support for plans. Part of the research at hand is to examine how well planning organizations take advantage of collaboration with citizens, and if that appears to correlate to higher quality plans.

Integrating the theories of learning organizations from Senge, and participation by workers from Follett, leads to the question of how these theories could affect planning institutions. Looking through the lens on organizations honed by Ostrom (1990), my research seeks to ascertain how planning departments organize as institutions to appropriate common resources (in this case, limited land for safe development) to reduce harm to the community. The planning department as an institution may extend beyond the boundaries of the departments themselves to include other divisions of the governments in which planning departments exists, as well as the general public swerved by these departments and external agencies they work with. Gopalkrishnan and Okada (2007) identify several critical elements that hazard related institutions specifically must possess to be effective. First, they must be aware of the hazards they face. Institutions also must be accountable for their work and for enforcement of their policies; this may be 
a particular challenge to planning agencies because they generally can be overruled by local county commissions that can grant "variances" to established plans, thus delegitimizing the authority of the Planning Department. Finally, Gopalkrishnan and Okada contend that institutions should operate in an equitable fashion, especially in the hazards context, where it is often necessary to "level the playing field" and ensure that, despite economic differences, there is some level of equality in the protection from natural hazards for all members of a community. Yet, comprehensive planning is not a panacea and has its own limitations. As long as economic differences exist, some people will be able to live in safer areas than others, and will be able to better harden themselves against hazards. Comprehensive planning cannot give everyone the resources to protect themselves from hazards to the maximum extent possible. If comprehensive planning required such a level of protection, it would create communities in which only the wealthy could afford to live in. Thus, the forces of economics and markets will always have an influence on the vulnerability of people within any community.

In planning, institutions can bring people from different networks together to solve problems and create plans that meet the needs of the entire community (Healey, 1999). The planning institution provides an opportunity to create a community of discourse in which parties come together and collaborate in the interest of the future of their community, and in the case at hand in this research, specifically in the context of natural hazards. Critical to the hazards perspective, institutions can bring together society, nature and culture to bear on the problems of natural hazards and human vulnerability (Gopalakrishnan \& Okada, 2007). 
One of the critical functions of institutions, under the paradigm of NeoInstitutionalism, is to align people to goals that may be lost in today's world of increasingly impersonal exchanges (Nee \& Ingram, 1998). In planning organizations, technical and legal requirements may provide achievable goals in the sense of "boxes to check" to meet planning mandates, and can contribute to quality plans, but these requirements also may make it easy to lose sight of overarching goals that go beyond technocratic elements. For example, a planning organization may be required to hold public hearings, but this requirement still may not, in reality, ensure access of disadvantaged groups to the planning process. Under the Neo-Institutional paradigm, the planning institution's unwritten rules, practices, and norms could make up for this deficiency in formal rules, and lead the members of the institution to make special efforts to include less advantaged groups in the process.

Critically, then, my research conceptualizes institutions as the framework which structures the information gathering systems used by planners, their decision making process, and ultimately the final plan. The aforementioned perspective guides the research as I explore how hazard mitigation planners obtain, process, and use information. In terms of my research, a well-functioning planning institution will help planners to gather information about natural hazards and mitigation from a variety of sources, combine the information with their experience and technical knowledge, and produce a plan that is high in quality when measured empirically against a defined set of goals. In a quality planning institution, as conceptualized in my research, the department will provide solid incentives for planners to engage in these activities effectively. Furthermore, since plans in Florida are also political documents that must be approved by 
local county commissions, it is imperative that there is public support, and especially no significant opposition, so that professional planners can pass good quality technical plans and so that community issues can be effectively addressed (Quarantelli, 2003; Sengezer \& Koc, 2005). However, given that plans are policy documents, developed by executive departments but considered and passed by local legislatures, there may also be political limitations. The politics of the day may ultimately temper true quality in plans.

\section{Conclusion}

Overall, comprehensive planning has proven to be an effective tool for preventing disasters via hazard mitigation. It provides planners and citizens the opportunity to come together and share information and build an implementable framework for a hazard resilient community. Research has shown that in states that require that local governments address hazard mitigation in comprehensive plans, there are less disaster losses in comparison to states without the requirement. While extensive research has been done on comparing states that have planning mandates with those that do not have mandates, there is little research on what drives plan quality within states that have planning mandates for hazard mitigation. Given a strong state requirement for incorporating hazard mitigation into comprehensive and/or land use plans at the local level, and prescriptive elements in this mandate that instruct the content of these elements, will the hazard mitigation elements vary in quality within that state, and if so, what drives this variation? My research fills these gaps. 


\section{METHODS}

My dissertation examines a relatively unexplored area. The methods used in the, existing research on land-use planning and comprehensive planning informed my research, but additional formative research was needed to fully understand the interconnected issues surrounding comprehensive planning for hazard mitigation. To merge the unique content with tried and true methods, I took a formative approach to formulating questions and gathering data, and fit the findings into research models typically used in similar research. Methods entailed a review of planning documents and analysis of demographic and hazard history factors; and a nationwide survey designed after an examination of relevant literature, practice, and interviews with comprehensive planning leaders in Florida counties.

Review of Hazard Mitigation Elements and Demographic and Historical Analysis In order to compare hazard mitigation elements to each other, I needed to create an index to provide a repeatable way to measure the quality of each plan. The quality measure forms the dependent variable in the analysis.

To construct an index to rate hazard mitigation elements, I reviewed methods from prior studies evaluating plans. These studies used a variety of scoring methods, including the additive index method presented here. I read one comprehensive plan (Miami-Dade County) in full to screen for relevant items outside of the state required Coastal Management Element (CME) of the plan, where most hazard mitigation items appear, and to become familiar with plan construction. 
Little literature exists on the topic of rating the quality of land use plans and $\mathrm{CPs}$ (Baer, 1997; Berke \& French, 1994). In order to rate hazard mitigation elements of comprehensive plans in the study area, I used features from the rating systems employed by several different authors to create a plan rating system that has been validated in both method (the $0,1,2$ rating system) and content (items selected for rating). The resulting rating system emphasizes important characteristics of quality research, including lack of bias, explicit methods (versus intuition), and repeatability of measures (Baer, 1997).

An explanation of each of the 24 items used to rate plans appears in the section on plan review results. I developed the list of items primarily using hazard mitigation and planning literature. Because this is formative research of hazard mitigation planning in the context of a state that requires hazard mitigation elements in CPs, I added novel elements that will aid in the exploration of plan quality.

Content analysis was used to analyze the hazard mitigation elements of comprehensive plans - more specifically, conceptual analysis was used. In this form of content analysis, specific concepts are identified and then are examined in the text being reviewed. The concepts are the 24 elements of hazard mitigation element quality identified from the literature and practice. These were listed out, and a rubric created to record evaluation of each coastal county hazard mitigation element. Then the hazard mitigation section of each plan was reviewed, and a score of 0 entered for each item not present, 1 for each item present, or 2 for an item presented and addressed in exceptional detail.

Only explicit terms were identified in this content analysis. Because the hazard mitigation elements are legal documents, implicit terms were not identified, as legal 
document are positive and explicit (only what is written is law). That said, different variations of words and phrases were utilized in rating. For example, the plan would get a "1" for prohibiting development in hazard zones if it said, "Increases in density are prohibited in the Coastal High Hazard Area," or if it said, "Increases in density are prohibited in the area that SLOSH model predicts will be flooded in a Category 1 Hurricane." is because both terms ("Coastal High Hazard Area" and "area that SLOSH model predicts will be flooded in a Category 1 Hurricane") mean the same thing.

The measure of quality is not based on outcomes, but rather, the quantity of hazard mitigation related plan elements. The rating system I use largely excludes normative judgment, but ensures that more thorough plans are rated higher because they address more items and in greater detail. Researchers have used similar systems of rating in planning research, including Brody (2003), Burby (2005), Burby \& Dalton (1994), Deyle \& Smith (1998), and Berke and French (1994). Notably, researcher William Baer (1997) evaluated Burby and Dalton and Berke and French's method of evaluating hazard mitigation elements, which is similar to the method I employ, as “... an exemplar of research and professional evaluation." Nelson and French (2002) used a system in which each included item counted for one point. In particular, the plan rating system designed for my research shares with these authors an ordinal scale of plan rating, which Baer points out, allows for statistical testing. That said, rating systems such as the one utilized in my research essentially substitute level of detail for a strong measure of outcomes based quality (Berke \& French, 1994). Using simple numerical coding removes normative judgments about what makes a "good" plan by instead focusing the measure on how many components are addressed and in what level of detail. 
One weakness of this rating system is that it does not account for plan outcomes and effectiveness (Baer, 1997; Deyle \& Smith, 1998). Addressing this topic more precisely would require in-depth creation of an independent variable that can measure plan outcomes (based on limited data from historical disaster strikes) under various plan components - such an investigation is a research project of its own. In order to keep the focus on the independent variable - drivers of plan quality - my research follows the typical method used by other hazard researchers and examines quantity and depth of issues addressed and depth of each issue rather than quality in terms of outcomes and effectiveness.

\section{Review of Rating Index}

As part of my research, I interviewed four land use planning leaders employed in county governments in Florida to help identify important issues and potential variables related to hazard mitigation element quality. These planners all have management responsibility for hazard mitigation elements in their respective counties - see the section on Interviews for more information. As part of the interviews, I asked them to review the rating instrument. All of the planners reported that they would not add any elements to the rating index. While four opinions is not sufficient for full validation, the instrument appears to have face validity.

I also asked interviewees what the three most important and least important plan rating elements on the list were. While three of the interviewees made it clear they would neither add nor remove any elements, they grouped the items as listed in Table 1 below. Some interviewees provided greater or fewer than three items to add and/or remove, 
hence counts may not add up as expected. Interviewees often identified data analysis and gathering elements, such as SLOSH modeling, as important to rating the plans. Factors supporting collaboration and communication with the public also received more support than other factors. In regard to what is not important to determining quality of hazard mitigation elements, there was very little consensus. However, two interviewees identified tax abatements for hazard mitigation projects as an item that is not important in rating hazard mitigation element quality. Again, all four interviewees expressed that they would not actually remove any items, even though they rated their bottom three choices for rating hazard mitigation elements. 


\begin{tabular}{|c|c|}
\hline Rating Item & $\begin{array}{c}\text { Count of Interviewees Rating as a Top } \\
\text { Three Item }\end{array}$ \\
\hline $\begin{array}{l}\text { SLOSH or an Alternative Formal Model is Utilized to } \\
\text { Model Flooding and Wind Hazards }\end{array}$ & 2 \\
\hline Hazard Education Component & 1 \\
\hline Public Participation in Planning is Codified in the Plan & 1 \\
\hline $\begin{array}{l}\text { Exposure of Property and/or Population to Hazards } \\
\text { Analyzed }\end{array}$ & 2 \\
\hline Identification of Hazards & 1 \\
\hline $\begin{array}{l}\text { Other Governments, Government Agencies, Non- } \\
\text { Governmental Organizations, and/or Stakeholders Identified } \\
\text { with at Least Some Intent to Collaborate Noted }\end{array}$ & 2 \\
\hline $\begin{array}{l}\text { Maps Delineating Coastal High Hazard Areas (CHHA), } \\
\text { Flood Zones, and/or Other Hazards }\end{array}$ & 2 \\
\hline $\begin{array}{l}\text { Exposure of Public Infrastructure and/or Critical Facilities to } \\
\text { Hazards Analyzed }\end{array}$ & 1 \\
\hline Development is Limited in Hazard Zones & 2 \\
\hline Development is Prohibited in Hazard Zones & 1 \\
\hline Building Codes are Mandated in Hazard Zones & 1 \\
\hline Rating Item & $\begin{array}{c}\text { Count of Interviewees Rating as a } \\
\text { Bottom Three Item }\end{array}$ \\
\hline $\begin{array}{l}\text { Tax Abatement for New Development Employing } \\
\text { Mitigation, and/or for Retrofits that Mitigate Hazards }\end{array}$ & 2 \\
\hline Learning from Hazards is Incorporated Explicitly & 1 \\
\hline Interviews Conducted with Key Stakeholders & 1 \\
\hline Use of Nature as a Hazard Barrier is Explicit & 1 \\
\hline Disaster and Hazard History & 1 \\
\hline
\end{tabular}

Table 1: Top three and bottom three plan rating factors as rated by professional planners

\section{Correlation with Hazard History}

To account for the history of hurricanes striking each county, I developed a unique index accounting for strength of hurricane strikes and time, with storms being assigned increasing weight as their landfall dates approach the present. To develop the index, I utilized National Hurricane Center data tracking all landfalls of tropical storms and hurricanes in Florida counties from 1978 through 2008. Data for each strike were taken from six hour interval measurements, from the last point along the storm's path prior to making landfall in a given county through the time it left Florida or dissipated. 
The data are arranged by county landfall, not storm, so if, for example, a storm cut across Florida from Miami to Naples, that storm would have two entries: one for Miami-Dade County and one for Collier County. Counting each county-level landfall ensures that each strike in each county is measured. For each landfall, the equation is as follows:

$($ Observation Year in Series/30) $\times$ Storm Strength

Observation Year in Series factors in the year a hurricane strikes, so for 1979 storms this figure is $1 / 30$, as 1979 is the first year in the series, whereas for a 2008 storm it is $30 / 30$ (1). Thus, the greater the time since a hurricane strike, the smaller its value on the strike index. Storm Strength is the Saffir-Simpson category of the storm, with tropical storms assigned a value of .5. Once I computed the overall numbers for all strikes, I indexed the strike values from 0 through 1 . Finally, I summed each county's landfalls to arrive at a total number representing hazard experience, which weights more recent storms and more severe storms higher than storms farther in the past and/or that were weaker.

Notably, a weakness of this index is that it measures hazard strikes, but not effects. While the index accounts for differences in intensity of hazards, it does not account for monetary loses or losses of life. These may actually be what impacts perception of prior hazards. However, because monetary estimates of damage from hurricanes typically only include insured properties, there is no reliable and consistent measure to incorporate here. This limitation should be considered.

The index has the unique advantage of factoring in both time and strength of hurricanes and tropical storms. Thus, more recent storms that would be fresh in the minds of policymakers and the public are weighted more heavily. Storm strength is also factored in, as stronger storms may have left a more lasting impact on a community and 
affected its policy apparatus for a longer period of time. My approach combines the effect of all storms which have struck each county over the last 30 years, thus providing a single "Storm Index" for the entire study period.

\section{Comparing Social Vulnerability and Hazard Mitigation Element Quality}

Vulnerability Theory posits that certain social factors, such as poverty, minority race, and lower income, will contribute to hazard vulnerability (Wisner, Blaikie, Cannon, \& Davis, 2004). I tested for this by comparing social vulnerability (vulnerability to natural hazards based on socioeconomic factors that contribute to people being less able to mitigate hazards) at the county level to hazard mitigation element scores. Several measures are used to account for social vulnerability, and I completed comparisons using Spearman's Rho correlation because of the small size of the data set. The variables utilized are listed in the results section dealing with hazard mitigation element quality.

\section{Summary: Assessment of Hazard Mitigation Elements and Correlation to Demographic and Hazard History Variables}

To answer the question of whether or not hazard mitigation element quality varies among counties, I reviewed the hazard mitigation elements of all 35 Florida coastal counties. I rated each element on a 24 item index, using additive scoring. I selected index items based on hazard, disaster, and planning research. To ascertain if the variation correlates with social vulnerability, I selected several variables typically reflecting social vulnerability and tested them against plan ratings for potential correlation. Further, to see if hazard mitigation element quality correlates with history of hazard strikes, which 
should theoretically improve mitigation efforts, I developed a custom index of historical hazard strikes over the last 30 years and tested results for each county for correlation with hazard mitigation element quality.

\section{Survey of Planning Professionals and Academics}

Finally, to provide further context on the findings from the interviews and document reviews, and learn about the normative standards the disaster and hazards community imbues upon hazard mitigation elements in CPs, I conducted a survey of professionals and academics involved with hazards and disasters. I constructed the survey on the basis of the literature reviewed, findings from plan reviews and the subsequent historical and demographic correlation analysis, and interview findings.

To help guide the survey design, I interviewed managers responsible for hazard mitigation elements in planning departments in four of the Florida coastal counties studied. Initially, the goal was to interview five planning leaders, in an effort to represent each of the five coastal regions of the state. However, many planning leaders refused to be interviewed, or ignored the interview request, and after a certain number in a given area refused, someone from another geographic region already represented would have had to be selected, thus over-representing that area.

I identified planning leaders by calling comprehensive planning departments in targeted counties and asking administrative staff to direct me to the manager responsible for the hazard mitigation element (also sometimes identified as the Coastal Management Element) of the plan. Before scheduling the interview, I verified with the interviewee that he had management responsibility for the hazard mitigation element. I interviewed 
planners with management authority and responsibility, rather than the planners actually responsible for writing hazard mitigation elements, in order to learn not only about the written components of the plans, but about the strategies and goals involved with each department's hazard mitigation element.

Using the telephone numbers provided, I called interviewees; I connected via Skype to facilitate recording. All interviews were audio recorded. I scheduled interviews at the convenience of the interviewees and they typically were 60-90 minutes. Following the interviews, I entered responses into a copy of the structured interview instrument assigned to each interviewee. However, interviews were not transcribed verbatim. I reviewed interview audio recordings and loaded answers to questions into a structured instrument to track answers by respondent. I qualitatively evaluated the interviews for patterns and unique ideas, and this information guided preparation of the survey instrument.

Using information from the interviews, results of the literature review, and ideas from practice, I designed a survey for professionals involved with comprehensive planning, disasters, and hazards. I loaded the 30 question survey into the Qualtrics electronic survey tool. I e-mailed potential survey respondents a letter, approved by the university's Institutional Review Board (IRB) on university letterhead. The letter was signed by me (the principal investigator), my major professor, and a professor who works in the hazards and disaster academic community. I sent a follow-up e-mail to those that did not complete the survey. After survey completion, I sent the survey respondent a thank you letter with a link to the survey and asked the respondent to pass the survey along to other interested persons. Because the survey collects information about 
employment, I was able to filter out any surveys from people whom did not work in fields related to comprehensive planning, hazards, or disasters. The survey was completely confidential. I completed survey analysis using SPSS and my own review of qualitative responses.

\section{Conclusion}

I used several approaches to understand the relatively unexplored drivers of quality behind hazard mitigation elements in CPs. To analyze Florida coastal county hazard mitigation elements, I employed document review and conducted a subsequent analysis of plan scores compared to hazard history and various demographic variables. To inform creation of a survey instrument, I interviewed four planning leaders in Florida coastal counties to learn more about what drives quality of hazard mitigation elements and how their counties create the elements. Last, I deployed a nationwide survey to inform my research about how planners and academics in the planning field believe hazard mitigation elements in CPs should be addressed. 


\title{
IV. QUALITY OF HAZARD-MITIGATION ELEMENTS
}

\author{
Introduction
}

The first question my research resolves is whether or not there is variation in the quality of hazard mitigation elements in Florida coastal county Comprehensive Plans. I reviewed the hazard mitigation elements of all 35 Florida coastal counties against a 24 measure scoring index to determine to what degree each plan addresses various critical elements of hazard mitigation for floods and hurricanes, as well as natural hazards in general. Overall, there was a great deal of variation in quality of hazard mitigation elements, with scores ranging from 5 to 25 (out of a possible total score of 48), with a normal distribution centered around a mean of 14 .

\section{Comprehensive Plan Conceptualization}

Comprehensive plans can be conceptualized in several different ways, including as visionary documents, blueprints, land use guides, remedies, administrative requirements for federal funding, processes, pragmatic actions, and responses to planning mandates (Baer, 1997). How researchers conceptualize plans colors how they evaluate them. Critically, to mitigate effectively against natural hazards, plans should address both social and physical issues (Hamza \& Zetter, 1998). In Florida, CPs must account for multiple factors (e.g., land use, economic development, infrastructure, etc.), must plan over a ten-year horizon, and are required by state law. On the basis of these requirements, and the requirement for hazard mitigation (discussed below), comprehensive plans of 
Florida counties are conceptualized under the following paradigms from Baer's list of plan conceptualizations:

- Visionary Documents - Florida plans must, by law, plan for at least a 10 year horizon, and the hazard mitigation element requirements of state law require that plans minimize human and infrastructure vulnerability to natural hazards. Further, it engages the public in planning for stronger, less vulnerable communities. These are clearly visionary, future oriented requirements.

- Land Use Guides - Florida plans are required to plan for future land use.

- Processes - In Florida, planning is done at the local level where citizens can engage government, plans are passed by local governing bodies, and the state reviews plans. It is a process that allows both direct participation and political representation to shape the plans, while also bringing in technical expertise via planner involvement and the state review process.

- Pragmatic Actions - Local comprehensive plans in Florida have a pragmatic component. Plans in Florida are integrative documents bringing together multiple elements to achieve larger societal goals. By state requirements, they must be financially feasible as well.

- Responses to State Mandates - Considering state law in Florida, the local plan is clearly a response to state mandates. 


\section{Individual Index Items}

The individual attributes used to rate plans are listed below. Each of the 24 elements includes a brief justification for its inclusion.

\section{Identification of Hazards}

The identification of hazards directly informs a community of the hazards it must prepare for and mitigate against. Hazard identification explicitly defines the hazards so that they can be effectively treated in the plan. Because CPs can serve as repositories of factual information about hazards, the identification of hazards also fulfills an important planning function of informing other hazard mitigation and emergency planning activities outside of the planning function (Burby, et al., 1999; Burby \& Dalton, 1994). Hazard identification not only informs government, but also can serve to tell the public about hazards. For example, hazard information can help people purchasing homes in a coastal area to weigh potential costs of purchasing closer to the coast, and to determine the risks posed by different home sites. It is critical, therefore, that plans explicitly cite hazards that threaten a particular community so that planners are aware of them, government officials can prepare for them, and homeowners can take mitigation into their own hands. Notably, planning professionals recognize the importance of hazard identification by itself as one of the most common forms of hazard assessment.

\section{Disaster and Hazard History}

A history of hazards and disasters is helpful on several fronts. Primarily, it helps to form an accurate picture of risk to a community based on the reality of past 
experiences (Tierney, 1999). Second, it brings color, life, and reality to a plan - it can be a key element in engendering public support of the plan because it sends a message that the threats planned for are real. Having a hazard history encourages higher quality planning for natural hazards (Brody S. D., 2003). There is clear value in providing a history of hazards both to show the value of the plan and its elements, and to inform the technical writing of the plan. For example, providing a history of hurricanes that have struck an area will help plan users to see that the measures (and sometimes sacrifices) taken in the plan are necessary to address a problem, and are justified; such a history will also help to identify vulnerabilities that must be addressed. Nelson and French (2002) also employed disaster and hazard history as a measure in their rating system.

\section{Identification of Hazard Mitigation as a Goal}

Comprehensive plans function in terms of broad goals, which lead to objectives, which are then backed by policies. Prior researchers have found that explicitly specifying hazard mitigation as a goal in plans directly correlates to better strategies for mitigation (Burby R. J., 2005). In fact, Brody, French, and Nelson (1998) found a significant ( $\mathrm{p}<$ .10) correlation between the number of hazard mitigation elements incorporated in local plans and reduction in damages from the Northridge earthquake. While some, such as Brody (Brody S. D., 2003), Berke and French (1994), and Nelson and French (2002), have broken hazard mitigation goals out into multiple categories of individual goal types, my research utilizes one broad category for overall identification of hazard mitigation as a goal. 
Maps Delineating Coastal High Hazard Areas (CHHA), Flood Zones, and/or Other

\section{Hazards}

Maps delineating hazards serve several critical functions in plans, and the research community considers them an important feature of quality hazard mitigation elements (Berke \& French, 1994; Davis, 2004; Nelson \& French, 2002). They are a primary form of vulnerability analysis and they can help planners in making and supporting decisions regarding trade-offs of sacrificing economically valuable land uses to instead designate areas for typically less valuable uses (such as parkland or low density areas) which reduce vulnerability (Deyle, et al., 1998; Nelson \& French, 2002). Maps show the location, and potential magnitude, of hazards, simplifying communication of hazards to the public and to professional plan users. These help the public to see hazards and make informed decisions, and engender support for the plan by clearly showing potential dangers (Deyle, et al., 1998; Hung \& Chen, 2007). Engendering support is critical because CPs may limit development in desirable areas, and also reduce potential tax collections through such limitations - the public has to know what the dangers are in order to support mitigation initiatives that may come with an economic cost. For example, a map based on hazard history and flood models might show the historical and potential effects of hurricanes on individual areas, and visually display the need to restrict certain types of development and land use. Maps are also useful tools for sharing hazard information and locations with other government departments (Olshansky, 2001). Finally, planning professionals also believe that maps are an important element to hazard mitigation planning; in a national survey of planners, respondents ranked maps as an important element of hazard mitigation elements (Steinberg \& Burby, 2002). 


\section{Forecasted Hazards and Magnitudes Presented}

In order to plan for hazards, their potential impacts must be known. Thus, it is important to present forecasted hazards and magnitudes (Deyle, et al., 1998; Olshansky, 2001; Quarantelli, 2003; U.S. National Committee for the Decade for Natural Disaster Reduction, 1991). Knowing the magnitude of hazards is critical to planning in a manner that exploits resiliency, mitigates geophysical risks, and uses a logical assessment of level of risk (e.g., planning for a 100-year versus 500-year flood risk). Assessing hazards helps planners to understand the costs and benefits of different land use ideas. Further, presenting hazard magnitudes communicates level of risk to the public. Prior researchers, including Berke and French (1994) and Nelson and French (2002), include presentation of forecasted hazards and magnitudes as a measure of plan quality.

\section{Learning from Hazards is Incorporated Specifically}

History can be one of the best teachers; while modeling hazards and trying to predict their impacts can be beneficial, learning from the effects of prior hazards can be one of the most important aspects of planning. ${ }^{1}$ Notably, Berke and French (1994) include several rating factors requiring learning from prior hazards in the Recovery phase of the disaster cycle.

\footnotetext{
${ }^{1}$ Peter Senge (1990) conceptualized learning organizations as those that not only adapt, but use experiences to grow their capacity. In the context of the planning organization working on hazards, a learning organization would, theoretically, take information from prior hazards, and apply it in future policymaking not only to make better policies, but to expand the organization's capacity to actually make hazard-related policies.
} 
The Hurricane Katrina disaster provides an anecdotal example of what can happen when planning does not account for disasters of the past. For example, under the National Flood Insurance Program (NFIP), which insures properties at high flood risk, repeated loss properties are tracked. Repeated loss properties are those for which the program has paid out multiple claims on the same property over time. The Orleans and Jefferson parishes of the New Orleans metro area ranked first and second for repeated loss claims under NFIP from 1978 through 1995, representing 20\% of American repeat loss properties in that time period (Brookings Institution, 2005). Had stronger measures to learn from prior losses been implemented and followed, some of these repetitive loss properties could have possibly been built to more flood-proof standards during recovery, or people living on them resettled to less risky areas. This likely would have been politically unfeasible, as people in the repeat loss areas would oppose forcible relocation, and others might oppose the high public cost of subsidizing better construction and/or buying out homeowners in hazard-prone areas and relocating them. Thus, the New Orleans area became a perfect example of moral hazard - governments "bail out" people living in a hazardous area over and over, when, in reality, the more fiscally and scientifically sound option is to consider a program of relocation.

\section{Explicit Use of the Vulnerability Concept}

Social vulnerability has only recently come to recognition as a critical element in planning. In part, this may be because of the bias of the planning profession toward the physical sciences rather than social science, as well as the difficulty of incorporating the rather new concept of social vulnerability (Davis, 2004). Social Vulnerability 
components should address the economic and social aspects of vulnerability, in concert with geophysical vulnerability. Comprehensive planning is an ideal vehicle to address social vulnerability, because the $\mathrm{CP}$ goes beyond land use planning to cover issues including economics, infrastructure, and education, all of which play into social vulnerability. Comprehensive planning provides a vast opportunity to tie together the physical science of hazards with social issues and to use both physical and social means in concert to mitigate risk.

\section{Encouraging Public Participation in Planning is Codified in the Plan}

Community participation in hazard planning is critical, and requires extensive discussion. The public has information to contribute to planning for hazard mitigation, and should be involved in policy-making to build plans for hazard-resilient communities (Berke \& Campanella, 2006; Burningham, et al., 2008; Comfort, 2006; Gopalakrishnan \& Okada, 2007; Heijmans, 2004). Often, people on the ground have experienced hazards, and are aware of their vulnerability and resilience capabilities. They have a wealth of knowledge that can help to mitigate future disasters (Wisner, et al., 2004).

Further, while people in a certain geographic area may appear obviously vulnerable to outsiders, other locally-known factors may come into play that are not known to outsiders (such as behaviors of individuals or groups during an evacuation order). Finally, public participation in policymaking is considered to be an important element of creating sustainable, just, effective policies (St. Bernard, 2004; Kapucu, 2008) and some planners consider it an important aspect of building a quality hazard mitigation element (Steinberg \& Burby, 2002). Overall, as Tewdwr-Jones (2002) points out, there is 
a broad spectrum of planners, including those "... bent on using strategic action to reach a desired pre-determined ends," and those who “...possess no clear idea of where they want particular decisions or plans to lead to." Likely, the right blend of balancing technical knowledge with public input, is somewhere in between, It may also help planners to use public input if they identify themselves as a part of the public whom the plan benefits (Harrison, 2002). Yet, as Tewdwr-Jones also points out, planners are in a somewhat difficult position because, while their professional training is very useful for technical planning, they must balance the value of their training with public input and knowledge.

Garnering public participation can be difficult (Kapucu, 2008), and thus requires intentional efforts from planning agencies. Further, factors may come into play that local people know about that are not known to outsiders, and planners may not even be aware of these factors at the micro level in their own communities. In the context of planning for natural hazards mitigation, public input can be extremely valuable, and can be gathered through a discourse in which planners educate the public about hazards affecting them, and the public provides information, values, and interests to planners for incorporation (Brody S. D., 2003).

Citizens often do not take the opportunity to be involved in hazard mitigation planning. For example, in studying public comment letters expressing opposition to developments in seismically sensitive areas in California, Olshansky (2001) found that people rarely spoke of natural hazards, and were typically writing about other development issues. Often, the people least likely to give input in policymaking are also the most likely to suffer in a natural hazard event (Vatsa, 2004). This points to a need to 
explicitly involve the public in hazard mitigation planning. Planners can engage in what Pelling (2003) refers to as "institutional modification" in which planning organizations create space in the policymaking and/or political process for citizens and organizations to participate. This is an intentional effort to bring the public into a system from which it might have, for whatever reason, been previously excluded.

\section{Interviews Conducted with Key Stakeholders}

While general input from the public is important, planners also can identify key stakeholders who may have highly relevant, and/or specific, information to provide in the planning process. These people can provide information about specific issues and communities that could inform the plan. For example, planners might speak to hospital directors and their staff to learn about needs of the medical community, especially in providing emergency care after a disaster. Also, planners might speak with representatives of various cultural groups to understand their connection to the land and their needs, and learn what they believe may help mitigate hazards.

Comprehensive plans can involve many key stakeholders - people who have critical information for the plan and/or a stake in planning outcomes. Examples include groups representing builders and businesses; local non-profit organizations serving the homeless and other disadvantaged populations; the religious community; environmental groups; local autonomous governing districts such as school districts; and civic associations that can give a voice to specific groups in the community, such as ethnic groups, sexual-orientation minorities, and the disabled. Interviews with these stakeholders can help to reveal their vulnerabilities and resilient features they possess that 
can possibly be shared with the community, and engender their support for the plan by letting them know that they are stakeholders.

\section{Exposure of Property and/or Population to Hazards Analyzed}

In order to reduce exposure to hazards, planners must be explicitly aware of that exposure - the problem should be understood so that decisions can be made between risk reduction and economics. An inventory of exposure to hazards also allows a community to assess its overall risk in the face of hazards. Finally, understanding severity of exposure also helps in making sound decisions that balance risk reduction with other benefits (Deyle, et al., 1998). Other authors who utilize this measure include Brody (2003) and Berke and French (1994).

\section{Exposure of Public Infrastructure and/or Critical Facilities to Hazards Analyzed}

For several reasons, analysis of exposure of public infrastructure and facilities to hazards is treated separately from overall analysis of general exposure of the population to hazards. Public infrastructure and critical facilities are needed for public services and may be required during and immediately after hazard onset - thus special attention should be paid to shoring up these facilities to mitigate against hazards, and plans should exhaustively list critical elements to give responders a framework to immediately restore critical functions (Deyle, et al., 1998). Secondarily, this element helps to provide an idea of the magnitude of a county's exposure to hazards, and may help plan users to fully visualize hazard dangers. Previously, Berke and French (1994) included analysis of 
infrastructure exposure as a plan quality element, and Deyle, French, Olshansky, and Paterson cite this as an important element in planning involving hazards (1998).

\section{Other Governments, Government Agencies, Non-Governmental Organizations, and/or}

\section{Stakeholders Identified with at Least Some Intent to Collaborate Noted}

Coordination, or lack thereof, among government entities is frequently cited as one of the failures of modern disaster governance. While this is normally considered an issue in the Response phase, coordination in the Mitigation phase is critical. Planning agencies can improve plans by getting information from, and coordinating actions with, neighboring governments, autonomous districts (such as school districts), response agencies, and human service agencies. For example, planning agencies can acquire information about existing shelter capacity at local schools, and can in turn inform schools about changes in development patterns that may affect shelter utilization.

A key problem in using CPs to effect hazard mitigation is that hazard boundaries and political boundaries do not always match. While some political boundaries match natural features, such as the U.S.-Mexico border along the Rio Grande River, political boundaries frequently do not match the boundaries of nature and hazards. Such is the case with floodplains: political boundaries are often drawn through watersheds and projects designed by political subdivisions could affect the entire watershed in which they lie, or vice versa (Association of State Floodplain Managers, 2007). A project implemented by a given county may redirect flooding to neighboring counties, could be negated by water coming from other neighboring counties, or could interfere with projects in neighboring counties. To mitigate this problem, counties can participate in 
meetings of regional water management boards and planning councils, and directly coordinate with other jurisdictions in the watershed. This is just one example of potential coordination among governments.

Sea, Lake, and Overland Surges from Hurricanes (SLOSH) or an Alternative Formal

\section{Model is Utilized to Model Flooding and/or Wind Hazards}

Scientifically grounded methods of modeling hazards is a critical component in aligning land use to the natural and built environment. While it is important to consider historical hazard impacts, history does not tell the entire picture for several reasons. Changing sea levels, whether human caused or a natural function of environmental cycles, have the potential to increase storm surge heights and penetration compared to prior storms, and decrease the potential for flood runoff to flow to coastal bodies of water. Changes in the built environment may also affect hazard performance compared to historical hazard strikes. For example, increases in impermeable surfaces (those which water cannot pass through) can increase flood runoff and channel water to other locations. Formal modeling can combine information from historical hazard strikes with information about the built environment and changes in underlying conditions to effectively predict future hazard strikes, severity, and coverage.

While hazard history can provide information that informs planners of potential future hazard effects, it also can be lacking because a) the hazard may have not occurred historically in exactly the same way it will in the future and b) changing environmental conditions (e.g., sea level rise) may change hazard magnitudes and effects. Yet, to mitigate against losses, planners must know what hazard effects to expect and where. To 
plan effectively for the future, we wanted to know if the plan requires formal modeling of potential hazards.

\section{Development is Limited in Hazard Zones}

Physical location is a strong determinant of vulnerability to natural hazards, furthermore, increasing urbanization often leads to increased vulnerability to natural hazards (Greenberg, et al., 2007; Hamza \& Zetter, 1998). Limiting development in areas known to be prone to natural hazards limits exposure to hazards, channels development to less hazard-prone areas, and may help to protect natural features of those areas that may act as hazard barriers (Brody S. D., et al.; Burby \& Dalton, 1994). States have been limiting development in flood zones since 1917, when New Jersey began to control building permits in order to prevent further encroachment of structures into floodplains (White, 1936). Limiting or prohibiting development in hazard zones, however, comes with an economic cost, as the land cannot be developed and taxed (Deyle, et al., 1998). Considering Florida's hurricane and flood hazards, this problem is particularly acute for local governments, as beachfront property is highly desirable (and thus has high potential to bring tax revenue), but bears the greatest degree of exposure to hurricane risk.

Similarly, but not to the same degree, waterfront property along canals and inland bodies of water is sought after in Florida, but comes with flood exposure risks.

In addition to the aesthetic and recreational drivers pushing people toward coastal land, rapid urbanization is pushing people into coastal areas and creating large concentrations of people and property in these hazard zones (Skertchly \& Skertchley, 2001). Increasing development not only puts more people in the path of hazards, but also 
can actually intensify hazard events. For example, adding impervious surfaces that cannot absorb water leaves less places for floodwater to go and can increase flood potential (Brody S. D., et al, 2007; Brody S. D., et al, 2008; Highfield \& Brody, 2006; Skertchly \& Skertchley, 2001). Recent research has shown that in Texas, where it should be noted that land use controls are less strict than in the study area of Florida, a 1\% increase in impervious surfaces has been found to increase risk of death in a flood by $6 \%$ (Zahran, et al., 2008).

Prior research has shown that in states with requirements for land use planning, local communities are more likely to adopt measures limiting development in hazard zones (Burby \& Dalton, 1994). For example, Burby and Dalton used linear regression modeling to examine the correlation between several policy and demographic factors, and found a statistically significant correlation $(\mathrm{p}<.10)$ between the number of development limitation measures adopted in hazard areas and state requirements for hazard mitigation planning. Notably, Brody (Brody S. D., 2003), and Nelson and French (2002) also use limitation of development as a measure of plan quality.

\section{Development is Prohibited in Hazard Zones}

Local governments can make the very conservative choice to entirely prohibit development in hazard zones (Burby \& Dalton, 1994). While I assumed this to be unlikely due to the economic benefits foregone (as discussed above in regard to limiting development), it was included in the plan assessment matrix. 


\section{Evacuation Feasibility Analyzed}

It is critical to be aware of evacuation times and feasibility in planning, so that densities can be limited to those which can be safely evacuated, or infrastructure improved to match increasing density and thus increase evacuation capacity. Hurricanes provide a unique opportunity compared to other hazards, because their location and severity can usually be ascertained before they strike, and thus evacuation is an effective option. Thus, it is valuable to monitor evacuation times and feasibility and incorporate this information into comprehensive planning. Brody (2003) also used addressing evacuation as a measure of plan quality.

While some authors include evacuation alone as an element for evaluation (1994), this element is broken into "Evacuation Times and/or Feasibility" and "Evacuation Routes Mapped" (see below). In the Florida context it is important to give weight to these elements individually, as the most risk prone areas are coastal barrier islands, which both tend to have high population densities and limited access to mainland road networks because the mainland is usually reached by bridges, which can become traffic bottlenecks in an evacuation. Thus it is critical to consider the location of evacuation routes in relation to population density, as well as to separately consider times and feasibility in order to guide development decisions to match increasing density.

\section{Evacuation Routes Mapped}

Similar to considering evacuation feasibility, it is important to map evacuation routes. Mapping these routes provides visual information in the policymaking process that helps to align densities and infrastructure with evacuation realities. 


\section{Evacuation Shelter Capacity Inventoried}

As a community plans for growth, it is critical that evacuation shelter capacity corresponds to that growth. While there are no standards or best practices, other than ensuring that evacuation over bridges is complete before the arrival of tropical storm force wind gusts, it is important for communities to carefully analyze their individual needs. This is especially important in Florida, where southern counties face evacuation hurdles due to limited highways to evacuate north. It is critical that evacuation capabilities be considered in concert with potential hazards to determine where shelters should be located and what their capacities should be. To maintain the proper balance between evacuation and sheltering, counties should be aware of existing capacity within their borders, and possibly in neighboring counties (Berke \& French, 1994).

\section{Mitigation Required from Developments that Increase Evacuation Time}

Especially in a coastal state, new development will occur in areas that may have to be evacuated in the face of a hazard event. One way to ensure that effective evacuation capacity exists, and to help people make rational economic decisions when choosing to live in risky areas, is to place the cost burden of additional evacuation needs in hazard zones on developers.

Increasing development in a given area can burden existing evacuation routes and shelters. It is critical to expand capacity of either or both in order to preserve evacuation abilities, and such expansion requires funding. If projects to increase evacuation capacity are not funded, and funded rapidly following population increases in hazard zones, 
evacuation capabilities could fall behind. In order to maintain effective evacuation abilities, developments contributing to reductions in evacuation capability can be assessed mitigation fees to fund requisite improvements. This is similar to using impact fees assessed on new development, which has been associated with increased public capital growth (Jung, Roh, \& Kang, 2009).

Specific Rule that Public Funding will not Improve Infrastructure Beyond Current Level of Service in Hazard Zones

Improving or adding public infrastructure in a hazard zone not only attracts more people to that area, but also puts public resources at risk. However, to be fair to existing residents, it is not appropriate to reduce service levels.

Infrastructure improvements in hazard zones carry both a direct and indirect risk. From a direct standpoint, adding infrastructure in hazard zones exposes local government to loss because the infrastructure could be damaged in a hazard strike. However, new infrastructure may be required if development is allowed in hazard zones; in this circumstance, rather than using public funding to construct the infrastructure at risk, private funds from those moving into the hazard area can be utilized.

Improving infrastructure in hazard zones carries an indirect risk of attracting development to hazard zones. While infrastructure can be maintained at existing levels of service, improvements can attract new development, when in fact counties should be discouraging development. For example, building parks in a hazard zone might inadvertently make the area more attractive to homeowners, or adding water lines 
through a hazard area might reduce the need for impact fees to fund infrastructure and make the area more attractive to development.

\section{Use of Nature as a Hazard Barrier is Explicit}

Nature can be a powerful hazard barrier. For example, mangrove swamps (common in coastal Florida) may help to buffer the shore from wave action in storms, and mangrove roots may help to hold the coast together, preventing erosion in storms and over time. Natural areas also provide flood protection by providing low-lying areas that can be allowed to flood and thus alleviate flooding in developed areas by absorbing floodwaters (Brody S. D., et al., 2007).

Conversely, destruction and reduction of the natural environment has been correlated with increased disaster severity. In a study of wetland alteration and flood events from 1997 through 2001, it was estimated that for every wetland eliminated in Florida, the average cost of each flood rose by $\$ 989.62$ (Brody S. D., et al., 2007). Highfield and Brody (2006) found over the same period that each permit issued for wetland alteration had a statistically significant impact on the monetary cost of countylevel flood damages $(\mathrm{p}<0.001)$. Another study of 423 flood events from 1997 through 2001 found that wetland alteration was the most significant of all functions of the built environment contributing to increased property loss in floods (Brody S. D., et al., 2008).

Natural features can help to protect against hazards. Planners can take opportunities to integrate natural features for this use, and can take explicit actions to protect natural features so that they thrive and can be features of resiliency. Therefore, my research includes explicit use of natural features as hazard barriers as a rating item. 


\section{Hazard Education Component}

Education about hazards can empower people at risk (Heijmans, 2004;

Quarantelli, 2003; U.S. National Committee for the Decade for Natural Disaster Reduction, 1991). Educating citizens with hazard information can equip them to participate in the plan making process and to apply their knowledge to take vulnerability reduction into their own hands (Nelson \& French, 2002).

A comprehensive plan is, in reality, an evolving document that embodies, in writing, an ongoing process of community visioning. Through the process of creating and updating a comprehensive plan, the public can become educated about many aspects relevant to the plan, including hazards (Brody S. D., 2003). Further, CPs are seen as a method of communicating hazard information to the public (Burby, et al., 1998; Inam, 1999). Communication of hazard information is critical outside of the planning arena as well, as people must be aware of the danger posed by a hazard. Hopefully, when informed of the risk, people are more likely to take hazard warnings seriously and support governmental hazard mitigation initiatives (Glavovic, et al., 2010; Perry \& Green, 1982). In fact, prior research by Burby, French, and Nelson (1998) showed a very significant and strong correlation $(\mathrm{p}<.01)$ between the number of public awareness policies and reductions in damage from the Northridge earthquake.

Those more aware of their risks are more likely to take mitigatory actions; following this line of reasoning, if people are educated about risks facing their community, they will be more apt to support policies to reduce risk. Thus, hazard education is even more valuable in instances when members of the public may be asked to make trade-offs in order to build a quality hazard mitigation element, such as forgoing 
coastal development in order to leave open space on the coast. In fact, if public risk perception differs from the perceptions of risk planners (e.g., public perceives low risk but planner prepare for high risk), the public may not see the plan as a sensible document and may even hamper plan passage and implementation (Peacock, et al., 2004). Other authors who embrace hazard education as a component in plan ratings include Brody (2003), Berke and French (1994), and Nelson and French (2002).

\section{Building Codes are Mandated in Hazard Zones}

While some authors look for building codes in the overall plan (Berke \& French, 1994), the evaluation rubric I use in this research looks for building codes specific to hazard zones. Building codes can compensate for construction of structures in hazardous areas by requiring that those structures be sited and built in such a way that makes them hazard resistant (Olshansky, 2001; Burby, et al, 1998). From a social perspective, however, this effectively could exclude the poor from hazardous zones. In the Florida case, these zones are often desirable locations such as beachfronts, and stringent building codes could restrict these areas only to the wealthy who can afford to meet stringent code requirements. Exclusion by price is a market force, not a policy one - in this case, the policy (building code) sets forth the bare minimum to safely build in an area, and the market provides housing that meets that minimum at a certain price, meeting demand for it. Since few people need to live in dangerous coastal areas, the market is able to charge a premium for construction of homes meeting these more stringent building codes.

Since my research focuses on the hazard mitigation element, and under Florida law certain geographic areas of each county are defined as Coastal Hazard Zones (thus 
giving counties a way to delineate between hazard and non-hazard areas), plans are evaluated for the presence of building codes in hazard zones only. Brody (2003) also includes "Building standards" as one of his measures of plan quality.

Tax Abatement for New Development Employing Mitigation, and/or for Retrofits that Mitigate Hazards

Often, lack of money is a barrier to hazard mitigation, and funds are needed to take mitigatory actions. Similar to other authors (Berke \& French, 1994), my evaluation looks for incentives/support from government for hazard mitigation. Especially because of the economic development aspects of $\mathrm{CPs}$, these documents are a good place to create programs to help pay for hazard mitigation retrofits of existing buildings. Such retrofits are one of the most critical aspects of mitigation in communities in hazard zones that are already built-out, and thus density cannot be lowered quickly (Godschalk, et al., 2003). Brody (2003) includes "Retrofitting of private structures" as a measure of plan quality; while this is not the same as the measure I selected, both Brody's measurement and the indicator used in my research evidence a government concern for retrofitting structures and a willingness to expend resources on such.

\section{Summary of Rating Index}

The index constructed covers 24 attributes that may appear in a hazard mitigation element, taken from the literature on planning and hazards/disasters, as well as from practice. In Table 2, below, the attributes are categorized by their importance to both planners and those focused on hazard mitigation. 


\begin{tabular}{|c|c|c|}
\hline Attribute & $\begin{array}{c}\text { Planner } \\
\text { Perspective }\end{array}$ & $\begin{array}{l}\text { Hazard Mitigation } \\
\text { Perspective }\end{array}$ \\
\hline Identification of Hazards & Fact Base & Hazard Assessment \\
\hline Disaster and Hazard History & Fact Base & Hazard Assessment \\
\hline Identification of Hazard Mitigation as a Goal & Goal & Mitigation \\
\hline $\begin{array}{l}\text { Maps Delineating Coastal High Hazard Areas (CHHA), } \\
\text { Flood Zones, and/or Other Hazards }\end{array}$ & Fact Base & Hazard Assessment \\
\hline Forecasted Hazards and Magnitudes Presented & Fact Base & Hazard Assessment \\
\hline Learning from Hazards is Incorporated Explicitly & Policy & Resiliency \\
\hline Explicit Use of the Vulnerability Concept & Policy & Vulnerability \\
\hline Public Participation in Planning is Codified in the Plan & Objective/Policy & Resiliency \\
\hline Interviews Conducted with Key Stakeholders & N/A & Resiliency \\
\hline $\begin{array}{l}\text { Exposure of Property and/or Population to Hazards } \\
\text { Analyzed }\end{array}$ & Fact Base & Hazard Assessment \\
\hline $\begin{array}{l}\text { Exposure of Public Infrastructure and/or Critical } \\
\text { Facilities to Hazards Analyzed }\end{array}$ & Fact Base & Hazard Assessment \\
\hline $\begin{array}{l}\text { Other Governments, Government Agencies, Non- } \\
\text { Governmental Organizations, and/or Stakeholders } \\
\text { Identified with at Least Some Intent to Collaborate } \\
\text { Noted }\end{array}$ & Objective/Policy & Collaboration \\
\hline $\begin{array}{l}\text { SLOSH or an alternative formal model is utilized to } \\
\text { model flooding and wind hazards. }\end{array}$ & Fact Base & Hazard Assessment \\
\hline Development is Limited in Hazard Zones & Policy & Vulnerability \\
\hline Development is Prohibited in Hazard Zones & Policy & Vulnerability \\
\hline Evacuation Times and/or Feasibility & Policy & Preparedness \\
\hline Evacuation Routes Mapped & Policy & Preparedness \\
\hline Evacuation Shelter Capacity Inventoried & Fact Base & Hazard Assessment \\
\hline $\begin{array}{l}\text { Mitigation Required from Developments that Increase } \\
\text { Evacuation Time }\end{array}$ & Policy & Resiliency \\
\hline $\begin{array}{l}\text { Specific Rule that Public Funding will not Improve } \\
\text { Infrastructure Beyond Current Level of Service in } \\
\text { Hazard Zones }\end{array}$ & Policy & Vulnerability \\
\hline Use of Nature as a Hazard Barrier is Explicit & Objective/Policy & Resiliency \\
\hline Hazard Education Component & Objective/Policy & Vulnerability/Resiliency \\
\hline Building Codes are Mandated in Hazard Zones & Policy & Resiliency \\
\hline $\begin{array}{l}\text { Tax Abatement for New Development Employing } \\
\text { Mitigation, and/or for Retrofits that Mitigate Hazards }\end{array}$ & Policy & Resiliency \\
\hline
\end{tabular}

Table 2: Plan rating attributes

\section{Sample}

Florida has a strong prescriptive mandate for hazard mitigation elements to be included in local land use plans (Burby R. J., 2005; Deyle \& Smith, 1998), and was one of the first states to implement such (Puszkin-Chevlin \& Esnard, 2009). In Florida, counties and lower-order governments prepare comprehensive development master plans 
(CDMPs), which address zoning and land use regulations, among other growth and development topics such as infrastructure, economic development, and education. The state mandates specific elements required in these plans; for coastal communities specifically, a Coastal Management Element, which must address coastal hazards, is one of the requirements. The state reviews all plans and advises as to whether or not they pass the state's requirements. The state can levy fines for plans not in compliance, although such action is rare. By using such a system, the state ensures that critical elements are addressed, but still leaves planning to the local level where local knowledge, values, and public input can be utilized in the planning process. Generally, local planning and zoning departments draft their sections of CDMPs (including the Coastal Management Element and its hazard mitigation components), then submit these drafts to the local government for legislative approval. Once approved, the local government transmits the plan to the state for review. At this point, state agencies formally submit comments and their advice as to whether or not the plan meets the state required elements - it is then up to the local government to act on comments and then pass the plan as a form of local ordinances.

Florida statutes require that CPs in coastal communities have a Coastal Management Element (Required and optional elements of comprehensive plan; studies and surveys, Florida Statutes, 163.3177, 2008). The Coastal Management Element must, per statute, provide for the "...balanced utilization and preservation...” of " ...all nonliving and non-living coastal zone resources." The aforementioned legal language, and how it is interpreted, is critical because natural resources, such as mangrove forests, may be able to buffer hazard impacts. The coastal management element must also limit public 
expenditures subsidizing development in hazard areas and must maintain or reduce hurricane evacuation times (Deyle, et al., 1998).

In addition to statutes, Florida sets forth other legally binding requirements related to hazard mitigation in the Florida Administrative Code (F.A.C.). Critically, CPs must contain goal statements reflecting legislative intent that the enacting government will “... protect human life and limit public expenditures in areas subject to destruction by natural disasters" (F.A.C. 9J-05.012). In line with this, local CPs must direct population concentrations away from hazard areas and maintain or reduce evacuation times. However, this language is clearly open to broad interpretation. Finally, development must be limited in coastal hazard areas. Analysis of proposed development or redevelopment of flood prone areas must include consideration of flood insurance rate maps, flood hazard maps, and hazard mitigation reports (F.A.C. 9J-5.006). Coastal area population densities must be coordinated with hurricane evacuation plans, and coastal hazard zones must be indicated on plan maps. Per F.A.C. 9J-5.012, CPs must comprehensively examine hurricane evacuation; the code sets forth several issues that must be addressed and requires that the local government consider measures to reduce or maintain evacuation times. The requirement to examine evacuation specifies that counties shall inventory infrastructure in the coastal hazard area evaluate the potential for relocating infrastructure at risk.

In addition to the requirement to have a hazard mitigation element, Florida has used statutory requirements to institutionalize strong planning overall - not just from a hazard perspective (in fact, hazard mitigation is only a small part of the $\mathrm{CP}$ ). Florida law requires that the plan elements be consistent with each other and financially feasible 
(Required and optional elements of comprehensive plan; studies and surveys, Florida Statutes, $163.3177,2008)$. The statute also mandates that local government plans have both a five and ten year planning horizon. Consideration of conservation of natural resources (including estuarine resources) is required; notably, while this is not the stated intent of this requirement, such an element may aid in preserving natural resources that can absorb hazard effects.

Florida was selected as the study state for several reasons. As the purpose of my research is to ascertain what factors drive quality of hazard mitigation elements in local CPs in a state with requirements for hazard mitigation elements in CPs, it was desirable to select a state with a high-quality requirement with enforcement mechanisms.

Essentially, a goal of my research is to ascertain if local governments make quality hazard mitigation elements when the state government has made a fairly strong effort to ensure this quality. Florida has a strong mandate and disincentives for non-compliance, and provides a supporting mechanism to craft quality hazard mitigation elements (Burby \& Dalton, 1994).

Florida also faces two significant hazards representing the majority of natural threats. The fact that Florida faces just two hazards, which in some ways are complementary in that both involve flooding, helps to reduce "noise" in the research data; otherwise, the planning approaches for various hazard types could produce "noise" that would have to be controlled for. Clearly, Florida is a hurricane prone state. Florida also faces flood hazards, both from coastal storms and wetland overflows. In fact, a recent estimate is that from 1990 through 2003, Florida suffered nearly $\$ 2.5$ billion in flood losses (Brody S. D., et al., 2007). 
Despite Florida's vulnerability to natural hazards, mitigation measures that could help to improve hazard mitigation planning have been reduced in recent years. Primarily, the Department of Community Affairs, which is responsible for regulating development of land and reviewed hazard mitigation elements in Florida county CPs, was largely dismantled in 2011 and integrated with the Department of Economic Opportunity (Pittman, 2011). The Florida legislature's action followed comments from newly elected Governor Rick Scott indicating that he believed the Department of Community Affairs was killing jobs and raising bureaucratic barriers to development (Pittman, 2011). Arguably, the move to consolidate a division charged with regulating development into one charged with promoting it could weaken the power of the regulating entity.

\section{Overall Summary}

The rating index is composed of 24 total items scored 0,1 , or 2 , meaning that the minimum score for a given hazard mitigation element is 0 and the maximum score is 48 . Overall, ratings revealed significant variation in the quality of hazard mitigation elements of Florida coastal county CPs. Plan scores were normally distributed with a range of 5 to 25. There was no noticeable correlation between geography and quality. The lowest rated plan was that of Jefferson County with a rating of 5, and the highest was Pinellas County with a rating of 25 . Ratings averaged 14.06 , with the median at 14 and a standard deviation of 4.759. With a skewness of .456 and a kurtosis of -.159 , the distribution of scores is relatively normal, as shown in Figure 2, below. 


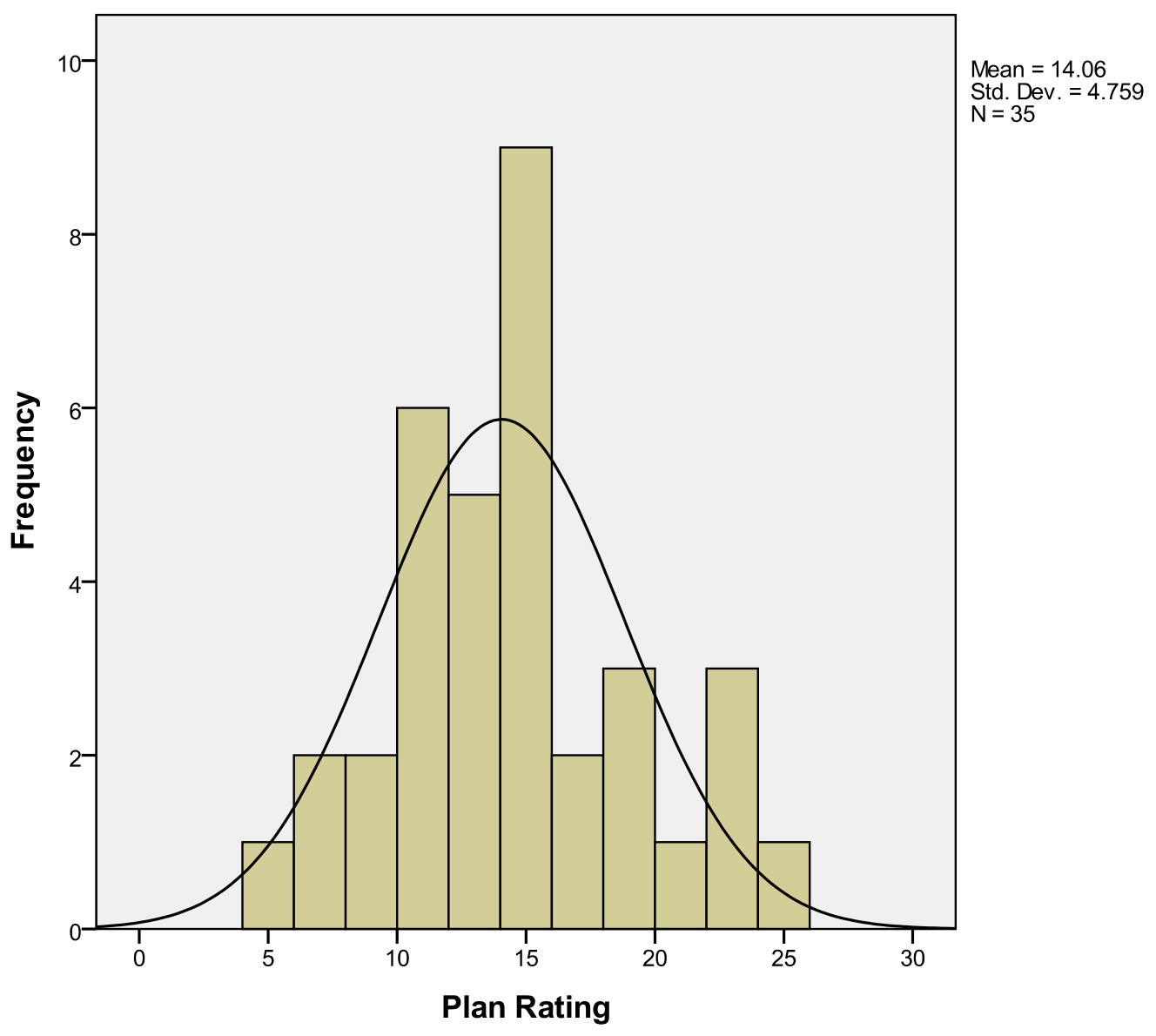

Figure 2: Distribution of ratings of hazard mitigation components of comprehensive plans in Florida coastal counties

In the interviews of land use planning leaders, referenced above and further explained below, I asked interviewees if they found the ratings assigned to the 35 coastal counties to be surprising. While no one rating came as a surprise to any of the interviewees, one interviewee did note that he would have expected the ratings to be more uniform and not as varied as they are.

Table 3 , below, is a matrix showing how many plans received each of the three score levels for each element. In particular, a few elements stand out and bear discussion. While it is possible to infer the hazards of concern by reading the plans, most plans (20) 
do not directly identify the hazards their respective communities face. Also notable, 29 plans do not contain a historical account of hazards and disasters affecting the community. While it certainly can be argued that the most effective planning departments should also be learning organizations that use past occurrences to shape future policies, my evaluation clearly reflects that local governments are not taking the opportunity to learn about hazards and disasters. Only two plans discuss forecasted hazards and magnitudes, which should be critical elements in hazard mitigation planning as local governments must know what they face in order to plan for it. Only approximately half of the plans mandate a public hazard education component.

On a stronger note, 31 plans directly identified hazard mitigation as a goal; this is critical as Florida CPs are built out in a structure in which goals are assigned objectives which the plan achieves through policies. Collaboration was a strong theme, with 32 plans identifying other units of government or agencies with which the local government would coordinate. All of the plans limited development in hazard zones, and 10 outright prohibited it. A total of 24 plans take advantage of the power of nature as a barrier to hazards. 


\begin{tabular}{|c|c|c|c|}
\hline \multirow[b]{2}{*}{ Rating Item } & \multicolumn{3}{|c|}{ Count of Plans by Rating } \\
\hline & $\begin{array}{c}0 \\
\text { Not } \\
\text { Present }\end{array}$ & $\begin{array}{c}1 \\
\text { Present }\end{array}$ & $\begin{array}{c}2 \\
\text { Discussed } \\
\text { in Detail }\end{array}$ \\
\hline Identification of Hazards & 20 & 11 & 4 \\
\hline Disaster and Hazard History & 29 & 6 & 0 \\
\hline Identification of Hazard Mitigation as a Goal & 2 & 31 & 2 \\
\hline $\begin{array}{l}\text { Maps Delineating Coastal High Hazard Areas (CHHA), } \\
\text { Flood Zones, and/or Other Hazards }\end{array}$ & 11 & 16 & 8 \\
\hline Forecasted Hazards and Magnitudes Presented & 33 & 2 & 0 \\
\hline Learning from Hazards is Incorporated Explicitly & 4 & 29 & 2 \\
\hline Explicit Use of the Vulnerability Concept & 34 & 1 & $\underline{0}$ \\
\hline Public Participation in Planning is Codified in the Plan & 24 & 3 & 8 \\
\hline Interviews Conducted with Key Stakeholders & 35 & 0 & 0 \\
\hline $\begin{array}{l}\text { Exposure of Property and/or Population to Hazards } \\
\text { Analyzed }\end{array}$ & 28 & 5 & 2 \\
\hline $\begin{array}{l}\text { Exposure of Public Infrastructure and/or Critical Facilities to } \\
\text { Hazards Analyzed }\end{array}$ & 27 & 8 & 0 \\
\hline $\begin{array}{l}\text { Other Governments, Government Agencies, Non- } \\
\text { Governmental Organizations, and/or Stakeholders Identified } \\
\text { with at Least Some Intent to Collaborate Noted }\end{array}$ & 3 & 13 & 19 \\
\hline $\begin{array}{l}\text { SLOSH or an alternative formal model is utilized to model } \\
\text { flooding and wind hazards. }\end{array}$ & 21 & 11 & 3 \\
\hline Development is Limited in Hazard Zones & 0 & 27 & 8 \\
\hline Development is Prohibited in Hazard Zones & 25 & 9 & 1 \\
\hline Evacuation Times and/or Feasibility & 23 & 4 & 8 \\
\hline Evacuation Routes Mapped & 14 & 15 & 6 \\
\hline Evacuation Shelter Capacity Inventoried & 24 & 5 & 5 \\
\hline $\begin{array}{l}\text { Mitigation Required from Developments that Increase } \\
\text { Evacuation Time }\end{array}$ & 19 & 11 & 5 \\
\hline $\begin{array}{l}\text { Specific Rule that Public Funding will not Improve } \\
\text { Infrastructure Beyond Current Level of Service in Hazard } \\
\text { Zones }\end{array}$ & 1 & 26 & 8 \\
\hline Use of Nature as a Hazard Barrier is Explicit & 11 & 15 & 9 \\
\hline Hazard Education Component & 18 & 13 & 4 \\
\hline Building Codes are Mandated in Hazard Zones & 10 & 23 & 2 \\
\hline $\begin{array}{l}\text { Tax Abatement for New Development Employing } \\
\text { Mitigation, and/or for Retrofits that Mitigate Hazards }\end{array}$ & 35 & 0 & 0 \\
\hline
\end{tabular}

Table 3: Scoring elements and results. 
In the sections below, the ratings are dissected based on several independent variables that could potentially influence each one. I tested the ratings for differences by geography, hazard history, and significant demographic factors.

\section{Geographic Differences}

There are several reasons why plans might differ based on geography. Primarily, different geographies have different hurricane exposures. Secondarily, different geographies in Florida contain different population groups and political influences. In order to test for geographic differences, I divided the state into the regions shown in Table 4, below.

\begin{tabular}{|l|l|}
\hline \multicolumn{1}{|c|}{ Region } & \multicolumn{1}{c|}{ Counties } \\
\hline Panhandle & $\begin{array}{l}\text { Jefferson, Taylor, Walton, Gulf, Wakulla, Okaloosa, Franklin, Santa Rosa, Bay, } \\
\text { Escambia, Hillsborough }\end{array}$ \\
\hline North Gulf & Dixie, Hernando, Levy, Pasco, Citrus, Pinellas \\
\hline South Gulf & Lee, Manatee, Monroe, Collier, Sarasota, Charlotte \\
\hline South Atlantic & Palm Beach, Martin, St. Lucie, Broward, Miami-Dade, Indian River \\
\hline North Atlantic & Nassau, Volusia, Brevard, Flagler, St. John's, Duval \\
\hline
\end{tabular}

Table 4: Regions and counties used in this study

In this analysis, I used ANOVA testing to compare the variation within and between plan rating scores in each region. With a result of $p=.148$, there is no statistically significant difference in scores when divided by regions. As shown in Table 5, below, the Panhandle and North Gulf Regions had the most variation in county level scores within them. Note that, while the 35 counties used in these tests represent the entire universe of counties in this study, this small set of cases should be kept in mind when interpreting results. 


\begin{tabular}{|l|r|r|r|r|r|}
\hline \multicolumn{1}{|c|}{ Region } & Mean & \multicolumn{1}{c|}{$\begin{array}{c}\text { Standard } \\
\text { Deviation }\end{array}$} & Minimum Score & Maximum Score & Range \\
\hline Panhandle & 11.27 & 4.606 & 5 & 22 & 17 \\
\hline North Gulf & 15.33 & 6.947 & 9 & 25 & 16 \\
\hline South Gulf & 16.83 & 3.371 & 14 & 22 & 8 \\
\hline South Atlantic & 15.33 & 3.266 & 11 & 20 & 9 \\
\hline North Atlantic & 13.83 & 3.312 & 9 & 19 & 10 \\
\hline
\end{tabular}

Table 5: Plan scores by region

\section{Correlation with Hazard History}

No correlation of statistical significance appears to exist between each county's

Storm Index score (representing number of storm strikes, recency of strikes, and strength of storms) and plan quality (Spearman's Rho $(\mathrm{P})=0.188, p=.288)$. The relationship, or lack thereof, is shown in Figure 3, below. 


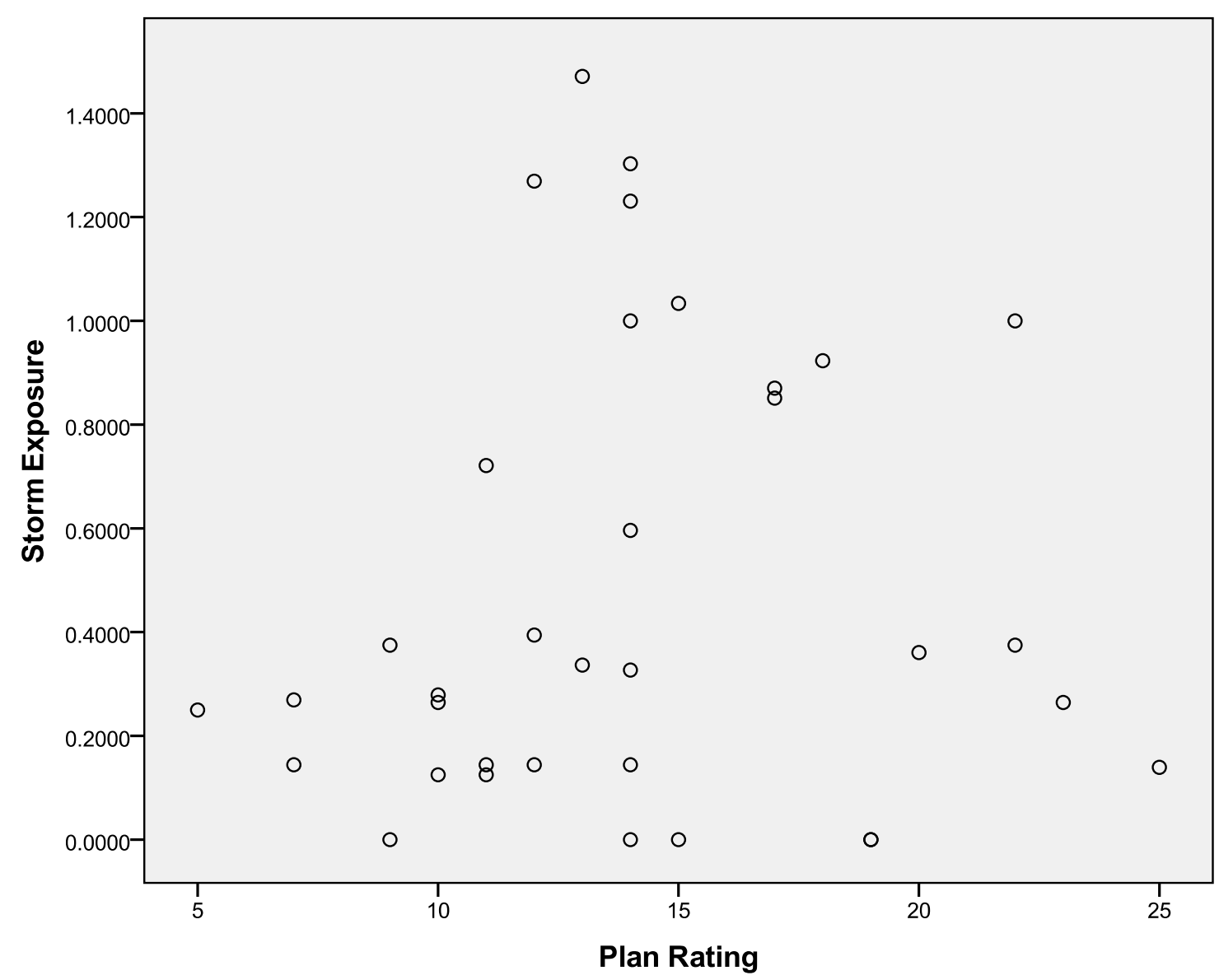

Figure 3: County plan ratings compared to historical storm exposure

\section{Analysis of Vulnerability-Related Variables Against Plan Quality}

Theories related to vulnerability to natural hazards generally posit that people of lower socio-economic standing, absent factors making them more resilient, will be more prone to disasters than those of higher socio-economic standing. To test this, I considered the socioeconomic variables below to measure vulnerability of the populations. 


\section{Median Household Income}

One of the major foci of the vulnerability paradigm is wealth, and the poor are generally considered more vulnerable to hazards than the wealthy (Cutter, et al., 2003; O'Hare \& Rivas, 2005; Parasuraman \& Acharya, 2000; Vatsa, 2004; Wisner, et al., 2004). The poor tend to suffer more in disasters for various reasons (Turner, 1979; Vatsa, 2004), and when experiencing a disaster, they have insufficient resources to fully recover and become resilient to the next hazard (Wahlstrom, 2007; Wisner, et al., 2004). While the wealthy can often buy protection from hazards by fortifying their homes, living in safe locales, diversifying their income sources, and buying insurance, the poor tend to lack insurance, have fewer resources for coping with hazards, have less diversity in income (a hazard can disrupt income earning activities), and live in more vulnerable structures in more vulnerable locations (Winchester, 2000). Often, hazardous areas, such as coastal zones and volcano slopes, are attractive locations for the poor to engage in economic activities (Wisner, et al., 2004). The ability to engage in economic activities

may attract people to live in these areas, and at the very least exposes them to a hazard if they are working at the time of a hazard strike. Furthermore, if a hazard strikes in these areas, it eliminates or reduces income earning capacity, and cuts into the ability to resiliently recover and prepare for future hazards.

In examining the vulnerability of 250 U.S. counties, Cutter, Boruff, and Shirley (2003) found that, among eleven factors, wealth alone accounted for $12.4 \%$ of the variation in vulnerability. The poor are generally found to be at greater vulnerability to natural hazards than the middle-class and wealthy for several reasons (Vatsa, 2004). In comparison to the upper and middle classes, the poor are less likely to have homes and 
businesses that are structurally capable of withstanding hazards, are less likely to have places to evacuate to, and are less likely to evacuate because of the associated costs both from the evacuation and lost wages during the evacuation. The poor are also more likely to be relegated to living in dangerous places, such as flood zones and mountainsides. Finally, the poor often have less of an ability to "bounce back" after a disaster and return to normalcy; for the poor, each successive hazard can chip away at their resiliency and increase their vulnerability.

Conversely, increased wealth increases resiliency (Cutter, et al., 2003) but can also increase the amount of property at risk. Wealth provides access to insurance, increased options to build structural mitigation measures, and the ability to leave incomeearning work to evacuate in the presence of hazards, and it increases ability to rebound from a disaster quickly and effectively - thus helping to close the disaster cycle.

From a resource perspective, the wealth of a community may have a bearing on planning for hazard mitigation. Community wealth both can purchase access to quality planning (i.e., more educated planners, updated GIS maps, more detailed maps, LIDAR surveys), and can present the community with the option to forego tax revenues and not allow development in hazard zones (Burby \& Dalton, 1994; Deyle, et al., 1998).

Age

Age is frequently cited as a characteristic of individual vulnerability (Cutter, et al., 2003; Kusenbach, et al., 2010). In my research, it serves, in aggregate, as a potential predictor of vulnerability. Age can have both positive and negative effects on vulnerability. In some situations, older people may be more vulnerable than young and 
middle-aged people, as they may need to rely on others to build resilient homes, prepare for oncoming disasters, and evacuate. However, in other situations, older people could have increased financial resources, allowing them to purchase these services, services that their less economically able counterparts may not enjoy, and possibly even making them less vulnerable than younger populations with less wealth. Furthermore, older persons may have access to greater social support networks to assist them, more formal social services, and more time to prepare for hazards. Thus, the aged may actually have some resilient characteristics that younger groups lack (Kusenbach, et al., 2010).

\section{Race}

Because of the potential for inequality, race is often cited as a factor in individual vulnerability (Cutter, et al., 2003; Oliver-Smith, 1996). Race can be associated with many other vulnerability-inducing factors, including income inequality, discrimination in the offering of services (i.e., evacuation, post-disaster recovery), and spatial segregation in which those discriminated against are relegated to living in more dangerous places.

In this analysis, race is captured as "White" or "Non-White" because of limitations in Census data. The U.S. Census data records people as having one race alone or a mixture of races. Because people reporting a mixture of White race and any other race category could potentially be treated socially and economically as either White or another race (depending on which culture the person identifies with, and how the community around the person perceives the person), people who are not reported as "White Alone" are treated as a minority in this analysis. 


\section{Ethnicity}

While race is often mentioned as a contributor to vulnerability, it is also important to examine ethnicity, especially in the Florida context (Cutter, et al., 2003; Oliver-Smith, 1996). Race and ethnicity are nearly universally held to be correlated with vulnerability, and research has shown that these demographics affect perception of and thus mitigation actions for natural hazards (Fothergill, et al., 1999). While research has found that minority race and ethnicity often contribute to a population's vulnerability (Kusenbach, et al., 2010), because they have a reduced access to resources (education, public services, economic resources, etc.), some authors have suggested that minority groups may utilize alternate, highly effective networks of communication (Peguero, 2006; Fothergill, et al., 1999; Perry \& Green, 1982). Certainly, race and ethnicity may also connect to vulnerability in terms of capacity for policymaking. Minority heavy communities may, under a traditional vulnerability paradigm, have fewer resources to devote to planning. Furthermore, while people of minority groups may be the most vulnerable to natural hazards, they also may be at significant risk for political and policymaking disenfranchisement.

While it has become recognized that effective hazard mitigation requires planners to gather information from vulnerable populations, both to determine their vulnerability and to gather information to capitalize on their resiliency, minority status may be a barrier that keeps planners from getting information from the most vulnerable. It is critical to explore the relationships between race and ethnicity and hazard mitigation element quality. 
My research only utilizes Hispanic and non-Hispanic ethnicity in the analysis. The only ethnicity recorded in U.S Census data is "Hispanic" and this is a limitation of the analysis.

\section{Education}

Level of education may have bearing on vulnerability (Hutton \& Haque, 2004). A higher level of education is thought to decrease vulnerability, while lower levels of education are thought to increase vulnerability (Cutter, et al., 2003). Higher education has a tripartite effect. The more educated, especially in countries with higher levels of inequality, tend to have more resources to influence the political process; further, formal education could contribute to a person's ability to understand hazards and potential solutions. Education may help people to gain access to, process, and use hazard information. Finally, with education may come increased economic abilities to take mitigatory actions, evacuate, and to rebuild in a resilient fashion; notably, the more educated are more likely to hold salaried jobs and jobs that, in today's electronic world, can be done remotely, thus enabling them to evacuate and not report to work in a disaster zone without significant income disruption.

\section{Population Density and Growth}

Communities with less room for development are less likely than those with more room to restrict development in hazard areas (Burby \& Dalton, 1994). Both population density and growth are oft-ignored components of "place inequalities" that contribute to vulnerability (Cutter, et al., 2003; Wisner, et al., 2004). Growth aside, higher population 
density is associated with a higher risk of death in natural hazards, especially floods, as more dense populations tend to be associated with greater impervious surface cover, which in turn increases flood flow rates and amounts of runoff (Zahran, et al., \& Grover, 2008). While some research has indicated that population density itself does not correlate with plan compliance with state mandates (Deyle \& Smith, 1998), other researchers have found that areas with more demand for development in hazard zones tend to have lower plan quality than areas with less demand for development (Brody S. D., 2003; Sengezer $\&$ Koc, 2005). Politically, it may be difficult to make hazard zones off- limits to development when other locations for development are already filled. Finally, in areas of rapid growth, social service networks and government services may not have caught up with the population, thus leaving people without essential networks to cope with disasters; similarly, planning for a rapidly growing area may tax planning departments, which could affect decision making and reduce the ability to make quality, wellconsidered decisions.

In their examination of vulnerability in 250 U.S. counties, Cutter, Boruff, and Shirley (2003) found that population density correlated with $11 \%$ of variation in vulnerability of the study counties. While a county-by-county examination of existing land use is beyond the scope of my research, I use population density as a proxy, hypothesizing that more densely populated counties will have fewer land options and will be less likely to create restrictions on land use that would make hazard zones unavailable for development. 


\section{Social Vulnerability Analysis Results}

While researchers have shown that social vulnerability affects the susceptibility of individuals and households to natural hazards (Zahran, et al., 2008; Burningham, et al., 2008), it may also play a role in the ability of an entire community to prepare for and mitigate against natural hazards. Socially vulnerable populations are more prone to suffering from property damage, injury, and death in the face of hazards, and less able to recover in a resilient fashion that prepares them for the next hazard. Thus, their vulnerability tends to increase with each successive hazard passage.

Prior research has shown a correlation between vulnerability to natural hazards and various social factors, such as minority status, age, wealth, and level of education. Factors including population, population density, and population growth may also affect hazard vulnerability. Because quality land use plans are one tool to reduce vulnerability, but also require a conscious decision to pursue and to devote resources to, it is hypothesized that these factors will correlate with plan quality.

Table 6, below, displays results of Spearman's Rho (P) correlations for each of the demographic variables with plan quality in Florida coastal counties. I chose this statistical measure because the data set is relatively small and it required a nonparametric measure. There was a fair degree of intercorrelation between the demographic variables, as well as several strong correlations between them and hazard mitigation element quality. These intercorrelations inform the discussion of correlations with hazard mitigation element quality. Keep in mind the limitation that while this represents the entire universe of counties in the study (Florida coastal counties), this is still a group of only 35 observations - a rather small number in terms of statistical testing. 


\begin{tabular}{|c|c|c|c|c|c|c|c|c|c|c|c|}
\hline & Pop. & $\begin{array}{c}\% \mathrm{w} / \mathrm{HS} \\
\text { Diploma or }+ \\
\end{array}$ & $\begin{array}{c}\% \mathrm{w} / \mathrm{BA} / \mathrm{BS} \\
\text { or }+\end{array}$ & $\begin{array}{c}\text { Med. H'hold } \\
\text { Income } \\
\end{array}$ & $\begin{array}{c}\text { Pop. Density } \\
\text { per Sq/Mi }\end{array}$ & $\begin{array}{c}\text { Density } \\
\text { Change: '00- } \\
\text { '10 } \\
\end{array}$ & $\% 62+$ & $\begin{array}{l}\% \text { Non- } \\
\text { White }\end{array}$ & $\begin{array}{c}\% \text { Hispanic } \\
\text { or Latino } \\
\end{array}$ & $\%$ Renting & Plan Rating \\
\hline \multirow[t]{2}{*}{ Pop. } & 1.000 & $.349^{*}$ & $.544 * *$ & .207 & $.946^{* *}$ & -.144 & -.008 & .276 & $.702 * *$ & $.650 * *$ & $.597 * *$ \\
\hline & & .040 & .001 & .232 & .000 & .408 & .962 & .108 & .000 & .000 & .000 \\
\hline \% w/ HS Diploma & $.349 *$ & 1.000 & $.614 * *$ & $.584 * *$ & $.345^{*}$ & -.102 & .133 & -.301 & .117 & .263 & $.341 *$ \\
\hline \multirow[t]{2}{*}{$\% \mathrm{w} / \mathrm{BA} / \mathrm{BS}$ or +} & $.544^{* *}$ & $.614 * *$ & 1.000 & $.733 * *$ & $.489 * *$ & -.076 & .055 & .013 & $.576^{* *}$ & $.566 * *$ & $.477^{* *}$ \\
\hline & .001 & .000 & & .000 & .003 & .666 & .752 & .939 & .000 & .000 & .004 \\
\hline \multirow{2}{*}{$\begin{array}{l}\text { Med. H'hold } \\
\text { Income }\end{array}$} & .207 & $.584^{* *}$ & $.733 * *$ & 1.000 & .120 & .084 & -.199 & -.034 & .180 & .317 & .096 \\
\hline & .232 & .000 & .000 & & .491 & .631 & .251 & .846 & .300 & .063 & .582 \\
\hline Density per Sq/Mi & $.946 * *$ & $.345^{*}$ & $.489 * *$ & .120 & 1.000 & -.110 & .071 & .242 & $.667 * *$ & $.578 * *$ & $.667 * *$ \\
\hline \multirow{2}{*}{$\begin{array}{l}\text { Pop. Density } \\
\text { Change: '00-‘ } 10\end{array}$} & -.144 & -.102 & -.076 & .084 & -.110 & 1.000 & .150 & -.266 & -.026 & $-.366^{*}$ & -.176 \\
\hline & .408 & .560 & .666 & .631 & .528 & & .391 & .123 & .881 & .031 & .313 \\
\hline \multirow[t]{2}{*}{$\% 62+$} & -.008 & .133 & .055 & -.199 & .071 & .150 & 1.000 & $-.553 * *$ & .246 & -.246 & .256 \\
\hline & .962 & .447 & .752 & .251 & .685 & .391 & & .001 & .154 & .153 & .138 \\
\hline \multirow[t]{2}{*}{$\%$ Pop. Non-White } & .276 & -.301 & .013 & -.034 & .242 & -.266 & $-.553 * *$ & 1.000 & .166 & $.423^{*}$ & -.042 \\
\hline & .108 & .079 & .939 & .846 & .160 & .123 & .001 & & .340 & .011 & .810 \\
\hline \multirow{2}{*}{$\begin{array}{l}\% \text { Hispanic or } \\
\text { Latino }\end{array}$} & $.702 * *$ & .117 & $.576^{* *}$ & .180 & $.667^{* *}$ & -.026 & .246 & .166 & 1.000 & $.651 * *$ & $.497 * *$ \\
\hline & .000 & .502 & .000 & .300 & .000 & .881 & .154 & .340 & & .000 & .002 \\
\hline \multirow[t]{2}{*}{$\%$ Renting } & $.650 * *$ & .263 & $.566 * *$ & .317 & $.578 * *$ & $-.366^{*}$ & -.246 & $.423 *$ & $.651 * *$ & 1.000 & $.439 * *$ \\
\hline & .000 & .127 & .000 & .063 & .000 & .031 & .153 & .011 & .000 & & .008 \\
\hline
\end{tabular}

$*=$ significant at $p \leq .05 * *=$ significant at $p \leq .01$
Table 6: Correlations of demographic variables and hazard mitigation element ratings 
Total population was positively correlated with hazard mitigation element quality at a moderate level $(\mathrm{P}=0.597, p \leq 0.000)$. This correlation may be because larger counties have more resources to build larger planning departments with planners able to focus on the hazard mitigation element, attract a higher caliber of planner, have increased exposure (and receive increased attention from state reviewers), or for other reasons.

Both the percentage of population over the age of 25 that at least graduated high school and the percent of population over age 25 with at least a bachelor's degree were correlated with hazard mitigation element quality $(\mathrm{P}=0.341, p=0.045$, and $\mathrm{P}=0.477, p$ $=0.004$, respectively). The correlation between plan quality and education follows typical trends expected of hazard vulnerability, and could be related to the population having more resources to build better plans, or being more involved in the planning process. Education was also intercorrellated with population, median household income, and population density, all of which could be drivers of plan quality, and are discussed elsewhere in this section.

Median household income was not correlated with plan quality at any level of statistical significance. Typically, other research has shown that higher income is associated with better hazard mitigation. However, it is possible that because of the stringent review that Florida's state government holds plans to, income differences were somewhat marginalized as all plans had to meet the same level of quality.

While population density was correlated with higher quality of hazard mitigation element $(\mathrm{P}=0.667, p \leq 0.000)$, change in population density over the last ten years was not $(\mathrm{P}=-0.176, p=0.313)$. I expected that changes in population density would correlate with plan quality in some way - either decreasing quality as density increased and 
government loosened rules to open avenues of development, or increasing it as governments saw a growing problem with people moving into the path of hazards and tightened rules to control land use. However, population density change was not correlated. Note also that population density was intercorrelated with education and population.

Population aged 62 or over did not bear a statistically significant correlation with hazard mitigation element quality, and, in fact, the positive correlation of $\mathrm{P}=0.256$ is not in the direction that traditional theories of vulnerability would suggest. Normally, age is considered to make persons more vulnerable; however, it is also known that the aged (and other groups considered to be "vulnerable") may have useful adaptation strategies. Potentially, in this context, people over the age of 62 have been more involved in local government and/or hazard mitigation issues specifically. Still further speculation is not warranted as the correlation is negligible at $\mathrm{P}=0.256$ and is not of statistical significance $(p=0.138)$

Because Census data groups people into many racial groups, I considered the proportion of the population that is not "White Alone" as a proxy to represent the "minority population" from a race perspective. Admittedly, this has two limitations. First, a person with even the smallest amount of any other race in his or her recent heritage would not be labeled "White Alone," but effectively may appear and act as a White person in the community. Thus, while the person in this category is technically in the correct category for analysis based on race, from a realistic social and economic perspective, he or she is not a minority person. Second, while not being "White Alone" may classify a person as a "minority" from many perspectives, in any given community 
cultural differences may enhance or diminish the effect of race. In other words, race may not always matter, and being of any given race could matter more in one community than another. While the minority race population did have a negative effect on plan quality, the affect was too slight at a correlation of $\mathrm{P}=-0.042$, and was not statistically significant $(p=0.810)$

I considered the Hispanic proportion of the population in the analysis. Not only does Hispanic population have a positive correlation with plan quality $(\mathrm{P}=0.497)$, but it is statistically significant at $p=0.002$. The measurement of Hispanic population was included with some hesitancy as there are a myriad of potential ethnicities, but the U.S. Census only provides data on Hispanic ethnicity. It is of interest that race bore no significant correlation, but ethnicity did. On the basis of the data in this analysis, speculation as to why Hispanic population correlates with increased plan quality would not be appropriate, but, this warrants further research. Note that Hispanic ethnicity is intercorrelated with education and population density, both of which are positively correlated with hazard mitigation element quality. Thus it is possible that in the case of Florida, Hispanic populations do not bear qualities often associated with minority groups. Finally, the percent of population in renter occupied housing was correlated with hazard mitigation element quality $(\mathrm{P}=0.439, p=0.008)$, but not in the anticipated negative direction. Typically a greater proportion of renter occupied housing would indicate that the population is poorer and has less resources to prepare for hazards, and would be expected to have a detrimental effect on hazard mitigation. Instead, the effect was positive. This could also be related to other factors with which the percent in renter 
occupied housing was correlated, including, population, education, and population density.

\section{Comparison of the Best and Worst Plans}

In the text above, I examine all Florida coastal counties, regardless of plan quality. However, this leaves the question of what trends exist among the best and worst rated plans, and how these two groups differ. In this section, a brief comparison is conducted between the five lowest rated plans (ratings of 5-9) and the top five rated plans (ratings of 20-25). The comparative analysis of best and worst plans could be of use to planners trying to improve their hazard mitigation elements.

Universally, the lowest rated plans did not identify hazards. However, all of the highly rated plans did, and three of these five were thorough enough to warrant a " 2 " rating for hazard identification. The difference in hazard identification is a key foundational element that planners could consider when building hazard mitigation elements.

The inclusion of maps delineating hazard zones also proved to be a distinguishing feature between the highest and most poorly rated hazard mitigation elements. Only one of the five lowest rated plans had these maps, while all of the top five had them, and two of them scored a " 2 " for the thoroughness of their maps. Maps can be extremely useful in making policies, implementing them (especially in zoning decisions), and showing the public the hazards that threaten a community.

Both the highest and lowest rated plans largely lacked either a history of hazards and disasters or a forecast of them. Two of the top five plans included these; three of the 
top plans did not include a history or forecast and none of the bottom rated plans included them. While the history can help to understand hazards and better plan for those that may arise, it is even more puzzling that there is not a forecast of expected hazard magnitudes to inform preparation and planning.

Two rating factors examine exposure to hazards: the first looks at population, the second public infrastructure. None of the lowest rated plans took stock of exposure to hazards in either regard, but all of the top rated plans did. Finally, four of the five lowest plans do not require use of a formal model for storm surge or other hazards, but four of the top five explicitly require such.

Except for one plan, the lowest rated plans considered neither evacuation times and feasibility, nor evacuation routes, nor evacuation shelter capacity; whereas four of the five top rated plans considered all three. While evacuations are not directly the province of planning departments, evacuation is very much affected by policies dictated in CPs (e.g., higher density may require wider roads for faster evacuation).

In summary, the lower rated plans generally do not incorporate potential sources for information that the higher rated plans do. Especially given that Florida has a significant and well documented hazard history that could inform planning in order to reduce hazards, this represents a significant loss of useful information that could benefit planning for hazards. 


\section{Conclusion}

The original research questions were:

1. Is there variation in the quality hazard mitigation elements of land use plans in a state that has a strong, prescriptive mandate for local land use plans to address hazard mitigation?

2. If so, what drives this variation?

In this chapter, the first question is answered (is there variation?) and some consideration given to the second (what drives variation?). In short, there is variation in the quality of hazard mitigation elements of land use plans in Florida coastal counties, and that variation is somewhat correlated with socio-economic variables typically thought to drive vulnerability to natural hazards.

My research employs a novel rating scale comprised of 24 factors to rate hazard mitigation elements of land use plans. Previous research utilized the majority of these index items, but some novel ones were added to my research. I scored each measure based on the level of detail presented $(0=$ Not Present, $1=$ Present, $2=$ Present in Exceptional Detail), and I summed scores for each plan, for a total possible score ranging from 0 through and including 48. Similar to prior research, this study did not judge the quality of each element alone, but rather the collective presence of elements to ascertain the thoroughness of plans.

Plan ratings come in at a low of 5 and a high of 25 , with a mean of 14.06 , median of 14 , and standard deviation of 4.759. ANOVA testing revealed that plan quality is not correlated with region. 
I examined the effects of historical hurricane strikes on hazard mitigation element quality, using an index that measured time since hazard strike, strength of hazards, and quantity of hazards. Tests revealed no correlation between hazard history and quality of the hazard mitigation element in land use plans. This finding is contrary to traditionally accepted knowledge of hazard vulnerability and mitigation, which would hold that communities that have experienced hazards tend to be better equipped to deal with future hazards than those that have not. However, given the finding that most plans do not formally incorporate knowledge from prior hazards, it makes sense that the plans are not typically bettered by hazard experience. Still, this brings up more questions for future research. Foremost, if communities are experiencing hazards but not learning enough to incorporate historical reality in planning documents, are planners aware of the effects of prior hazards and just ignoring them? Even if planners are aware of prior hazard strikes, is it possible that communities do not want to acknowledge the hazards and incorporate this knowledge? Finally, are communities intentionally being myopic in their future views, and building plans based upon a reality that they prefer versus one constructed from past experiences? If so, why?

Finally, I tested a spectrum of socio-economic variables typically thought to influence vulnerability to see if they correlate with hazard mitigation element quality. While researchers have not hypothesized that these variables directly influence quality of hazard mitigation elements in land use plans, they are known to affect vulnerability to natural hazards overall. Quality of hazard mitigation elements correlated directly with population, education, population density, Hispanic proportion of the population, and percent of population in rental housing. median household income, population density 
change, age, and race bore no correlation with hazard mitigation element quality. It is also notable that population was intercorrellated with several other variables that could be drivers of hazard mitigation element quality, including education and population density, which I discuss in greater detail below.

Taken collectively, these results are inconsistent, and cannot be taken to either support or refute the operation of Vulnerability Theory in the context of a developed, First-World state. It is notable that many of the socioeconomic variables correlated with vulnerability also are correlates to urbanity; these include population itself, education level, population density, and percent of population in renter occupied housing. This may indicate that while the individual variables are not strongly driving hazard mitigation element quality, urban areas fare better in terms of hazard mitigation element quality. This could be because of programs focused on increasing urban safety, increased attention to urban areas from the state planning review department, or simply a tendency of people to gather in locales more prone to hazards (and where growing populations increase hazard effects) that then results in greater care in hazard mitigation element design. The findings would have been more consistent had median household income shown a correlation with hazard mitigation element quality, as it could be theorized that some of these variables relate to higher wealth and thus abilities of a community to "buy" stronger planning organizations; however, such is not the case. Notably, also, all of the variables that correlated with hazard mitigation element quality also bear a statistically significant correlation with population. Possibly, these "large counties" get more attention from state plan reviewers, simply have more people at risk in coastal zones (which may weight the planning organization's attention toward hazard mitigation in 
comparison to areas with less coastal population), and/or have more resources to focus on individual plan elements due to sheer size of planning staff. This finding warrants further investigation in future research, and may prove important to helping improve state laws, rules, and procedures to ensure better hazard mitigation planning in "smaller" counties. 


\title{
V. SURVEYS: EXPLAINING VARIATION IN QUALITY OF HAZARD MITIGATION ELEMENTS IN LOCAL COMPREHENSIVE PLANS
}

\author{
Introduction
}

In this chapter I examine possible drivers of the quality of hazard mitigation elements in local land use plans. I have established that variation exists, even in Florida, where the state government has a strong, prescriptive mandate for local governments to include these elements. Essentially, the various local governments have, from distinct angles, approached the task of incorporating hazard mitigation into land use planning, rather than creating the uniform plans expected from stringent state regulation.

To study the variation in hazard mitigation element quality, I conducted a survey of the land use planning community in Florida and beyond via an online tool. I expanded the survey beyond Florida for several reasons. Because the survey responses were not intended to be tied to individual counties, there was no need to limit the surveys to Florida; the low marginal cost of expanding the survey population to collect more varied data from practitioners nationwide was also attractive. Furthermore, the purpose of the survey was not only to learn about mitigation in Florida plans, but also learn what professionals in general think contributes to quality hazard mitigation elements.

I based the survey questions and design on three significant sources of information: literature on planning, hazards, and disasters; practice; and the interviews of coastal county planning leaders (see the Appendix for the questions and topics covered and sources for each). I asked interviewees several questions in conversational interviews which were approximately 60 to 90 minutes in duration. Questions dealt with a) how the 
interviewees' counties were working to create high quality hazard mitigation elements, b) the nature of planning for hazard mitigation in CPs, c) what these planning leaders believe are important qualities of a good hazard mitigation element in a comprehensive plan, and d) how their Planning Departments coordinate within their own counties and with other governments. Further interview details can be found in the Appendix and the paragraphs below.

All four interviewees were aware of the legal requirements for hazard mitigation elements in Florida coastal county plans, as well as administrative codes interpreting the statutory requirements. The planning leaders interviewed reported that plans in their counties exceeded state requirements in several ways, including expansion of the geographic coastal area in which the county must plan for coastal storms, additional taxes used to purchase lands prone to hazards, and several other specific policies aimed at hazard reduction.

Interviewees listed several potential improvements for the hazard mitigation elements of their CPs, including lowering density in coastal zones, prohibiting mobile home development in these areas, and addressing sea level rise and climate change. Interviewees reported that the hazard mitigation element should guide policy implementation, address pre-disaster mitigation, and guide populations away from hazard zones. However, they had no consensus on what the most important components of a hazard mitigation element are.

Interviewees listed several specific actions they take to create high quality hazard mitigation elements, including the following: working closely with municipalities; using interdepartmental groups to strengthen policies and coordinating with other county 
departments; working with local environmental groups to make policy; working with a regional planning councils; completing plans in-house (versus contracting them out); and, actively working to maintain better ratings in FEMA's Community Rating System (which rewards communities for taking mitigatory action). Planning leaders cited several sources of information they consult including: their Emergency Management Department, Sherriff's Office, Fire Rescue Department, other local governments (both neighboring and within the county), civic associations, models (example: SLOSH), LIDAR [topographical] data, Flood Insurance Rate Maps, and Forest Service wild fire data.

Planning leaders said that some of the hallmarks of a quality hazard mitigation element include going beyond natural hazards; having a strong link between emergency response plans (i.e., evacuation) and land use planning; a holistic approach to planning that creates a plan realistic to implement; public information and outreach; focus on preparing infrastructure to survive a disaster; and coordination with other departments.

In terms of public interaction, interviewees said that, overall, the public is not very interested in providing input related to the hazard mitigation element unless there has been a recent disaster to draw attention to that element. Most public input comes from environmental groups, and some from business groups. While interviewees perceived public input as valuable for bringing people's experiences to the table, generally, they reported leaving public communication (aside from required hearings) up to their local emergency management departments. 


\section{Sample}

I directly invited a total of 581 people to participate in the survey. Additionally, I asked survey respondents who completed the survey to invite others who might be interested (snowball sample). Finally, I sent a mass survey invitation to the members of the Section on Emergency and Crisis Management (SECM) of the American Society for Public Administration. The survey was confidential.

The initial group of 581 people consisted of personnel involved with planning and/or natural hazards and disasters. The group composition was a) people who attended a natural hazards and disasters convention, and b) land use planners in all Florida counties. To obtain the latter list, I reviewed websites for each Florida county to obtain email addresses of all planners, and if they were not listed online, I contacted departments via e-mail, with two follow-up telephone calls, to obtain the list. I (the principal investigator) and sponsoring faculty sent direct invitations to the survey group via email on electronic university letterhead. I sent a reminder e-mail to non-respondents to request participation. I provided each participant with an individual link to the survey to track participation and conduct follow-up.

I e-mailed a link to the survey via the Section on Emergency and Crisis Management (SECM) of the American Society for Public Administration. The SECM is a subsection of the American Society for Public Administration for members with an interest in emergency and crisis management.

Additionally, I employed snowball sampling. After invited participants completed the survey, I emailed them to express gratitude for their participation. The "thank-you e- 
mail" contained a link to the survey and asked participants to forward the link to other persons who might be interested in participating.

Table 7, below, summarizes usable responses to the survey. A usable response is any one in which the respondent answered all survey questions for the primary survey section regarding plan quality.

\begin{tabular}{|l|l|r|l|}
\hline \multicolumn{1}{|c|}{ Group } & \multicolumn{1}{|c|}{ Invitations Sent } & Complete Responses & Response Rate \\
\hline $\begin{array}{l}\text { Planners and } \\
\begin{array}{l}\text { Hazard/Disaster } \\
\text { Professionals (Original } \\
\text { List) }\end{array}\end{array}$ & & & \\
\hline Snowball Sample & & & \\
\hline SECM & Unknown & 97 & $16.70 \%$ \\
\hline \hline Total & Unknown & 24 & Unknown \\
\hline
\end{tabular}

Table 7: Survey responses by contact group

In order to check for response bias, I examined the organizations represented by respondents. Table 8 , below, details the number of invited people from each type of organization and how many responded. 


\begin{tabular}{|l|r|r|r|}
\hline \multicolumn{1}{|c|}{ Organization Type } & Persons Surveyed & \multicolumn{1}{c|}{ Responses Received } & \multicolumn{1}{c|}{ Response Rate } \\
\hline Association & 6 & 2 & $33.33 \%$ \\
\hline Consultant & 24 & 6 & $25.00 \%$ \\
\hline Federal Government & 43 & 7 & $16.28 \%$ \\
\hline Finance & 1 & 0 & $0.00 \%$ \\
\hline Insurance & 1 & 0 & $0.00 \%$ \\
\hline Legislative & 3 & 0 & $0.00 \%$ \\
\hline Local Government & 230 & 35 & $15.22 \%$ \\
\hline Media & 3 & 0 & $0.00 \%$ \\
\hline Medical & 1 & 0 & $0.00 \%$ \\
\hline NGO & 2 & 0 & $0.00 \%$ \\
\hline Other/Unknown & 5 & 1 & $20.00 \%$ \\
\hline Regional Planning & 48 & 3 & $6.25 \%$ \\
Council & 18 & 5 & $27.78 \%$ \\
\hline Science/Think Tank & 20 & 7 & $35.00 \%$ \\
\hline State Government & 166 & 29 & $17.47 \%$ \\
\hline University/Academic & 8 & 1 & $12.50 \%$ \\
\hline Voluntary Organizations & 2 & 0 & $0.00 \%$ \\
\hline $\begin{array}{l}\text { Water Management } \\
\text { Districts }\end{array}$ & & 3 & \\
\hline
\end{tabular}

Table 8: Survey responses by organization

Clearly, response rates varied greatly by organization type; however, it is notable that for some of the organization types surveyed, there were very few people in the initial survey group. Thus, even one or two non-responses significantly affect the response percentage. Notably, while federal and local government responded at a similar rate, $16 \%$ and $15 \%$, respectively, state government responded at a rate of $35 \%$. However, because the number of people surveyed in the state and federal groups was so small, this number is easily affected.

To learn about the respondents, the survey included a free form, fill-in-the-blank box that recorded position and level. Although I received sufficient data to analyze positions, the information on level reflected a great degree of subjectivity and variation in responses (e.g., some people entered "senior" while others gave a career history) that 
precluded it from analysis. Table 9, below, shows the breakdown of respondents. Note that some respondents either did not give a position, or entered a vague one. For them, I consulted the original survey contact list to find their position, or if they were part of the snowball or SECM sample, I used their e-mail address, if provided, to research the type of organization they worked for.

\begin{tabular}{|l|r|r|}
\hline \multicolumn{1}{|c|}{ Job Category } & \multicolumn{1}{c|}{ Count } & Percent \\
\hline Planning & 44 & $34 \%$ \\
\hline Research/Academic & 39 & $30 \%$ \\
\hline Unknown & 14 & $11 \%$ \\
\hline Hazard mitigation & 11 & $9 \%$ \\
\hline Disaster Response & 8 & $6 \%$ \\
\hline Science & 5 & $4 \%$ \\
\hline Consulting & 3 & $2 \%$ \\
\hline Disaster Recovery & 2 & $2 \%$ \\
\hline Advocacy & 1 & $1 \%$ \\
\hline Law & 1 & $1 \%$ \\
\hline
\end{tabular}

Table 9: Respondents and professions

About one-third of respondents were from the planning field, and approximately another third were researchers or academicians. Of the 128 respondents with complete responses, 22 did not indicate their state or county. Table 10, below, shows, of the remaining 106 , any states which accounted for $5 \%$ or greater of the complete responses.

\begin{tabular}{|l|r|r|}
\hline \multicolumn{1}{|c|}{ State } & Respondents & Percent \\
\hline Florida & 40 & $38 \%$ \\
\hline California & 9 & $8 \%$ \\
\hline Colorado & 7 & $7 \%$ \\
\hline Washington & 5 & $5 \%$ \\
\hline Georgia & 5 & $5 \%$ \\
\hline Louisiana & 5 & $5 \%$ \\
\hline
\end{tabular}

Table 10: Respondents by State (over 5\%) 


\section{Results and Analysis}

Below, I present findings from each question in the survey. On the basis of data collected, I examine differences in how professionals from each category responded. I used ANOVA testing; however, because some professions are represented by such a small number of respondents, I excluded respondents from any profession that represented less than $5 \%$ of the sample and all respondents with an unknown profession. The exclusion of respondents that did not represent more than $5 \%$ by profession means that I only included respondents in the professions of Planning, Research/Academic, Hazard Mitigation, and Disaster Response in the ANOVA tests. It is important to note that, with 128 respondents and four professional groups, sometimes the ANOVA test showed statistically significant differences between responses by professional group, but that in practical terms, the average responses given by the groups differed little. Note that the percentages presented in Columns 2-5 include all respondents.

\section{Elements of a Quality Hazard Mitigation Element in a Comprehensive Plan}

One of the primary research questions was what constitutes a quality hazard mitigation element in a comprehensive plan. To help ascertain what represents a quality hazard mitigation element, the survey asked respondents to rate several potential elements on a scale from 1 (Strongly Disagree with Including the Item as a Measure of Quality) to 5 (Strongly Agree with Including the Item as a Measure of Quality). Table 11, below, presents the percentage of respondents who selected each response, followed by the ANOVA results for the test for differences between the four largest professional 
groups represented in the sample groups. If ANOVA testing revealed significant results, the question is marked with an "*" for further examination, below.

\begin{tabular}{|l|c|c|c|c|c|}
\hline & \multicolumn{2}{|c|}{ Percent of Respondents Selecting Each Option } \\
\cline { 2 - 6 } & $\begin{array}{c}\text { 1 } \\
\text { Strongly } \\
\text { Disagree/ } \\
\text { Do Not } \\
\text { Include } \\
\text { in Rating }\end{array}$ & $\mathbf{2}$ & & & $\begin{array}{c}\text { 5 } \\
\text { Strongly } \\
\text { Agree/ } \\
\text { Include } \\
\text { in Rating }\end{array}$ \\
\hline $\begin{array}{l}\text { Planners interview key hazard } \\
\text { mitigation stakeholders (e.g., } \\
\text { community leaders other than elected } \\
\text { officials) }\end{array}$ & $1.56 \%$ & $1.56 \%$ & $10.94 \%$ & $32.03 \%$ & $53.91 \%$ \\
\hline $\begin{array}{l}\text { The plan uses Sea, Lake and Overland } \\
\text { Surges from Hurricanes (SLOSH) or } \\
\text { an alternative formal model* }\end{array}$ & $3.13 \%$ & $3.13 \%$ & $24.22 \%$ & $30.47 \%$ & $39.06 \%$ \\
\hline Development limited in hazard zones* & $3.13 \%$ & $4.69 \%$ & $6.25 \%$ & $25.78 \%$ & $60.16 \%$ \\
\hline $\begin{array}{l}\text { Development prohibited in hazard } \\
\text { zones }\end{array}$ & $6.25 \%$ & $21.88 \%$ & $14.06 \%$ & $33.59 \%$ & $24.22 \%$ \\
\hline $\begin{array}{l}\text { No additions or improvements to } \\
\text { public infrastructure in hazard zones }\end{array}$ & $12.50 \%$ & $22.66 \%$ & $16.41 \%$ & $23.44 \%$ & $25.00 \%$ \\
\hline $\begin{array}{l}\text { Mitigation required from } \\
\text { developments that increase evacuation } \\
\text { times }\end{array}$ & $3.91 \%$ & $3.13 \%$ & $17.19 \%$ & $42.19 \%$ & $33.59 \%$ \\
\hline $\begin{array}{l}\text { Nature used as a barrier against } \\
\text { natural hazards (e.g., mangrove } \\
\text { protection to maintain coastline) }\end{array}$ & $2.34 \%$ & $0.78 \%$ & $12.50 \%$ & $25.00 \%$ & $59.38 \%$ \\
\hline $\begin{array}{l}\text { The Planning Department is mandated } \\
\text { to hold public meetings throughout the } \\
\text { planning process }\end{array}$ & & & & & \\
\hline $\begin{array}{l}\text { Required consultation with special } \\
\text { districts and local governments in } \\
\text { county (e.g., school boards, } \\
\text { municipalities, etc.) }\end{array}$ & $0.78 \%$ & $6.25 \%$ & $7.81 \%$ & $32.03 \%$ & $53.13 \%$ \\
\hline $\begin{array}{l}\text { Building codes employed in hazard } \\
\text { zones* }\end{array}$ & $1.56 \%$ & $0.00 \%$ & $2.34 \%$ & $16.41 \%$ & $79.69 \%$ \\
\hline
\end{tabular}

*Significant difference $(\mathrm{p}<.10)$ between top four professional groups represented in the survey

Table 11: Value of various components of hazard mitigation elements in comprehensive plans

Overall, respondents agreed (responses of "Strongly Agree" or "Agree") that it is important that hazard mitigation elements should incorporate interviews of stakeholders, SLOSH or other formal models, limitation or prohibition of development in hazard zones, mitigation from developments that increase evacuation times, use of nature as a hazard barrier, public meetings, and building codes. 
Outright prohibition of development in hazard zones was not as supported as limitation of development. The lack of support for prohibition of development may be related to the fact that development brings with it income for local governments - an especially salient issue, given that economic climate present at the time of this survey (e.g., declining budgets, significant cutbacks).

Over three quarters of respondents were in favor of using nature as a hazard barrier. Because it is relatively unique, I expected the notion of nature as a hazard barrier to be less supported, but there is clear support for the use of nature to mitigate hazards.

In four areas, there were significant differences in how people from the fields of Planning, Research/Academic, Hazard Mitigation, and Disaster Response responded. Table 12, below, shows the results of ANOVA testing examining how these groups responded to the question of how important certain plan elements are, as well as the mean response for each group by element. Higher numbers in the right four columns indicate that the group found the element to be more important, while lower numbers indicate the converse. Notably, while the differences between groups are statistically significant, the average responses differ little in practice. 


\begin{tabular}{|l|c|c|c|c|c|c|}
\hline & \multicolumn{2}{|c|}{ ANOVA } & \multicolumn{3}{c|}{ Average Importance by Profession } \\
\hline & $\boldsymbol{P}$ & $\boldsymbol{F}$ & Planning & $\begin{array}{c}\text { Research/ } \\
\text { Academic }\end{array}$ & $\begin{array}{c}\text { Hazard } \\
\text { Mitigation }\end{array}$ & $\begin{array}{c}\text { Disaster } \\
\text { Response }\end{array}$ \\
\hline $\begin{array}{l}\text { Planners interview key } \\
\text { hazard mitigation } \\
\text { stakeholders (e.g., } \\
\text { community leaders other } \\
\text { than elected officials) }\end{array}$ & 0.013 & 3.750 & 4.05 & 4.51 & 4.73 & 4.75 \\
\hline $\begin{array}{l}\text { The plan uses Sea, Lake and } \\
\text { Overland Surges from }\end{array}$ & & & & & & \\
$\begin{array}{l}\text { Hurricanes (SLOSH) or an } \\
\text { alternative formal model }\end{array}$ & 0.039 & 2.899 & 4.25 & 3.64 & 3.82 & 4.25 \\
\hline $\begin{array}{l}\text { Development limited in } \\
\text { hazard zones }\end{array}$ & 0.094 & 2.187 & 4.55 & 4.25 & 3.73 & 4.50 \\
\hline $\begin{array}{l}\text { Building codes employed in } \\
\text { hazard zones }\end{array}$ & 0.022 & 3.341 & 4.80 & 4.74 & 4.82 & 4.00 \\
\hline
\end{tabular}

Table 12: Differences between groups on importance of specific components in hazard mitigation elements

While planning is typically considered an iterative method of making policy, with collaboration throughout, when asked about the necessity of interviewing key stakeholders, planners actually were the group that found this least important, with an average importance of 4.05. Similarly, but not quite so profoundly, Researchers and Academics rated it a 4.51, which was the second lowest. This score is clearly in the "strongly agree" range indicating that respondents from both professions see value in talking with key stakeholders; but, this does show significantly lower support for conducting interviews with key stakeholders than other professional groups (Hazard Mitigation and Disaster Response) gave. One possible reason is that Planners and Researchers and Academics see interviewing stakeholders as a time consuming activity that is not accompanied by a payoff worth the amount of time it takes, whereas Hazard Mitigation and Disaster Response professionals saw this as a good idea, but do not understand the cost/benefit calculus involved in interviewing stakeholders. Planning professionals and Researchers/Academics may also have a salient understanding that interviewing just a few stakeholders could provide an unrepresentative sample, which for 
planners could be especially problematic if the public was to perceive this as poor data gathering, or worse, favoritism toward a particular interest. Another explanation is that these groups may be realists, or at least so in their own perception, about the facts of public participation, and may see it as required by law, but not very useful. The difference in responses by professional group could be fueled by the fact that, as interviewees for my research noted, the public is often not interested in hazard mitigation in comprehensive planning, but rather leans toward more prominent issues of zoning and land use.

Hazard Mitigation practitioners gave the concept of limiting development in hazard zones the lowest rating of any group, at 3.73; however, Planners gave an average importance of 4.55. This reflects a possible difference between the two groups in that Hazard Mitigation professionals may be more focused on accommodating development by mitigating, while planners see limitation of development as a stronger option.

\section{Use of the Vulnerability Concept in Hazard Mitigation Elements of Comprehensive Plans}

The survey defined the concept of vulnerability as "Vulnerability, in this context, is the idea that 'disadvantaged' groups (the poor, minorities, etc.) are more prone to experiencing a disaster than others, and less able to prepare for and mitigate against disasters." The survey prompted "Generally speaking, Comprehensive Plans should incorporate the concept of vulnerability," and provided respondents with the same 1 (Strongly Disagree) to 5 (Strongly Agree) rating scale used in the rest of the survey. Table 13, below, shows these results. 


\begin{tabular}{|l|r|r|r|r|r|}
\hline & \multicolumn{3}{|c|}{ Percent of Respondents Selecting Each Option } \\
\cline { 2 - 6 } & $\begin{array}{c}\mathbf{1} \\
\text { Strongly } \\
\text { Disagree }\end{array}$ & $\mathbf{2}$ & $\begin{array}{c}\mathbf{3} \\
\text { Neutral }\end{array}$ & $\mathbf{4}$ & $\begin{array}{c}\mathbf{5} \\
\text { Strongly } \\
\text { Agree }\end{array}$ \\
\hline $\begin{array}{l}\text { Generally speaking, comprehensive } \\
\text { plans should incorporate the concept } \\
\text { of vulnerability* }\end{array}$ & $1.56 \%$ & $0.78 \%$ & $14.84 \%$ & $26.56 \%$ & $56.25 \%$ \\
\hline
\end{tabular}

*Significant difference $(\mathrm{p}<.10)$ between top four professional groups represented in the survey

Table 13: Importance of using the vulnerability concept

With $82.81 \%$ of respondents rating use of vulnerability in plans as something they agree with, including over 50\% indicating "Strongly Agree," there is strong support for incorporation of vulnerability in planning for hazards. It would be interesting to further explore, in future research, if respondents were aware of and/or applying the vulnerability concept prior to hearing of it in the survey. Being able to see how many respondents were already employing the concept, versus how many saw it as a novel, but useful concept, would shed interesting light on applications of vulnerability in a First World setting.

Notably, there was a difference in responses from people from the fields of Planning, Research/Academic, Hazard Mitigation, and Disaster Response. Table 14, below shows each group's average response, with higher values indicating a greater agreement with the idea of employing the vulnerability concept in planning. While the differences were statistically significant, the average responses were not very different in practice.

\begin{tabular}{|l|c|c|c|c|c|c|}
\hline & \multicolumn{2}{|c|}{ ANOVA } & \multicolumn{3}{c|}{ Average Importance by Profession } \\
\hline & $\boldsymbol{P}$ & $\boldsymbol{F}$ & Planning & $\begin{array}{c}\text { Research/ } \\
\text { Academic }\end{array}$ & $\begin{array}{c}\text { Hazard } \\
\text { Mitigation }\end{array}$ & $\begin{array}{c}\text { Disaster } \\
\text { Response }\end{array}$ \\
\hline $\begin{array}{l}\text { Generally speaking, } \\
\text { comprehensive plans should } \\
\text { incorporate the concept of } \\
\text { vulnerability. }\end{array}$ & 0.056 & 2.604 & 4.11 & 4.56 & 4.18 & 4.75 \\
\hline
\end{tabular}

Table 14: Differences between groups on use of the vulnerability concept in planning

The survey also asked planners an open-ended question related to addressing vulnerability. The question was discrete in that it did not call out the term "vulnerability" 
specifically, and reads: "Thinking of areas composed of minority and/or low-income

populations, what do you believe are specific actions that could be undertaken to improve

hazard mitigation elements in Comprehensive Plans in these areas?” Table 15, below, summarizes relevant responses.

\begin{tabular}{|l|r|}
\hline \multicolumn{1}{|c|}{ Improvement Action for Minority and/or Low Income Areas } & \multicolumn{1}{|c|}{$\begin{array}{c}\text { Count of } \\
\text { Respondents } \\
\text { Suggesting }\end{array}$} \\
\hline Financial support (such as low-interest loans) to improve individual structures & 12 \\
\hline Seek external funding to help these areas & 2 \\
\hline Reach out through communications not reliant on computer and internet access & 16 \\
\hline $\begin{array}{l}\text { Increased focus on incorporating these populations in the planning and/or hazard } \\
\text { mitigation process }\end{array}$ & 1 \\
\hline $\begin{array}{l}\text { Adjust focus from "classic" issues (crime, poverty, etc.) in these areas and } \\
\text { emphasize hazard mitigation }\end{array}$ & 1 \\
\hline Don't just make mitigation about a cost//benefit analysis & 20 \\
\hline Increased public education and outreach relating to hazard mitigation & 3 \\
\hline $\begin{array}{l}\text { Help communities with low-cost mitigation measures (e.g., emergency kits, moving } \\
\text { heavy items off shelves to prevent earthquake hazards, etc.) }\end{array}$ & 3 \\
\hline Provide financial incentives for developers to build mitigation into their projects & 1 \\
\hline Planners should be aware of disproportionate distributions of risk & 3 \\
\hline $\begin{array}{l}\text { Improve affordable housing options in areas with vulnerable housing stock and high } \\
\text { risk [exposure to hazards] }\end{array}$ & 1 \\
\hline Strong relocation incentives & 1 \\
\hline Hold landlords more accountable for code violations & 1 \\
\hline $\begin{array}{l}\text { Provide more explicit disclosure of hazards affecting properties, especially in the } \\
\text { purchase process }\end{array}$ & 5 \\
\hline $\begin{array}{l}\text { Planners need to understand minority and low-income communities better in order to } \\
\text { serve them }\end{array}$ & \\
\hline Relocation to less hazard-prone areas & \\
\hline Table 15: & \\
\hline
\end{tabular}

Table 15: Ideas for improving hazard mitigation planning for vulnerable populations

One respondent offered a very interesting perspective on the need for external

funding. He advised that getting external funding will help avoid "shorting" minority and

low-income populations in the municipal budget process. The statement about external

funding brings to light a possible way to offset the fact that often, minority and low-

income groups are not as well represented in local government decision making, and thus

in this case, may not get adequate local funds for hazard mitigation. 
In regard to education and community involvement, respondents offered the perspective that low-income and minority populations may require expanded efforts to reach them. Respondents stressed using methods that fit in the cultural contexts of these communities.

\section{Other Important Characteristics of Hazard Mitigation Elements}

Finally, the survey asked an open-ended question to learn what respondents think is an important characteristic in hazard mitigation elements of land use plans, in addition to those listed in the more direct questions. Table 16, below, summarizes these characteristics and counts how many respondents mentioned them.

\begin{tabular}{|l|r|}
\hline \multicolumn{1}{|c|}{ Characteristics } & \multicolumn{1}{|c|}{$\begin{array}{c}\text { Count of } \\
\text { Respondents } \\
\text { Suggesting }\end{array}$} \\
\hline Facilities serving vulnerable populations should not be in hazard zones & 1 \\
\hline Take an all hazards approach & 2 \\
\hline $\begin{array}{l}\text { Coordinate between plans related to hazards and disasters (e.g., national mitigation } \\
\text { plans, response plans, etc.) }\end{array}$ & 5 \\
\hline Identify repetitive loss areas and target them for mitigation & 1 \\
\hline Include measurable components and make the plan a performance-based document & 1 \\
\hline $\begin{array}{l}\text { Assess a community's capacity, both from a government standpoint and that of } \\
\text { community organizations, to mitigate and deal with hazards }\end{array}$ & 2 \\
\hline Link the Comprehensive and Capital Improvement Plans & 1 \\
\hline $\begin{array}{l}\text { Inventory all buildings in a hazard zone, especially to learn about vulnerability that } \\
\text { may pre-date modern codes and planning }\end{array}$ & 1 \\
\hline Integrate plans with local transportation providers & 1 \\
\hline
\end{tabular}

Table 16: Additional characteristics respondents said are in important in hazard mitigation elements of land use plans

Five respondents suggested increased coordination, both laterally (within the same geographic area) and vertically (hierarchically with governments above and below). Certainly, coordination presents a significant opportunity. Coordination can ensure the most effective use of resources, both in the planning process and in implementing plans. 
Coordination would help by reducing redundant work in the planning process, and leveraging resources in implementation.

\section{Professional Qualities of Planners Working on the Hazard Mitigation Element}

To learn what respondents think are important qualities in the planner assigned to the Hazard Mitigation Element, they were asked to rate the importance of certain subjects planners could have studied in school, certain experiences planners could have had on the job, and certain professional activities. Respondents rated these qualities from 1 (Less Important) to 5 (Essential), or Not Applicable. The percent of respondents assigning each rating, and the ANOVA test results for differences between the top four professional groups responding, appear in Table 17, below.

\begin{tabular}{|c|c|c|c|c|c|}
\hline & \multicolumn{5}{|c|}{ Percent of Respondents Selecting Each Option } \\
\hline & $\begin{array}{c}1 \\
\text { Less } \\
\text { Important }\end{array}$ & 2 & $\begin{array}{c}3 \\
\text { Somewhat } \\
\text { Important }\end{array}$ & 4 & $\begin{array}{c}5 \\
\text { Essential }\end{array}$ \\
\hline $\begin{array}{l}\text { Education in Environmental } \\
\text { Sciences }\end{array}$ & $0.99 \%$ & $2.97 \%$ & $12.87 \%$ & $58.42 \%$ & $24.75 \%$ \\
\hline Education in Natural Sciences & $1.00 \%$ & $3.00 \%$ & $22.00 \%$ & $57.00 \%$ & $17.00 \%$ \\
\hline $\begin{array}{l}\text { Experience in Environmental } \\
\text { Conservation and Resources }\end{array}$ & $0.00 \%$ & $5.32 \%$ & $13.83 \%$ & $58.51 \%$ & $22.34 \%$ \\
\hline Experience in Natural Science & $0.00 \%$ & $4.30 \%$ & $19.35 \%$ & $52.69 \%$ & $23.66 \%$ \\
\hline Experienced a Disaster Firsthand & $7.78 \%$ & $15.56 \%$ & $27.78 \%$ & $32.22 \%$ & $16.67 \%$ \\
\hline $\begin{array}{l}\text { Attends at least one conference } \\
\text { annually, focusing on } \\
\text { hazards/disasters, the } \\
\text { environment, planning, public } \\
\text { administration, or a related topic }\end{array}$ & $2.94 \%$ & $7.84 \%$ & $13.73 \%$ & $41.18 \%$ & $34.31 \%$ \\
\hline
\end{tabular}

*Significant difference $(\mathrm{p}<.10)$ between top four professional groups represented in the survey

Table 17: Importance of professional qualifications and activities

There was no statistically significant difference between the responses from the top four professional groups (Planning, Research/Academic, Hazard Mitigation, and Disaster Response). 
In terms of education and experience for planners, respondents showed the most preference for planners with education in the environmental sciences $(83.17 \%$ rated this a 4 or 5) and experience in environmental conservation and resources $(80.85 \%$ rated this a 4 or 5). Education or experience in natural science was a close second, with $74.00 \%$ and $76.34 \%$, respectively, of respondents giving a rating of 4 or 5 for importance. Just above three-quarters of respondents (76.67\%) rated experiencing a disaster firsthand as "Somewhat Important" (3) or above.

Finally, $89.22 \%$ of respondents rated annual attendance of a conference in one of the fields related to natural disasters and planning as important. The importance placed on conference attendance reflects significant support for the notion that it is important to keep practitioners abreast of the latest developments in their fields.

Making Better Plans: Factors That Affect Plan Quality and Ways to Create Better Plans Governments cannot conduct comprehensive planning in a vacuum devoid of information exchanges. The importance of information exchange is especially salient for hazard mitigation, because hazards tend to go beyond political boundaries. Especially when dealing with water issues and flooding, governments must coordinate to operate together to achieve meaningful change; they must think beyond the boundaries of political divisions and instead consider environmental boundaries. Further, especially in the case of floodwaters, what one government does may affect the welfare of another political subdivision. Table 18, below, presents answers to questions about coordination. 


\begin{tabular}{|l|r|r|r|r|r|}
\hline & \multicolumn{3}{|c|}{ Percent of Respondents Selecting Each Option } \\
\cline { 2 - 6 } & $\begin{array}{c}\text { 1 } \\
\text { Less } \\
\text { Important }\end{array}$ & \multicolumn{1}{|c|}{$\begin{array}{c}\mathbf{3} \\
\text { Somewhat } \\
\text { Important }\end{array}$} & $\mathbf{4}$ & \multicolumn{1}{|c|}{$\begin{array}{c}\mathbf{5} \\
\text { Essential }\end{array}$} \\
\hline $\begin{array}{l}\text { Coordination between Planning } \\
\text { Departments and local water } \\
\text { management districts }\end{array}$ & $0.00 \%$ & $2.80 \%$ & $6.54 \%$ & $38.32 \%$ & $52.34 \%$ \\
\hline $\begin{array}{l}\text { Coordination between Planning } \\
\text { Departments and local Emergency } \\
\text { Management Departments }\end{array}$ & $0.00 \%$ & $0.00 \%$ & $4.50 \%$ & $19.82 \%$ & $75.68 \%$ \\
\hline
\end{tabular}

*Significant difference $(\mathrm{p}<.10)$ between top four professional groups represented in the survey

Table 18: How coordination is perceived to effect hazard mitigation element quality

While respondents were strongly in favor of coordination with both water management districts and emergency management departments, the greatest importance was placed on emergency management departments. The greater importance placed on coordination with emergency management departments is congruent with the results of the interviews, in which interviewees consistently stated that planning departments coordinate with emergency management departments, while coordination with water management districts was not as strongly stressed.

Socio-economic factors usually relate to hazard vulnerability; factors such as education levels, race, and wealth typically influence vulnerability to natural hazards. In this case, it is important to consider that a community's wealth may be able to buy better planning services. Table 19, below, presents practitioner opinions on the potential correlation between several demographic variables and hazard mitigation element quality. 


\begin{tabular}{|l|c|c|c|c|c|}
\hline & \multicolumn{3}{|c|}{ Percent of Respondents Selecting Each Option } \\
\cline { 2 - 6 } & $\begin{array}{c}\mathbf{1} \\
\text { Strongly } \\
\text { Disagree }\end{array}$ & $\mathbf{2}$ & $\begin{array}{c}\mathbf{3} \\
\text { Neutral }\end{array}$ & $\mathbf{4}$ & $\begin{array}{c}\text { Strongly } \\
\text { Agree }\end{array}$ \\
\hline $\begin{array}{l}\text { Communities with a wealthier } \\
\text { population base are more likely to } \\
\text { have higher quality hazard mitigation } \\
\text { elements in comprehensive plans }\end{array}$ & $3.31 \%$ & $16.53 \%$ & $30.58 \%$ & $36.36 \%$ & $13.22 \%$ \\
\hline $\begin{array}{l}\text { Communities with a higher percentage } \\
\text { of minority residents are more likely } \\
\text { to have lower quality of hazard } \\
\text { mitigation elements in comprehensive } \\
\text { plans }\end{array}$ & & & & & \\
\hline $\begin{array}{l}\text { Communities that have experienced } \\
\text { disasters are more likely to have } \\
\text { higher quality hazard mitigation } \\
\text { elements in comprehensive plans }\end{array}$ & $3.33 \%$ & $24.17 \%$ & $32.50 \%$ & $28.33 \%$ & $11.67 \%$ \\
\hline
\end{tabular}

*Significant difference $(\mathrm{p}<.10)$ between top four professional groups represented in the survey

Table 19: Relationship between socio-economic factors and plan quality

Similar to the views observed above on vulnerability of populations being related

to plan quality, respondents overall did not express support for the idea that community

wealth or minority status would affect plan quality. In fact, respondents indicated that

minority status has even less of an effect than wealth of a community. ${ }^{2}$ Respondents

varied by profession in their response to the question regarding correlation between

minority population and hazard mitigation element quality, as reflected in Table 20,

below.

Nearly universally, respondents agreed that having experienced a disaster is likely to correlate with a community having a higher quality hazard mitigation element. The response regarding disaster experience correlating with hazard mitigation element quality contrasts, however, findings from plan reviews, which reflect that CPs do not require

\footnotetext{
${ }^{2}$ Note that in the analysis above comparing plan quality to various demographic factors, median household income and race had no significant effect on plan quality, and percent of Hispanic persons in the community was directly correlated with hazard mitigation element quality
} 
historical analysis, do not review prior hazards, and rarely have components requiring learning from hazards in future plans. It also contrasts the fact that analysis of plan quality compared to historical hazard strikes showed no correlation. Thus, while survey respondents make a normative response that historical hazard strikes will result in learning for future hazards, neither the effort nor the reality of such appear in Florida coastal county hazard mitigation elements.

\begin{tabular}{|l|c|c|c|c|c|c|}
\hline & \multicolumn{2}{|c|}{ ANOVA } & \multicolumn{3}{c|}{ Average Importance by Profession } \\
\hline & $\boldsymbol{P}$ & $\boldsymbol{F}$ & Planning & $\begin{array}{c}\text { Research/ } \\
\text { Academic }\end{array}$ & $\begin{array}{c}\text { Hazard } \\
\text { Mitigation }\end{array}$ & $\begin{array}{c}\text { Disaster } \\
\text { Response }\end{array}$ \\
\hline $\begin{array}{l}\text { Communities with a } \\
\text { wealthier population base } \\
\text { are more likely to have } \\
\text { higher quality hazard } \\
\text { mitigation elements in } \\
\text { comprehensive plans }\end{array}$ & 0.005 & 4.591 & 3.000 & 3.684 & 3.000 & 3.875 \\
\hline $\begin{array}{l}\text { Communities with a higher } \\
\text { percentage of minority } \\
\text { residents are more likely to } \\
\text { have lower quality of hazard } \\
\text { mitigation elements in } \\
\text { comprehensive plans }\end{array}$ & 0.008 & 4.210 & 2.744 & 3.459 & & \\
\hline $\begin{array}{l}\text { Communities that have } \\
\text { experienced disasters are } \\
\text { more likely to have higher } \\
\text { quality hazard mitigation } \\
\text { elements in comprehensive } \\
\text { plans }\end{array}$ & 0.022 & 3.345 & 4.302 & & & \\
\hline
\end{tabular}

Table 20: Average importance of socio-economic factors by profession

The responses of the four major professional groups to questions about socioeconomic effects on hazard mitigation element quality varied. Researchers/Academics and Disaster Responders were much more supportive of the notion that wealth and minority status of a community are correlated with quality of hazard mitigation elements than were professionals engaged in Planning and Hazard Mitigation. However, disaster responders saw far less of an effect of prior disasters on hazard mitigation element quality than did the other three groups. Perhaps professional responders and academics have a 
broad view from seeing many disasters, and are keenly aware of the reality of the impact that wealth can have on helping to mitigate disasters. Conversely, Planners and Hazard Mitigation specialists may be more involved in their own communities and not see comparative effects between communities - or they may hold an ideal that a quality plan can exist regardless of social circumstances. On the question of whether or not prior hazard strikes correlate with plan quality, Planners, Researchers/Academics, and Hazard Mitigation professionals universally agreed that prior disasters correlate with higher quality hazard mitigation elements. These groups all have the opportunity to see the longitudinal effect of disasters and incorporate their observations into the work and study of planning, potentially influencing their answers more than responders, whom may have a shorter horizon.

Planning departments have multiple stakeholders, including state and federal governments that regulate their plans, citizens, businesses, and other groups. Ultimately, planning departments are part of governments headed by elected officials. The survey asked planners how support of elected officials, who must be responsive to the public, affects plan quality. Table 21, below, presents responses to two related questions.

\begin{tabular}{|l|c|c|c|c|c|}
\hline & \multicolumn{3}{|c|}{ Percent of Respondents Selecting Each Option } \\
\cline { 2 - 6 } & $\begin{array}{c}\mathbf{1} \\
\text { Strongly } \\
\text { Disagree }\end{array}$ & $\mathbf{2}$ & $\begin{array}{c}\mathbf{3} \\
\text { Neutral }\end{array}$ & $\mathbf{4}$ & $\begin{array}{c}\mathbf{5} \\
\text { Strongly } \\
\text { Agree }\end{array}$ \\
\hline $\begin{array}{l}\text { Hazard mitigation elements in } \\
\text { comprehensive plans will be improved } \\
\text { if elected officials are actively } \\
\text { involved with writing these elements* }\end{array}$ & $6.61 \%$ & $16.53 \%$ & $26.45 \%$ & $28.10 \%$ & $22.31 \%$ \\
\hline $\begin{array}{l}\text { Hazard mitigation elements in } \\
\text { comprehensive plans will be improved } \\
\text { if elected officials are engaged in } \\
\text { oversight of implementing new hazard } \\
\text { mitigation measures* }\end{array}$ & & & & & \\
\hline
\end{tabular}

*Significant difference $(\mathrm{p}<.10)$ between top four professional groups represented in the survey

Table 21: Relationship between support of elected officials and plan quality 
Respondents saw some value in having elected officials involved in writing hazard mitigation elements, but saw even greater value in having them involved in implementation. The dichotomy in results is not surprising, as planning is a highly technical job, and elected officials may not be qualified to take on roles in planning (although their input may be of value). The four professional groups differed in their responses to these questions, as shown in Table 22, below.

\begin{tabular}{|l|c|c|c|c|c|c|}
\hline & \multicolumn{2}{|c|}{ ANOVA } & \multicolumn{3}{c|}{ Average Importance by Profession } \\
\hline & $\boldsymbol{P}$ & $\boldsymbol{F}$ & Planning & $\begin{array}{c}\text { Research/ } \\
\text { Academic }\end{array}$ & $\begin{array}{c}\text { Hazard } \\
\text { Mitigation }\end{array}$ & $\begin{array}{c}\text { Disaster } \\
\text { Response }\end{array}$ \\
\hline $\begin{array}{l}\text { Hazard mitigation elements } \\
\text { in comprehensive plans will } \\
\text { be improved if elected } \\
\text { officials are actively } \\
\text { involved with writing these } \\
\text { elements }\end{array}$ & 0.001 & 5.560 & 2.953 & 3.763 & 4.200 & \\
\hline $\begin{array}{l}\text { Hazard mitigation elements } \\
\text { in comprehensive plans will } \\
\text { be improved if elected } \\
\text { officials are engaged in } \\
\text { oversight of implementing } \\
\text { new hazard mitigation } \\
\text { measures }\end{array}$ & & & & & & \\
\hline
\end{tabular}

Table 22: Average importance of elected official involvement by profession

Planners and Disaster Responders saw the least value in elected officials participating in writing of hazard mitigation elements. The gap was broad between them and Researchers/Academics and those working in hazard mitigation, with the latter group almost universally rating this participation as important. Possibly, these groups, again, have a broader viewpoint on the subject, and recognize that elected official involvement early on helps to not only gain their buy-in, but to incorporate the public's perspective which will be important to both writing a quality plan and implementing it successfully. It is also possible that Planners and Disaster Responders, who likely already work in government, perceive that elected officials either cannot contribute to the hazard 
mitigation element, or are biased toward development in ways that would hinder their ability to contribute to a quality hazard mitigation element.

Comprehensive planning involving topics such as land use, economic development, infrastructure, hazard mitigation, and beyond, is typically seen as an iterative method of making public policy. It is one in which public input is typically required at some base level (through public hearings at least); however, this input must be blended with the technical knowledge of planners, as well as policy mandates and incentives from higher governments. Sometimes these three inputs (public desires, technical knowledge, and government mandates) are contradictory and must be balanced. The survey asked Planners about the value of community participation in the planning process; there responses are reported in Table 23, below.

\begin{tabular}{|l|r|r|r|r|r|}
\hline & \multicolumn{4}{|c|}{ Percent of Respondents Selecting Each Option } \\
\cline { 2 - 6 } & $\begin{array}{c}\mathbf{1} \\
\text { Less } \\
\text { Important }\end{array}$ & $\mathbf{2}$ & $\begin{array}{c}\mathbf{3} \\
\text { Somewhat } \\
\text { Important }\end{array}$ & $\mathbf{4}$ & \multicolumn{1}{|c|}{\begin{tabular}{|}
$\mathbf{5}$ \\
Essential
\end{tabular}} \\
\hline $\begin{array}{l}\text { Community participation } \\
\text { throughout the planning process }\end{array}$ & $0.00 \%$ & $1.79 \%$ & $6.25 \%$ & $40.18 \%$ & $51.79 \%$ \\
\hline
\end{tabular}

Significant difference $(\mathrm{p}<.10)$ between top four professional groups represented in the survey

Table 23: Importance of community participation in hazard mitigation planning

Respondents strongly supported the importance of community involvement in the process of creating hazard mitigation elements of land use plans - this is the expected response from planners, given the level of public involvement typically incorporated into comprehensive planning. Of all responses in the entire survey, it is notable that this is the only time not one person chose the bottom level of importance. Over $90 \%$ of respondents ranked community involvement at a 4 or 5 , with over half reporting it as "essential." There was no statistically significant difference in the response among the top four professional groups. However, the lack of difference in responses by professional group 
does not corroborate well with other findings in my research. Note that interviewees, even from counties with highly rated hazard mitigation elements, reported that public participation is a struggle, and review of planning documents revealed no special efforts to encourage public participation. In the examination of plans, there was little reference to formally working to solicit community participation; in fact, only about one-third of hazard mitigation elements reviewed explicitly mentioned community participation.

The concept of "moral hazard" reflects that governments often subsidize people's choices to do business in or live in hazard-prone areas by providing insurance and aid that essentially offsets the true cost of living in these areas. For example, in Florida, the state subsidizes a windstorm insurance corporation to provide rates lower than the private insurance market will bear in areas heavily prone to windstorm risk. In theory, people might find it more palatable to take stronger mitigatory action, potentially through stronger hazard mitigation elements, if the personal risk of non-mitigation was higher than it presently is. Table 24 , below, presents responses to a question about how changes in windstorm insurance pricing would affect hazard mitigation element quality.

\begin{tabular}{|l|c|c|c|c|c|}
\hline & \multicolumn{4}{|c|}{ Percent of Respondents Selecting Each Option } \\
\cline { 2 - 6 } & $\begin{array}{c}\mathbf{1} \\
\text { Strongly } \\
\text { Disagree }\end{array}$ & $\mathbf{2}$ & $\begin{array}{c}\mathbf{3} \\
\text { Neutral }\end{array}$ & $\mathbf{4}$ & $\begin{array}{c}\text { Strongly } \\
\text { Agree }\end{array}$ \\
\hline $\begin{array}{l}\text { If the state windstorm insurer, } \\
\begin{array}{l}\text { Citizens, charged market rates for } \\
\text { its product, hazard mitigation } \\
\text { elements in comprehensive plans } \\
\text { would be improved }\end{array}\end{array}$ & & & & & \\
\hline
\end{tabular}

*Significant difference $(\mathrm{p}<.10)$ between top four professional groups represented in the survey

Table 24: Perceived effect of state windstorm rates on quality of hazard mitigation elements

While many respondents expressed agreement that allowing market rates to filter through to consumers would improve quality of hazard mitigation elements, about $10 \%$ of respondents expressed strong disagreement with this idea. Certainly, the question 
about market rates alone could bear more research to explore a) why people who felt strongly either way did so, and b) what happens to hazard mitigation quality as state insurance subsidies change. The top four professional groups differed on this response, and their average agreement with this statement, is shown in Table 25, below. Note that while the differences between groups are statistically significant, in practice these differences are small.

\begin{tabular}{|l|c|c|c|c|c|c|}
\hline & \multicolumn{2}{|c|}{ ANOVA } & \multicolumn{3}{c|}{ Average Importance by Profession } \\
\hline & $\boldsymbol{P}$ & $\boldsymbol{F}$ & Planning & $\begin{array}{c}\text { Research/ } \\
\text { Academic }\end{array}$ & $\begin{array}{c}\text { Hazard } \\
\text { Mitigation }\end{array}$ & $\begin{array}{c}\text { Disaster } \\
\text { Response }\end{array}$ \\
\hline $\begin{array}{l}\text { Communities with a } \\
\text { wealthier population base } \\
\text { are more likely to have } \\
\text { higher quality hazard } \\
\text { mitigation elements in } \\
\text { comprehensive plans }\end{array}$ & 0.029 & 2.723 & 2.810 & & & \\
\end{tabular}

Table 25: Average importance of socio-economic factors by profession

Finally, to capture elements the survey questions may have missed, the survey asked, "As a practitioner or academic with experience in planning, please tell us what you believe contributes to quality of hazard mitigation elements in Comprehensive Plans?" Responses are summarized in Table 26, below. 


\begin{tabular}{|c|c|}
\hline Characteristics & $\begin{array}{c}\text { Count of } \\
\text { Respondents } \\
\text { Suggesting }\end{array}$ \\
\hline $\begin{array}{l}\text { Planners have knowledge of the communities they plan for an appropriate mitigation } \\
\text { options for those communities }\end{array}$ & 4 \\
\hline Community buy-in for plans and/or projects & 5 \\
\hline Community participation in planning & 13 \\
\hline Informing people of risk in real terms (e.g., Dollars) & 1 \\
\hline Coordination beyond the political subdivision & 4 \\
\hline Holistic planning involving broad stakeholders & 7 \\
\hline Multi-disciplinary input into the plan & 4 \\
\hline Planners must know how to identify hazards and vulnerabilities & 4 \\
\hline Setting deadlines and providing evaluation criteria for mitigation strategies & 4 \\
\hline Funding mitigation strategies & 6 \\
\hline Make elected officials accountable for mitigation/Elected official support & 7 \\
\hline Coordination among key parties & 3 \\
\hline Coordination with technical people to set goals & 1 \\
\hline Planning with implementation in mind & 1 \\
\hline Experts need practical experience & 1 \\
\hline Use of nature as a hazard buffer/barrier & 2 \\
\hline Community has experienced a disaster & 4 \\
\hline Use of science-based maps of vulnerable areas & 2 \\
\hline Input from higher-order governments & 2 \\
\hline Cost/benefit analysis of mitigation plans & 3 \\
\hline Learning from and/or benchmarking against similar communities & 2 \\
\hline Planners attend related conferences & 1 \\
\hline Planners attend relevant FEMA courses & 1 \\
\hline State requirements & 1 \\
\hline Community Support & 2 \\
\hline Incorporate resilience & 1 \\
\hline Clear identification of goals & 1 \\
\hline Including a hazard history & 1 \\
\hline Collaboration with property owners & 2 \\
\hline Preparing for diverse populations & 1 \\
\hline Keeping mitigation measures cost reasonable & 1 \\
\hline
\end{tabular}

Table 26: Additional characteristics respondents report contribute to quality of hazard mitigation elements in comprehensive plans.

\section{Benchmarking}

Benchmarking provides distinct advantages in that it makes those involved in an activity compare their work with that of others. While the end product is a comparison, the act of benchmarking can help planners see where individual areas of their plans could be improved as compared to other plans. Table 27, below, shows respondent opinions on benchmarking. 


\begin{tabular}{|l|c|c|c|c|c|}
\hline & \multicolumn{3}{|c|}{ Percent of Respondents Selecting Each Option } \\
\cline { 2 - 6 } & $\begin{array}{c}\mathbf{1} \\
\text { Strongly } \\
\text { Disagree }\end{array}$ & $\mathbf{2}$ & $\begin{array}{c}\mathbf{3} \\
\text { Neutral }\end{array}$ & $\mathbf{4}$ & $\begin{array}{c}\text { S } \\
\text { Strongly } \\
\text { Agree }\end{array}$ \\
\hline $\begin{array}{l}\text { Communities should benchmark } \\
\text { their hazard mitigation elements } \\
\text { in comprehensive plans against } \\
\begin{array}{l}\text { communities of similar size and/or } \\
\text { hazard exposure. }\end{array}\end{array}$ & $1.65 \%$ & $9.09 \%$ & $27.27 \%$ & $47.11 \%$ & $14.88 \%$ \\
\hline $\begin{array}{l}\text { Communities should benchmark } \\
\text { their hazard mitigation elements } \\
\text { in comprehensive plans against a } \\
\text { model hazard mitigation element. }\end{array}$ & $0.83 \%$ & $4.13 \%$ & $28.93 \%$ & $47.93 \%$ & \\
\hline $\begin{array}{l}\text { County Planning Departments } \\
\text { have the time and resources to } \\
\text { benchmark their plans. }\end{array}$ & & & & & \\
\hline
\end{tabular}

*Significant difference $(\mathrm{p}<.10)$ between top four professional groups represented in the survey

Table 27: Perceived effect of benchmarking hazard mitigation elements

Benchmarking the hazard mitigation element, both against others and a model, received a good measure of support across all four professional fields. However, respondents clearly said that the resources to perform such benchmarking are not readily available. The divergence in what respondents believe should be done (benchmark) and what they believe can be done is important. Benchmarking is an important way to add an objective measure of quality to planning, yet respondents are saying that they do not have the resources to do so. Benchmarking may be one of many good practices falling to the wayside in a time of fiscal austerity, but, possibly creative solutions could be employed to benchmark inexpensively at least at some level.

\section{Miscellaneous Observations from Respondents}

Speaking to the regional nature of hazards and disasters (vs. following political boundaries), one respondent pointed out that there is no system in place to incentivize jurisdictions to engage in mitigation if a hazard or disaster occurs in a neighboring jurisdiction. 
In the entire Disaster Management Cycle (Mitigation $\rightarrow$ Preparedness $\rightarrow$

Response $\rightarrow$ Recovery) the federal system is very prevalent in the fact that responsibility starts locally, then is assumed by the states, and then the federal government. The "tripwire system" can sometimes be inefficient, as each jurisdiction needs to seek out its own capabilities to address the parts of the cycle. One respondent noted, in this vein, that the risk assessments used by communities for planning are of varying quality and may overlap.

\section{Summary}

Overall, large groups of respondents favored most survey answers, reflecting consensus on most answers. From the 581 surveys sent out, 97 people responded; additionally, 31 responses were gleaned from snowball sampling and a mailing to the American Society for Public Administration's Section on Emergency and Crisis Management (SECM), resulting in 128 usable responses. Planning professionals and researchers and academicians made up $64 \%$ of respondents.

Respondents strongly favored methods of getting more information for the hazard mitigation element. The survey recorded strong, favorable responses for conducting interviews of stakeholders, public involvement through the planning process, and consultation with the public, other agencies, and governments. Additionally, in free-form text responses to a question asking what contributes to quality hazard mitigation elements, respondents reported frequently that community participation in planning is important. This support for community involvement and intergovernmental coordination 
is not consistent with planning department actions recorded in the interviews of planning leaders and is discussed further below.

Measures to either slow or mitigate development in hazard zones also found high support, as did using nature as a hazard barrier; this indicates potential for future planning efforts that aim for a balance between reasonable development in hazard zones while preserving the natural features of areas that may absorb hazard impacts. The support for slowing development and using nature as a hazard barrier also was not consistent with the action of planning departments, and is inconsistent with Florida government choices to dismantle the state land use regulation body.

Respondents also supported using the concept of social vulnerability in comprehensive planning related to natural hazards. Given the overall support of development controls, communication with the public, and employing nature as a means of hazard mitigation, this indicates a strong potential for support from planners for a planning process that takes a holistic view that includes other measures in addition to technocratic and structural measures. In fact, in their free form text responses, respondents often cited increased public outreach and communication as ways to help mitigate hazards for socially vulnerable populations. However, these findings must be tempered by the fact that respondents may not fully support (while they appear to understand) the concept of social vulnerability. There was weak support for the notion that wealthier communities were likely to have better hazard mitigation elements, and minority communities to have lower quality ones. 


\section{FINDINGS, LIMITATIONS, IMPLICATIONS, AND FUTURE DIRECTIONS}

My research set out to answer the following two questions in the context of a U.S. state with stringent (compared to most states) rules for hazard mitigation planning in comprehensive plans:

1. Is there variation in the quality of hazard mitigation elements of local land use plans?

2. If so, what are the factors that explain this variation?

The objectives of these questions are: to examine the effect of state mandates for including hazard mitigation elements in local land use plans, and to consider how the mandates could be improved. Consideration of improving the use of hazard-mitigation mandates is important to consider because land use planning for natural hazards is just one way that states may engage in mitigation to prevent natural hazards from becoming disasters that harm their populations. Further, every $\$ 1$ of mitigation spending is expected to save $\$ 7$ on post-disaster spending - a significant number that provides a powerful argument for increased investments in effective mitigation measures.

Florida, a state with stringent, prescribed requirements for coastal jurisdictions to include in their CPs a Coastal Management Element that addresses natural hazards, was selected as the study area for this research. The state provides, in its administrative codes, specific guidelines as to what the Coastal Management Element must address. The state enforces these rules, through its review process for local plans.

Florida was selected because of the fact that it is considered to be a state with stronger requirements for hazard mitigation elements in CPs; it is one of only 10 states requiring hazard mitigation elements in comprehensive or land use plans. Florida also 
was an attractive choice because a) it faces hazards routinely, and b) it only faces two significant hazards (hurricanes and floods). Having only two disaster types reduces "noise" in the data that could come from having more disaster types, and might have clouded the results (e.g., the effects of mitigating against multiple disaster types could be difficult to separate from other issues covered in my research). Finally, Florida uses comprehensive planning instead of simple land use planning. This provides more mitigation opportunities as comprehensive planning requires holistic plans that incorporate land use, economic development, growth management, environmental concerns, and other features. It is an iterative policymaking method that involves the public in policymaking and provides excellent mitigation opportunities.

\section{Major Findings}

A central question of my research is whether or not hazard mitigation elements vary in quality in a state which has a strong mandate for hazard mitigation to be addressed in CPs. The answer, derived from a review of 35 Florida coastal county plans, is that yes, there is a clear variation in quality. I reviewed plans using 24 separate elements related to quality of hazard mitigation elements, and based scoring on the presence or absence of each element, with additional weight given if the element included a description with greater detail (vs. a simple mention of the element). The 35 plans scored from 5 to 25 with an average rating of 14.06 and a median of 14 .

To further explore potential drivers of variation in hazard mitigation element quality, I conducted analyses considering geography, hazard experience, and various demographic factors with the hazard mitigation element quality scores as the dependent 
variable. Neither geography nor experience with prior hazards was correlated with quality of hazard mitigation elements. Median Household Income, Population Density Change, Percent of Population Over Age 62, and Percent of Population Non-White, were not correlated with hazard mitigation element quality. Population, Education, Population Density, Percent of Population Hispanic, and Percent of Population Renting, all directly correlated with hazard mitigation element quality. Typically, an indirect correlation would have been expected given that Vulnerability Theory postulates that poorer people and minorities are more at risk from natural hazards. That said, many of the variables that correlate with higher quality of hazard mitigation elements also typically correlate with higher urbanity - and urban areas tend to be less vulnerable to disasters. Thus, the results based on demographic analysis are mixed.

To get a broad perspective on issues related to the hazard mitigation element, I conducted a survey of land use planners, professionals, and academics. I sent the survey to all land use planners in Florida county governments, to a list of practitioners and academics involved with hazards and disasters work, and to the members of the American Society for Public Administration Section on Emergency and Crisis Management.

While the explanation of survey results appears in more detail above, certain aspects stood out. Respondents heavily favored conducting interviews with key stakeholders, with just over $85 \%$ seeing this as important in hazard mitigation elements. In fact, more thought this was important than using models, such as SLOSH, in planning, which only garnered about $69 \%$ of respondents' support. 
While $85 \%$ of respondents support limiting development in hazard zones, $57 \%$ support an outright prohibition. The latter number seems small in comparison, but it shows a remarkable level of support given that prohibition of development could have economic consequences by reducing taxable development on valuable coastal land. The $57 \%$ of respondents willing to prohibit development in hazard zones also may recognize that there is a limit to how much mitigation can do to make a population safer.

Eighty-four percent of respondents supported using nature as a hazard barrier. Approximately $90 \%$ of respondents supported coordination with Water Management Districts and local emergency management departments.

About $83 \%$ of respondents indicated support for incorporating the concept of vulnerability in hazard mitigation elements, and, when asked if communities with prior hazard experience would have higher quality hazard mitigation elements, $85 \%$ of respondents thought these would be correlated. However, less than $50 \%$ of respondents support the notion that communities with lower wealth or higher minority populations would have lower quality hazard mitigation elements.

\section{Comparisons of Interest}

The analyses and surveys revealed several key contrasts of interest. Some of these may challenge the beliefs of planners and academics in the field, and may warrant a subsequent change in approaches to planning for hazard mitigation in $\mathrm{CPs}$, or additional research to explore these issues.

Traditional theories of Vulnerability hold that when people experience hazards or disasters, they learn from them and can better mitigate for the future. Survey respondents 
also generally expressed a belief that prior hazard or disaster experience would result in improved hazard mitigation elements. This did not prove true in the analysis of plans, which showed that hazard mitigation element quality was not correlated with prior hazard and disaster experience and historical analysis of hazards and disasters was not required by planning documents. This finding is symptomatic of organizations that do not learn. Certainly planners said they value learning from the past, but no evidence of such learning was found in the organizations' behaviors as exemplified in the product they produce (comprehensive plans). This may indicate a need to do a better job of incorporating knowledge gained from prior hazard strikes into the comprehensive planning process.

Neither wealth, nor race/ethnicity was inversely correlated with hazard mitigation element quality. In fact, the percent of Hispanic population was directly correlated with hazard mitigation element quality. This, by itself, is incongruent with traditional ideas of vulnerability, which would predict that higher poverty, and higher minority presence, would be correlated with lower quality of hazard mitigation. Notably, however, the individual elements that did correlate with vulnerability (education, density, population, and population in rental housing) also correlate with urbanity. It is possible that these more urban areas, by their nature of being urban, have better opportunities for strong planning mechanisms.

Survey respondents strongly favored efforts to include the public in planning for hazard mitigation. However, neither planning documents nor survey responses reflected special efforts to educate the public on hazard mitigation elements or draw the public into this part of the planning process. This presents a distinct dichotomy. While planning 
practitioners and researchers say that inclusion of the public is important in designing hazard mitigation elements, in practice, it appears that efforts are not made to a great degree to do this, and that the public is not especially interested in the matter. One possible reason, raised by one interviewee, is that hazard mitigation issues are not nearly as important to most members of the public as are traditional land use issues.

Finally, comparing what people say should happen (normative statements) to what happens in practice, it is notable that while survey respondents strongly favored development controls, over the last two years, Florida has nearly dismantled the agency charged with growth management. This reflects a clear disconnect between what professionals believe is the best practice, and what is implemented by elected government (at least, in Florida).

\section{Research Questions and Answers}

Question 1: Is there variation in the quality of hazard mitigation elements of local land use plans?

Prior research has shown that, even with Florida's prescriptive planning mandates, there is broad variation in plan quality. For example, in the late 1990s, Deyle and Smith (1998) examined the CPs of 18 Florida counties for compliance with state planning regulations across 60 categories. At very best, average compliance with any category was $76.92 \%$, with a standard deviation of $22.65 \%$ - this indicates a high level of variation in compliance with state planning regulations. No research prior to this 
dissertation, however, has examined if hazard mitigation elements specifically vary in quality.

In order to study the question of whether or not there is variation in quality under a regime of specific laws and rules dictating hazard mitigation requirements, I reviewed all 35 Florida coastal county CPs and graded them on an index of 24 items. Ratings for each item were on a scale of 0 (item not mentioned), 1 (item mentioned), or 2 (item mentioned and discussed in detail). Therefore, a plan could score from 0 (which technically is not even in compliance with state law) through 48 (which would rate as perfect in terms of the index). This rating methodology has been used by several prior researchers and is well regarded. However, it does not examine outcomes of the plans. Rather, it investigates how thoroughly plans address individual topics of concern.

To get outside opinions on the rating tool, I asked the four planners interviewed to review the tool and rank the top three and bottom three items in terms of importance. All four interviewees stated that the index appeared valid as presented. They also rated their top and bottom three items. The only item that more than one rater ranked as a "Bottom Three" item, indicating possibly that practitioners might not find this item important, was if plans require tax abatements for construction that employs mitigation measures - two raters saw this as one of their "Bottom Three" items. Still, because this was not universally agreed on, it was left in the index.

The distribution of plan scores across the 35 plans was normal, and, overall, there was a high degree of variation in the quality of plan elements, as evidenced by the spread in scores. Scores ranged from a low of 5 to a high of 25 , with a standard deviation of 4.759. The variation was correlated neither with geography nor history of hazard strikes. 
Notably, while the index had a maximum score of 48 , no plan achieved a rating over 25; thus, while some plans were better than others, none were of exceptionally high quality based on this scale.

In the context of a state with strict planning mandates, where there is a reasonable expectation that local governments would create relatively uniform hazard mitigation elements, this degree of variation shows a "double-edged sword." On one hand, it is clear that local governments were able to exercise local control in the planning process including what they saw as important and leaving out what they did not. On the other hand, this approach appears to have resulted in very differential quality of hazard mitigation elements among counties. This finding is significant because it shows that while state policymakers are trying to make Florida a "resilient" place in terms of hazards, this is not happening statewide. The policies for resiliency are there, but they are neither routinely followed nor enforced. This begs the question "What's stopping enforcement?" Potential explanations include a lack of political will, lack of resources (perhaps the state development agency was busier with seemingly more pressing tasks), lack of enforceability (no real "teeth" in the law), or simply that it was not financially feasible to slow development that brings in taxes (and proportionally more taxes when considering coastal development),

\section{Question 2: What are the factors that explain this variation?}

I used a multipronged approach to ascertain what drives variation in hazard mitigation element quality. My research examines correlations between demographic factors related to social vulnerability to natural hazards and plan quality. Because there is 
little existing research in this arena, I conducted formative interviews with planners in four Florida counties, both to capture their ideas and to elicit information that would help in designing questions for a broader survey. Following this, I surveyed planners and other people involved with hazard mitigation and disaster related topics, nationwide, to find out what they think drives hazard mitigation element quality.

My research examined what drives variation in plan quality by looking for correlations between hazard mitigation element quality and factors typically related to social vulnerability (race, ethnicity, age, income, education, size of community, population density, population density change, and population in renter occupied housing). Typically, Vulnerability Theory holds that minority groups, those with less education, the elderly, and dense populations, are more vulnerable to natural hazards than more "advantaged" groups. The correlations between demographic factors and plan quality were mixed, and individually were not aligned with expectations typically associated with Vulnerability Theory.

Several demographic variables were correlated with hazard mitigation element quality. Population was positively correlated with hazard mitigation element quality $(\mathrm{P}=$ $0.597, \mathrm{p}=0.000$ ). This is not surprising, as larger counties likely are able to increase the size of their planning staff and gain broader expertise and more resources. Supporting this notion, population was positively intercorrelated with all other variables that positively correlated with hazard mitigation element quality. Both the percent of population with a high school diploma or higher $(\mathrm{P}=0.341, \mathrm{p}=0.045)$ and the percent with a bachelor's degree or higher $(\mathrm{P}=0.477, \mathrm{p}=0.004)$ were positively correlated with plan quality, and as the education level increased, so did the degree of correlation. It may be tempting to 
say that this could be the result of these populations having more wealth and thus resources to plan, as both measures had a moderate to strong, positive intercorrelations with median household income. However, median household income was not correlated with hazard mitigation element quality. Possibly more educated persons give more input into public policymaking processes, including planning, regardless of income.

Population density was both positively and strongly correlated with hazard mitigation element quality $(\mathrm{P}=0.667, \mathrm{p}=0.000)$. This flows against typical concepts of Vulnerability Theory, which normally holds that as population density increases, the built environment overwhelms natural abilities to cope with hazards and increases disaster severity. However, in the context of Florida, it is possible that a) increased population and population density result in more attention from the state level to enforce planning rules on counties; b) increased population density brings more wealth to the community thus improving planning resources; and c) as population density increases more care simply has to be put into the planning process, especially planning to mitigate against hazards.

While race was not correlated with hazard mitigation element quality, the percent of population that is Latino or Hispanic, was directly correlated with hazard mitigation element quality $(\mathrm{P}=0.497, \mathrm{p}=0.002)$. This does not comport with traditional theories of vulnerability, which hold that minority race and ethnicity are correlated with higher vulnerability.

Percent of population in renter occupied housing was positively correlated with hazard mitigation element quality $(\mathrm{P}=0.439, \mathrm{p}=0.008)$. Typically, this is not an expectation that is consistent with Vulnerability Theory, which considers renters to be 
less economically advantaged compared to homeowners and less represented in the political and policymaking process regarding land use.

Several other demographic variables tested were not correlated with Hazard Mitigation Element quality. Median household income was not correlated in either direction with hazard mitigation element quality $(\mathrm{P}=0.96, \mathrm{p}=0.582)$. This is not consistent with traditional theories of Vulnerability, which hold that a higher degree of wealth facilitates better preparation for natural hazards. Population density increase was not correlated with Hazard Mitigation Element Quality $(P=-0.176, p=0.313)$. Normally, an increasing population density would be expected to be correlated with increased vulnerability to natural hazards, so this may be an indicator that Florida's planning system is effectively mitigating increasing population by balancing it with stronger planning.

The percent of population aged 62 and over was not correlated with quality of hazard mitigation elements $(\mathrm{P}=0.256, \mathrm{p}=0.138)$. While typically higher age is associated with increased vulnerability, this was not the case, which may indicate that the state planning mandates are working to effectively reduce vulnerability regardless of demographics. The percent of population Non-White was not correlated with quality of hazard mitigation elements $(\mathrm{P}=-0.42, \mathrm{p}=0.810)$. Similar to age above, this is evidence that planning for natural hazard mitigation in Florida is at least on a somewhat "even playing field" regardless of the social demographics that typically affect vulnerability.

Overall, these results present a mixed outlook on Vulnerability theories. Aside from education, none of the variables indicating social vulnerability were individually correlated with quality of hazard mitigation elements in the direction and strength 
expected (some variables correlated, and some did not, but of those that did, the relationship was in opposition to the expectations associated with theories of vulnerability). However, given the intercorrelations of the demographic variables with population size and density, the two correlations with the greatest correlation with hazard mitigation element quality, it seems likely that these two (population size and density) are the likely contributors to increased hazard mitigation element quality. This fact, and that that many of the variables that correlated with hazard mitigation element quality also correlate with urbanity, may indicate that more urban areas have higher quality hazard mitigation elements, are less vulnerable in this aspect. The association of higher urbanity with lower vulnerability would be expected under Vulnerability Theory. These mixed results warrant further investigation in future research.

My research used surveys to explore plan quality issues with a larger audience. I conducted the survey electronically in 2011. The respondent set was seeded by inviting land use planners from all 67 Florida counties, as well as participants from a major conference focused on natural hazards. I asked these people to forward website-links to the survey to others who might be interested in participating.

Overall, respondents favored increased information in the hazard mitigation element planning process (interviews of stakeholder, public meetings, and using formal modeling of hazards); limiting development in hazard zones; and using nature as a barrier to hazards. There was less support for options that might place a burden on the public, such as limiting infrastructure in hazard zones and requiring mitigation from new developments that would result in increased evacuation times. 
Coordination with entities outside of the Planning Department also proved to be an important element to survey respondents. A strong $90 \%$ said that planning departments should coordinate hazard mitigation elements with local water management districts, and 96\% said planning departments should coordinate with local emergency management departments.

Lost Opportunities: Two Disconnects in the Process of Planning for Hazard Mitigation Combining the observations from the plan reviews, analysis of hazard history, interviews, and surveys, it is clear that there are two significant disconnects between normative ideals for how planning organizations should prepare hazard mitigation elements, and how this is actually done. On the basis of Vulnerability Theory, and normative ideas about how organizations "should" learn, there is an expectation that historical hazard strikes would inform the process of hazard mitigation planning. However, the analysis revealed no correlation and there was no mechanism established for such learning in planning documents. This has heavy implications for planning organizations because it is one of several "lost opportunities" to improve Hazard Mitigation Elements identified in my research. As noted above, hazard strikes are an excellent opportunity to learn - they show a reality that scientific models may not. The fact that planning organizations are not fully employing the information gained in hazard strikes indicates that these organizations may be missing important opportunities, despite planners in surveys often favoring methods to bring more information into the planning process. However, given common organizational behavior to operate in silos, this is not surprising. 
Another important disconnect to note is that, while planners said in interviews and surveys that planning departments should coordinate with other governments and agencies, and seek public input, evidence of special efforts to do this was lacking based on the evidence from plan reviews. The lack of coordination also represents a significant "lost opportunity" because the people who have experienced a hazard, on the ground, first hand, often have information and knowledge individually and collectively, that could improve the hazard mitigation element of the CP. As mentioned above, the disconnect between planners and the public may be because, both for the public and planners, hazard mitigation is just one small part of the process of comprehensive planning, and it appears to become lost in the fray of larger issues.

One potential hypothesis explaining both of these disconnects is simply that, in the context of a state requiring a hazard mitigation element, local governments are often just "checking the box" and meeting minimum state requirements. When governments consider the cost of "risk" in terms of how much a disaster might cost versus how much cost could be averted through stronger comprehensive planning for hazard mitigation, going above and beyond the level of a basic plan is simply not worth it to them. This would be consistent with the results of plan reviews conducted for my research, which showed a variety of scores, but still did not find any plans scoring exceptionally high (the highest score was 25 out of a possible 48). Possibly, the cost of implementing stronger hazard mitigation elements (more planner time focused on hazard mitigation instead of other concerns, and possibly, more development restrictions) is too high for administrators and politicians to consider worthwhile. 
If governments want to increase the focus on hazard mitigation in the comprehensive planning process, they might consider dedicating more resources exclusively to comprehensive planning for hazard mitigation, empowering planners charged with hazard mitigation to work directly with the public and other agencies and departments (and requiring them to use that empowerment to better the process), and working with political leaders to help raise this issue on the agenda of the public in their constituencies.

\section{Moral Hazard}

Earlier, I introduced the issue of moral hazard. Particularly in the case of hazards and disasters, moral hazard occurs when government, at any level, pays to repair properties damaged in the same manner (known as "repeated losses") over and over again. For example, if a particular home floods on a regular basis, and a unit of government either subsidizes repairs or subsidizes the insurance used to make those repairs, moral hazard exists.

In Florida, there is clear evidence that moral hazard exists, given the unsound rates charged by the state windstorm insurer (which survives because it is backed by bond sales and has authority to levy special assessments on policy holders), combined with the lack of learning from historical hazards and compounded by poor state-level willingness to enforce mitigation measures in county CPs. Exacerbating the issue, if the federal government is going to make a policy of assisting homeowners in repetitive loss areas following disasters, moral hazard is worsened if there is not sufficient action to prevent reoccurrence of disasters. 
In the case of Florida, I found no correlation between hazard mitigation element quality in CPs and hazard history at the county level. Such a correlation (or an overall high quality of hazard mitigation elements in every county) was expected in order to compensate for repetitive losses. Areas with a higher incidence of hazards should show more attention to preventing future losses. This was not the case. Further, planning documents almost never required any form of historical hazard analysis. Meanwhile, the state windstorm insurer, originally conceived to be an insurer of last resort, is not charging actuarially sound rates to cover potential losses. Florida is essentially putting taxpayers at risk for a large insurance payout in the event of an expensive disaster, but not doing all it can to reduce risk to the hazards that may cause such a disaster.

Going beyond the state level, when the federal government steps in to "bail out" repetitive loss properties, moral hazard is compounded. If the state government is not taking sufficient hazard mitigation efforts, and then the federal government steps in after a disaster, as was the case following Hurricane Sandy, moral hazard is compounded. For the traditional system of handling hazards and disasters to work, under which hazards and disasters are first a local, then state, then federal responsibility, reconsideration of mitigation at the local and state level needs to be considered.

Implications for the Theories of Vulnerability and Neo-Institutionalism

Theory is important in research because it gives researchers a lens through which to conceptualize information. The theories of Vulnerability and Neo-Institutionalism ground my research. Research findings provide important implications for both. 


\section{Vulnerability}

Vulnerability Theory essentially contends that certain factors make some people and communities more prone to the effects of natural hazards than others. Typically, Vulnerability Theory views people with minority traits (e.g., lower socioeconomic status, minority race, extreme age, etc.) as more vulnerable to the effects of hazards than the majority. This is because a) some minority traits (such as low income) lessen abilities to cope with hazards, even on an individual basis; b) some minority traits (such as race) often correlate directly with others mentioned in (a) (e.g., minority race is often associated with lower income, and in less developed countries, housing discrimination); and c) minority groups may be less well served in mitigation, response, recovery, and preparedness due to prejudices, low economic power, and low social and political power.

The fact that plan quality was not correlated with hazard history is inconsistent with some aspects of the theory of vulnerability. In this review of plan quality, I found no evidence that counties with more hazard experience (including factoring in strength of hazards) had better hazard mitigation elements, or vice versa. Certainly, this is not a refutation of the concept of vulnerability, but it does reflect that in the Florida context, the notion that prior hazards teach those who experience them is not necessarily applicable. It also should be considered that planning organizations may not be motivated to learn from hazards because the state and federal government essentially subsidizes risk taking. While the state subsidizes insurance in hurricane prone areas, the federal government often steps in with aid after disasters. This may reduce planning organizations" incentive to "deal with" hazards, because of the low consequence to the citizenry in the event of a disaster. Essentially, hazards may not bear a high enough cost 
to gain the attention of local governments, especially when compared to many other land use issues that have more salient and routine economic effects. This warrants further exploration.

Most of the significant correlations between demographic factors and hazard mitigation element quality do not comport with Vulnerability Theory, when taken individually. Three explanations may explain this apparent disconnect. First, much of the research on vulnerability has been conducted on either individuals, families, or communities in comparison to larger groups (e.g., indigenous persons living in nonindigenous communities, minority populations compared to majority groups, etc.). In this dissertation, I studied entire counties, each of which, when compared to each other, has a broad population spectrum - this may "wash out" the effects of minority groups in each county. Second, much of the existing vulnerability research is conducted in situations in which the differences between socioeconomic classes is more profound than these differences are in coastal Florida. As a caution, it must be noted that this is a very small sample ( 35 counties) and that my research examines the county level, which in and of itself is too large of a level for detailed hazard analysis. Third, many of the variables that correlated moderately with hazard mitigation element quality also correlate with urbanity. Often, urban areas have access to programs to plan and prepare for natural hazards, and they may get more attention in hazard mitigation activities due to large population concentrations. It is possible that these variables, when taken together, represent urbanity, and reflect that more urban areas actually do have stronger hazard mitigation elements. This should be further investigate in future research. 
Survey results reflected broad support for employing the concept of vulnerability in land use planning for hazard mitigation, with $82 \%$ of respondents supporting the use of vulnerability. Further, when asked an open-ended question about improving hazard mitigation elements in low-income and minority areas, respondents showed a consistent understanding of addressing the needs of vulnerable populations. For example, in freetext responses, 20 respondents cited a need for increased public education and outreach; 16 stated there should be an increased focus on including these populations [minority and low income] in the hazard mitigation process; and 12 stated that offering financial incentives to improve structures was important.

While respondents expressed support for incorporating the concept of vulnerability, they presented mixed thoughts on the actual principles of Vulnerability Theory when asked less directly. For example, only $49 \%$ agreed with the notion that wealthier communities are more likely to have better hazard mitigation elements. Similarly, only $40 \%$ said that communities with higher minority populations would be more likely to have lower quality hazard mitigation plans. However, they did agree with one aspect of Vulnerability Theory - that prior hazard experience is correlated with increased resilience. The majority (86\%) said that communities that had experienced a disaster were more likely to have stronger hazard mitigation elements.

Finally, this raises important questions of just how far government should go to protect people when they increase their vulnerability by choice (and at a deeper level, when vulnerability is the result of a "choice" versus factors that unwittingly push people into vulnerable situations). If people choose to increase their vulnerability, should government try to adjust for it? Or should government let the private market sort this out 
through higher insurance rates and costs to build homes to standards that can withstand hazards in dangerous areas? Possibly by requiring safe land use and buildings, which may make living in vulnerable geographies more expensive, government may be helping the "invisible hand" along to compensate for that increased vulnerability by essentially pricing out those who cannot afford the cost of safely living in these areas, or do not place enough priority on living in these areas to expend the resources required.

Ultimately, a line must be drawn at which governments stop trying to compensate for vulnerability and allow people to take on the cost of their decision-making - however, where to draw that line has not yet been determined.

\section{Neo-Institutionalism}

Neo-Institutionalism is the theory used to conceptualize planning organizations and the environments in which they operate. It holds that institutions are built from the rules and human-created constraints that affect the behavior of the actors in the institutions. Neo-Institutionalism posits that institutions are, at their core, routines that are born from a need to cope with uncertainty. This is an ideal explanation for how the planning institution operates - a great deal of technical and social information goes into the creation of a comprehensive plan, and planning organizations establish methods to collect, sort, analyze, and assimilate that information. These methods may or may not encourage open information gathering from and collaboration with the public, other departments, and other governments.

Institutions affect action and interaction by controlling information and how people can use it. This is very important in the context of comprehensive planning, 
because it is a public policymaking process that is managed by technical experts planners are responsible for incorporating public input with their technical knowledge, but both as the owners of the process and "experts" have a controlling stake in the process. Both the institutions planners are a part of, and those they create, can have an implication for the quality of hazard mitigation elements. If planners create highly bounded institutions stymieing creativity and public input, plans may be of less quality than if intuitions are open to new ideas and to learning about public knowledge of hazards and public needs.

Results of this study support the notion that each planning department operates as its own institution with its own norms and practices, despite prescriptive mandates in state law and administrative code, and state-level enforcement mechanisms. Many of the state mandates for hazard mitigation elements did not show up universally in hazard mitigation elements, and many elements were of poor quality (which would not be the case if state laws were followed). This reflects that while the state takes a top-down approach to instituting quality, this does not necessarily carry down to the ground level where policies are implemented.

Results shed some interesting light on planning organizations as institutions. While one might expect planning institutions to lean toward technocratic solutions to routinize the science of planning, this was not borne out by the results of my survey. For example, while $82 \%$ of respondents said that planners should interview key hazard mitigation stakeholders, $85 \%$ said the planning process should mandate public meetings, and $85 \%$ said there should be required consultation with special districts and local governments in the county, only $69 \%$ said that the SLOSH or another model should be 
used. The first three items (interviews of stakeholders, public meetings, and consultation with special districts) are rather traditional planning elements that are staples of the profession. Using hazard modeling, however, is a newer, and still developing concept. While this certainly warrants more investigation, this favoritism toward "traditional" methods and lower regard for more cutting edge methods, provides some evidence that institutional boundaries based in tradition are boxing in planners, at least somewhat. Other factors could be at play here, and future research should investigate this further, along with the interplay between the normative value planners express of gathering public input, but the reality that they do little in this area for the hazard mitigation element.

There, also were differences in how much planners favored limiting versus prohibiting development in hazard zones. While $86 \%$ of respondents favor limiting development in hazard zones, only $58 \%$ favored completely prohibiting development in hazard zones. Similarly, only $48 \%$ favored not building additional infrastructure in hazard zones. Again, these drastic differences may be indicators that institutions do operate within learned boundaries. While the options of prohibiting development in hazard zones and forbidding new infrastructure in these zones are some of the strongest ways to prevent disasters and increase overall resilience, they clearly are unpopular, as hazard zones are often attractive places to live and tremendous tax generators (especially in the case of multi-story buildings). This may provide evidence that political concerns, learned through years of agencies working under leadership of elected bodies, have put boundaries on making the most correct technical decisions. That said, other explanations 
are possible (e.g., planners may believe that structural mitigation can compensate for the dangers of building in these areas).

Finally, the finding that prior hazard experience does not improve plan quality has implications for theories of institutions, and particularly institutional learning. Florida is routinely struck by significant hazards, and even minor ones, that cause damage. This lack of correlation between hazard history and hazard mitigation element quality suggests that planning organizations are not learning organizations. This is a critical finding because each hazard event provides an opportunity to learn from reality, rather than models based on limited information. It appears, however, that planning organizations are not using this information.

\section{Merging What Professionals Say with What Governments Do}

Overall, it appears, based on the Florida example, that what practitioners express normatively ("should do") as goals for hazard mitigation planning as a part of comprehensive planning is not realized in government actions. In fact, even legally mandated hazard mitigation components embodied in state law and administrative code were often not included in hazard mitigation elements; no matter what even the state government says, mandates did not always translate to actions at the local level. Hazard mitigation elements across Florida are not of uniform quality, and many are of low quality. The public is not substantially involved in hazard mitigation planning in comprehensive planning, and government makes little effort to encourage such involvement. In a similar vein, professionals and researchers say social vulnerability 
exists, but they do not acknowledge its potential effects on hazard mitigation elements in CPs.

This raises an important question: "How can normative standards that the planning community sets for hazard mitigation elements in CPs be realized in government actions?" While an answer is beyond the scope of this dissertation, ideas to further a solution are presented here. Based solely on the Florida example, it appears that to realize these normative goals, governments need to better recognize the importance of comprehensive planning for hazard mitigation. For example, state and local governments could give support to planners charged with this duty in Planning Departments to act on the same level that their corresponding Emergency Management departments do, especially in the matter of public interaction. Armed with this support these planners would have the responsibility to reach out directly to the people they serve, hopefully incorporate more mitigation into the public lexicon. State and local government can fund the planners charged with hazard mitigation elements better, and help them focus more on these duties as a core role, and these planners can take up this challenge and do a better job of outreach and public involvement. Second, state agencies charged with reviewing hazard mitigation elements could be given a distinct identity and mission that places responsibility on them to provide both technical advice to counties and enforcement of relevant regulations.

Ideas for Practice

The finding that hazard mitigation element quality varies, despite Florida having strong, prescriptive mandates in state law and administrative code, presents challenges at 
both the state and local level. From a state perspective, there are clearly opportunities to improve local hazard mitigation elements by using best practices employed in some counties and requiring and/or encouraging, and facilitating, their use in all coastal counties. For counties, even without state intervention, this provides an opportunity to look to their peers and find ways to improve their hazard mitigation planning.

Some targeted solutions, and implementation options for states and counties, appear in Table 28, below. These suggestions align with the needs of coastal counties in hurricane and flood prone geographic areas. 


\begin{tabular}{|c|c|}
\hline Finding & Potential Activities \\
\hline $\begin{array}{l}\text { Higher Education Levels were } \\
\text { correlated with higher plan quality. }\end{array}$ & $\begin{array}{l}\text { 1. Prepare materials for local use that explain hazard mitigation and opportunities for involvement in clear, } \\
\text { understandable terms. Materials should be of multi-cultural appeal, and also should be available in the major } \\
\text { languages spoken in the state. } \\
\text { 2. Engage people with less than a bachelor's degree through industry-specific outreach, especially through } \\
\text { employers and associations. For example, use hotel and restaurant associations to reach out to hospitality } \\
\text { industry workers. This is a good opportunity for planners to use guest speaking as a tool to connect. } \\
\text { 3. Explain hazards, and the potential for mitigation, in clear terms understandable to most people. Connect } \\
\text { potential actions of the population being communicated with to benefits. }\end{array}$ \\
\hline $\begin{array}{l}\text { Planning departments tend to leave } \\
\text { the bulk of hazard related } \\
\text { communication to Emergency } \\
\text { Management departments. }\end{array}$ & $\begin{array}{l}\text { 1. Craft unified messages that the Planning and Emergency Management Departments can focus on in public } \\
\text { interaction. } \\
\text { 2. Separate hazard mitigation communication responsibilities related to comprehensive planning and give } \\
\text { ownership to the Planning Department. The Planning Department should educate the public about hazards and } \\
\text { vulnerabilities in the community, and elicit input from the public to support planning for hazard mitigation. }\end{array}$ \\
\hline $\begin{array}{l}\text { Nature is not used as a hazard } \\
\text { barrier to a great extent. }\end{array}$ & $\begin{array}{l}\text { 1. Conduct statewide historical studies of coastal areas and floodplains to ascertain how much protection appears } \\
\text { to be correlated with natural areas in hazards specific to the states. Provide detailed data to counties. } \\
\text { 2. Mandate that new construction in the Coastal High Hazard Area and flood zones must fully fund mitigation } \\
\text { projects that ensure that these developments do not adversely affect the ability of the area to weather hazards. } \\
\text { 3. Study options to entirely prohibit new development in the Coastal High Hazard Area and flood zones. If } \\
\text { appropriate, apply these measures. } \\
\text { 4. Use natural features for mixed use. For example, floodplains can be turned into recreational areas that are } \\
\text { allowed to flood as needed. This will help garner public support over the option of just making these areas "off- } \\
\text { limits." } \\
\text { 5. Work with other departments to use the power of nature in their projects. For example, selecting trees } \\
\text { appropriate to storm-prone tropical climates over deciduous trees. }\end{array}$ \\
\hline $\begin{array}{l}\text { Most counties use the minimum } \\
\text { state required Coastal High Hazard } \\
\text { Area to determine which areas face } \\
\text { increased vulnerability. }\end{array}$ & $\begin{array}{l}\text { 1. Change the CHHA to apply to all areas expected to be inundated in a Category } 2 \text { Hurricane instead of only a } \\
\text { Category } 1 . \\
\text { 2. Even if the state does not take the recommended action, apply CHHA restrictions to all areas that are expected } \\
\text { to be inundated in a Category } 2 \text { storm instead of just the state required Category } 1 \text { storm. }\end{array}$ \\
\hline
\end{tabular}




\begin{tabular}{|c|c|}
\hline Finding & Potential Activities \\
\hline $\begin{array}{l}\text { Coordination among county } \\
\text { departments is often ad hoc rather } \\
\text { than built on constant relationships. }\end{array}$ & $\begin{array}{l}\text { 1. Clearly delineate responsibilities between the Planning and Emergency Management Departments - giving each } \\
\text { appropriate roles and consultation in the mitigation, preparedness, response, and recovery phases. } \\
\text { 2. Increase the role of Planning Departments in communicating with the public. While the Planning Department } \\
\text { and Emergency Management Department should work to create a unified message to prevent public confusion, } \\
\text { the Planning Department should drive discussions around mitigation and should be constantly working to elicit } \\
\text { public input. }\end{array}$ \\
\hline $\begin{array}{l}\text { Coordination with planning } \\
\text { councils and water management } \\
\text { districts is often ad hoc, and is } \\
\text { sometimes filtered through } \\
\text { administrators above Planning } \\
\text { departments who may not be } \\
\text { familiar with hazard mitigation } \\
\text { planning in comprehensive plans. }\end{array}$ & $\begin{array}{l}\text { 1. Communicate to water management districts and regional planning councils that part of their role is to } \\
\text { coordinate planning activities among municipalities in their districts. } \\
\text { 2. Require that, at minimum, local water management districts and regional planning councils review local hazard } \\
\text { mitigation elements prior to submission for state level review. } \\
\text { 3. Elicit the assistance of water management districts and regional planning councils throughout the process of } \\
\text { planning for hazard mitigation. } \\
\text { 4. Work through water management districts and regional planning councils to coordinate with other } \\
\text { municipalities. }\end{array}$ \\
\hline $\begin{array}{l}\text { There is no statistically significant } \\
\text { correlation between prior hazard } \\
\text { incidence and hazard mitigation } \\
\text { element quality. This suggests that } \\
\text { planning organizations are not } \\
\text { learning from hazard history. }\end{array}$ & $\begin{array}{l}\text { 1. Catch up with knowledge lost by analyzing prior hazard strikes and damages and applying that information to } \\
\text { the hazard mitigation element in the next planning cycle. } \\
\text { 2. Incorporate analysis using satellite photos, ground observations, and damage estimates into the plan revision } \\
\text { cycle following natural hazards. } \\
\text { 3. After a hazard, convene groups with professional experts (e.g., engineers, environmental scientists, etc.), } \\
\text { government employees involved in the Disaster Management cycle, and citizens to determine how the hazard } \\
\text { mitigation element could have done better, and how it should be modified for the future. This should begin } \\
\text { immediately following a hazard to approve and apply modifications to the hazard mitigation element before } \\
\text { rebuilding (Recovery) begins, thus driving mitigation forward for the next hazard. }\end{array}$ \\
\hline
\end{tabular}

Table 28: suggested actions for governments to improve hazard mitigation elements 
Additionally, based on the feedback from survey respondents, hazard mitigation elements in land use plans could benefit from several improvements. Interviews of key stakeholders in hazard mitigation can be used to procure more information about community goals, hazards, conditions on the ground in communities, and potential resiliency. To better inform planning, formal models should be used to determine potential effects of hazards, especially in the face of changing sea levels.

While the economic consequences may be initially difficult, planners should consider the prohibition of development in the highest hazard zones. Allowing these areas to remain barriers against hazards (e.g., mangrove forests, or open parks that can absorb flood runoff in hazard situations) could prove very useful and keep people out of harm's way. When local governments allow development in hazard zones, they should consider requiring mitigation offsets to fund mitigation projects that will reduce hazards and aid in evacuation if applicable to the particular area. This will have the added element of bringing a degree of economic decision making to the calculus people must undergo when deciding to live in a hazard-prone area.

\section{Limitations}

While my research provides great insight into hazard mitigation planning as a part of comprehensive planning in Florida coastal counties, it is limited by several factors of note. Most prominently, while the state government requires all Florida coastal communities to have hazard mitigation elements in their CPs, my research only examined the county level. Possibly, planning behaviors are different at the municipal level, where government may be closer to the people. Further, my research is limited to Florida - 
including other states in the sample may affect how the geography, politics, laws, and rules of Florida may influence the research. Finally, my research is limited to hurricanes and floods. While including other disasters might confound some of the results, doing so also might provide important perspective.

The number of counties studied is also inherently limiting. With only 35 counties in the research universe, any statistical analysis must be carefully considered and should not be generalized (in a purely statistical sense) to other states.

Conducting the study at the county level is a limitation. Typically, vulnerability is studied at the individual, family, social group, or community level. County level analysis may "wash out" vulnerability as communities of varying levels of vulnerability are combined into larger counties with more homogenous populations. A finer-grained examination at the sub-county level might reveal that individual communities of varying levels of vulnerability are more tightly correlated to hazard mitigation element quality. Further, because municipalities tend to form around more dense populations than the rural, less populated unincorporated parts of counties, there may be a difference in how the two government types approach hazard mitigation element planning. Possibly, because county governments tend to be responsible for rural areas that have lower population density than typical sub-county municipalities, the county governments are not as concerned with natural hazards and are more focused on other topics (such as land use planning) than are the more densely populated sub-county municipalities.

The hazard history index developed bears a limitation in that it measures history, but not consequence of hazards. The actual damages resulting from hazard strikes may have more of a bearing than the strikes themselves on institutional learning. While it is 
difficult to get reliable estimates of hurricane damages, it would be useful to incorporate such into a measure of prior hazard effects.

Finally, both the number of interviews and percent of survey respondents should be noted as potentially reducing the ability to generalize the findings of my research. There were only four interviews with county planning leaders. While the interview design helped shape the research, this number is still small. Also notably, several potential interviewees turned down interview requests, and thus self-selection could have biased interview results. In regard to the surveys, while the sheer number of respondents is acceptable $(n=128)$, the response rate of $16.27 \%$ is low. Also, when analyzing respondents by employer/group, some groups had much higher response rates than others, introducing the possibility that self-selection may have played a role in the findings.

\section{Future Directions}

While my research answers the question of whether or not hazard mitigation element quality varies in a state with a strong prescriptive mandate for such elements, the question of what drives this variation, while partially answered, requires further exploration.

The biggest question left unanswered here is what effect public participation has on the quality of hazard mitigation elements of CPs. Certainly, practitioners have indicated that such input is important, but in reality, it appears that both the input itself and efforts to get that input are largely lacking. Further research should examine hazard 
mitigation elements in correlation with public participation in their design. Results of this would greatly inform policymaking activities of planning departments.

While some demographic factors appeared to correlate with hazard mitigation element quality, demographic factors could not explain all of the variation in hazard mitigation element quality. Also, it is notable that the quality of hazard mitigation elements generally hovered around the same level - my research found more uniformity in quality than expected. Possibly, strict and prescriptive state mandates establish a "floor" on quality that is unaffected by demographic variables of the population. My research also did not investigate potential interactions between the insurance industry, insurance rates, and future risk of hazards in correlation with plan quality. Thus, future research should examine plans in states with varying levels of requirements for hazard mitigation elements in CPs, and include comparison to demographic variables, insurance rate information, measures of insurance industry involvement in the hazard market, and future risk from hazards, to better ascertain where the drivers of plan quality variation lie.

Conclusion: The Role of the Public in Planning for Hazard Mitigation At the beginning of this dissertation, I noted that comprehensive planning is an iterative method of policymaking. Especially in Florida, where public meetings and opportunities for input are legally required, and the state monitors both the planning process and the output, comprehensive planning provides the opportunity for public input to come together with technocratic skill to build strong policies.

Despite the possibilities of the planning process, it appears that the public largely is not directly involved with comprehensive planning related to hazard mitigation. 
Interviewees said that the public simply is not especially interested in this process, and planning documents generally do not require encouraging public input into the hazard mitigation element. Yet, when surveyed, planners said that public input into hazard mitigation element planning is important. Overall, it appears that while planners say public input is important, efforts to go above and beyond to solicit it, and public interest in providing the input, are lacking.

A distinct possibility is that, especially in a state that requires hazard mitigation elements with specific components, there is a base level of plan quality - and that when the reality of the planning process happens, planners simply meet the requirement. Instead of "spinning their wheels" trying to garner public input into hazard mitigation elements that the public has little interest in, and likely little technical knowledge to contribute, planners may be directing their energy to areas where the public has more interest and can provide critical input. Both the merits of public input (especially given the tradeoff between higher insurance rates in instances of lower mitigation, and vice versa) into the hazard mitigation element, and the perceptions of planners surrounding this input, deserve greater consideration in future research. 


\section{APPENDICES}

Interviews of County Comprehensive Planning Department Managers

In order to inform the development of a survey instrument, I interviewed several planning leaders in local government. The major objective of the interviews was to assimilate impressions of what drives quality of hazard mitigation elements from planning leaders in practice. Their input was used to drive design of the fourth and final phase of data collection, a survey of land use planners and people involved with land use planning (see next chapter).

Table 29, below, shows the breakdown of the counties represented in interviews; note that all counties are coastal, Florida counties.

\begin{tabular}{|l|r|r|r|}
\hline \multicolumn{1}{|c|}{ Region of Florida } & 2010 Population & \multicolumn{1}{c|}{ Hazard Index } & \multicolumn{1}{c|}{ Plan Quality } \\
\hline North-Gulf & 500k-1m & 0.1394 & 25 \\
\hline North-Gulf & $100 \mathrm{k}-500 \mathrm{k}$ & 0.2644 & 23 \\
\hline South-Atlantic & $1 \mathrm{~m}-2 \mathrm{~m}$ & 0.7212 & 11 \\
\hline South-Atlantic & $2 \mathrm{~m}+$ & 0.8701 & 17 \\
\hline
\end{tabular}

Table 29: Summary of land use planning officials interviewed

Below, each question and a summary of responses appears.

Question 1: Thinking specifically of Comprehensive Plan elements related to natural hazards, what guides and/or mandates the elements that appear in the Comprehensive Plan?

Three interviewees reported that Chapter 163 of Florida Statutes (the Growth Management Act) and Florida Administrative Code 9J5 (the Florida administrative rule governing local comprehensive plans), govern this. One interviewee also noted that 
Florida Administrative Code 9J11 covers topics relevant to hazard mitigation planning.

Overall, interviewees were well aware of the legal basis for planning regulations, and in conversation, tended to focus on the administrative rule rather than the law requiring hazard mitigation in CPs.

Certainly in our county the mandates are in $9 \mathrm{~J} 5$.

Chapter 163 has all the statutes and codes regarding comprehensive planning... there are several rulings about the section, such as $9 \mathrm{~J} 5$. The statutes basically require certain elements in the Comprehensive Plan, and one is the Coastal Management Element.

Chapter 163 of the Growth Management Act does [require the Hazard Mitigation Element], as well as $9 \mathrm{~J} 5$, which is the rule that sets the minimum requirements for preparing local government comprehensive plans.

The mandates, of course, our hazard part is basically under our Coastal Management Element, there's a section there about hazard planning, but overall, that's as far as mitigation. That kind of dovetails with a lot of other environmental issues. ...the county constituents actually voted to tax themselves; a part of that goes specifically for environmentally sensitive land, which is all these coastal properties mainly. Several thousand acres have been acquired over the years because of stewardship.

Table 30: Select responses to Question 1

Question 2: In what ways would you say your county's hazard mitigation element exceeds Florida's requirements?

One county reported expanding its coastal high hazard area (CHHA) beyond the state mandated Category 1 inundation zone to the Category 2 inundation zone. Note that Florida statutes and administrative codes delineate a specific Coastal High Hazard Area (CHHA), which consists of the coastal area that the government expects will flood in a Category 1 hurricane or above. Per Florida statute, local governments on the coast are required to plan for hazard mitigation in this geographic area. If a county increases its CHHA to an area covered by storm categories higher than the state minimum of a Category 1 , it is expanding the geographic area in which it must apply stricter standards for coastal development. This expansion protects additional land areas in the event of a 
storm, but may also come with additional costs from meeting stringent coastal requirements, and economic loss due to development restrictions.

One interviewee, in a county with a plan that was rated very highly in hazard mitigation element ratings conducted prior to the interview, reported that his county had several special programs that exceed state requirements for the Coastal Management Element. In particular, this county reported that its plan is tightly woven with many environmental conservation issues that arose in the 1970 s, when residents of the county became sufficiently concerned with the environmental state of their county that they voted in a referendum to pay a tax to purchase environmentally sensitive land. In fact, the series of meetings in the 1970s in which residents became aware that the county faced a potential problem with too much development still carries an informal name, which the interviewee used in the discussion - this indicates the importance of this decision and how it is ingrained within the culture of the Planning Department, as well as longstanding political support for hazard mitigation activities. Some of this money has been used to purchase repetitive loss properties (properties which have been affected by a hazard and incurred property losses several times) and turn them into a watershed.

Interviewees also reported other specific areas in which their county's plans exceed state standards, including addressing transportation issues, especially improving roadway links critical to evacuation; policies to regulate the construction of any new mobile home parks in the CHHA; maps of sites suitable for post-disaster relief staging and debris collection; and prohibiting new development in the CHHA or requiring more stringent review standards for new development. 
I don't know if it exceeds, but it has a couple of components, I think, that help guide the county in determining how to continue to develop coastal management areas, areas to avoid, and what kind of issues we're going to address along the way when we're doing that.

We have policies dealing with things like making sure that evacuation routes are not susceptible to blockage by trees in tropical storm force winds. We have policies that say what kinds of plants and trees can go along certain roadways. We have a policy in here about educating the public about disaster preparedness. We have policies in here to always map areas suitable for postdisaster relief staging.

....in protection from hurricanes, we've gone to the extent of taking the Category 1 SLOSH extent, SLOSH model, mapping that out, and using that as a Coastal High Hazard area designation. In doing so, we've put controls on the allowable density you can have in those areas as a review requirement for new construction as well as new plans... we've directly taken that hazard in terms of storm surge and converted it into a regulatory line on our zoning plans. It extends from our Comprehensive Plan policies into our actual land development policies.

We do acquire properties for stormwater management purposes. We've taken flood-prone properties and put them into public hands, these are properties that typically had flooding records, the had been part of the repetitive loss properties, and we've taken those off the books and incorporated those properties into the water management area to provide more storage for our creeks.

There are several areas which we could say we might exceed the requirements. The first one is that there is a Coastal High Hazard Area in Florida, and there is a definition of a Coastal High Hazard Area that it should be a Hurricane 1 inundation zone... in our county our Coastal High Hazard Area is determined by the Hurricane [Category] 1 and Hurricane [Category] 2 inundation zone.

...we have a prohibition on increasing densities in Coastal High Hazard Areas. Some counties allow for mitigation and things like that; we basically prohibit increasing densities in coastal areas.

Table 31: Select responses to Question 2

Question 3: Are there any ways in which you would say your county's hazard mitigation element could use improvements in terms of Florida's requirements?

Several respondents reported that their hazard mitigation elements could incorporate more mitigation measures, but there was a concern that doing so would create an appearance of safety in the CHHA and might encourage greater levels of development. Other ideas mentioned include lowering density in the CHHA, prohibiting new mobile home developments in the CHHA, and addressing climate change and sea level rise. 
Question 4: What do you see as the important functions of the hazard mitigation element of the CDMP?

Interviewees reported a variety of functions for the hazard mitigation elements of CPs. Some saw broad possibilities, such as serving as guidelines for policy implementation (especially in guiding development), versus policies in and of themselves. Others cited highly specific functions including addressing pre-disaster mitigation, and directing people away from high risk areas.

A theme that was highlighted slightly here, and showed up in several other interviews, is that the $\mathrm{CP}$ is not just a policy document, but an implementation guide. Interviewees often noted the importance of turning the $\mathrm{CP}$ into more than a policy document, and using it to communicate information to actually help implement policies. One example of this is using maps to make policy more concrete and actionable. 
What kind of measures are you planning for pre-disaster mitigation? It's important to include post-disaster; how do you mobilize? How do you ensure the population is directed away from high-risk areas, and having a plan for moving people out before a storm and back after a storm. How to decide whether to rebuild or not to rebuild? But then you run into property rights. I think the primary issue is the fact that those hazards are identified and that policies are developed that translate into some type of development control or regulation that attempts to mitigate for those issues.

A function of the Comprehensive Plan is to enable implementation of those policies. They [the policies] enable the activities of the Emergency Management Division. The Hazard Mitigation Plan is to provide that guidance for local government to implement emergency management measures.

Here in Florida it's extremely important because we have competing priorities. You like to have the growth because you like to see the economy grow here, but at the same time, what attracted people here in the first place might be negatively affected. It's important to find that balance, because it's just too easy to say, 'We could just simply fill in a wetland area, we could fill in a floodplain area.' That's the balance act we need to play here..

Table 32: Select responses to Question 4

Question 5: What are some critical elements of a hazard mitigation element that help to achieve those functions [see Question 4]?

Interviewees came back with a variety of responses to this question, but there was little consensus among them. Some respondents talked about outputs and outcomes, including balancing economic development and growth, and encouraging individuals and businesses to take responsibility for their own mitigation. Others talked about planning processes, including analyzing potential disaster effects, analyzing the capacity of infrastructure to withstand a storm strike, and mapping hazards, infrastructure, and land use zones. Most likely, achieving hazard mitigation functions are better supported by plan processes that help to enhance the element itself, rather than by the actual outputs. 
You have the mapping function, which translates Into your zoning maps. You have your building code, which is regulated by the state, which the state building code does have windload requirements for construction in different areas of the county. We also, in terms of hazard mitigation... are doing a project with the Water Management District with improving our Flood Insurance Rate Map system and making that digital... It's all based on new LIDAR data, I think it's probably 20 times more accurate a map of flooding than we had before.

The drive on trying to put the onus not so much on the government, we're here to help you, but to impress on people their own responsibility to protect their property, to build their homes, to be more resilient.

Table 33: Select responses to Question 5

Question 6: In your department and county, what are you doing to create and maintain a high quality hazard mitigation element?

Most respondents took this question as an opportunity to discuss the culture around and process of creating a quality hazard mitigation element. Some respondents cited communication and collaboration with municipalities, other government departments, local environmental groups, and regional planning councils as important paths to a high quality hazard mitigation element. For example, one interviewee answered:

One of the things we do well that we want to continue is our relationship in working with our departments and our jurisdictions. We do have some very interested focus groups, some citizens groups, we bounce some things off of to get their perspective.

One interviewee said that better plans can be created by creating plans within the local government than by hiring outsiders to write the plan - this may be true given that local planners likely have intimate knowledge of their communities that outside planners may not have. 
Instead of addressing planning processes, some interviewees listed specific plan elements they believe are important to hazard mitigation. Elements listed include an emergency management plan (separate from the hazard mitigation element in the comprehensive plan), implementing a local mitigation strategy (again, separate from the $\mathrm{CP}$ ), having a post-disaster plan, and having specific plans for local hazards (i.e., dike failure).

Question 7: What sources of information are used to build the hazard mitigation element? Comprehensive plans, and hazard mitigation elements, are policy documents, which must be built on solid information about the communities for which they are written. Interviewees listed several sources of information that inform their plans. For some, information came from coordination with other departments and organizations including their local emergency management department, the Sherriff's Office, Fire Rescue departments, other local governments (both neighboring and within the county), and civic associations. Other interviewees cited references and scientific information including models (example: SLOSH), LIDAR [Light Detection And Ranging topographical] data, Flood Insurance Rate Maps (FIRMs), and Forest Service wild fire data. 
...we're using data from the LIDAR project, we're using data from the Forest Service on wildfire hazards, we work with the Sherriff's Office on his data.

We work in complete coordination with the Emergency Management Division. The Emergency

Management Division is the public safety department of the county, so that includes coordination with the Sherriff's Department, Fire Rescue, civic associations, etc. So basically the data and analysis that is used to prepare and maintain the coastal mitigation and hazard mitigation part of it is collected through the Emergency Management Department.

The county has put money toward updating LIDAR data, which is contributing toward an updated SLOSH model. The county also contributed to modernizing its Flood Insurance Rate Maps.

Table 34: Select responses to Question 7

Question 8: What do you think are the hallmarks of a quality hazard mitigation element?

While Florida sets minimum standards for hazard mitigation elements in state statute and administrative codes, planners proffered many ideas for going beyond these minimums to create stronger hazard mitigation elements. From a planning perspective, interviewees suggested addressing hazards beyond hurricanes and floods hazards (e.g., terrorism, sea level rise, and fire); strong linkages between emergency response plans and land use plans (e.g., coordination between the evacuation plan and land use plans); and a holistic planning process that results in implementable plans that are realistic. From a programmatic perspective, interviewees recommended increased public information and outreach; hardening infrastructure; encouraging people to take responsibility and harden their homes and businesses against hazards; and coordinating with other departments. 
It needs to address all aspects of all hazards, not just natural hazards...

It needs to provide guidance on how to deal with emergencies. In the case of hurricanes, of course, it is important to provide for the evacuation of areas that are impacted by the disasters. I would put at the top of my list coordination with other agencies, requirements for information, and operational effectiveness; because when you do the best type of plan of action, you want it to be implementable... It needs to have very practical actionable... things that can be utilized.

I think the way we approach it holistic. I think the public information and outreach is important, we have such a turnover in population and new people coming in, that they need to know this information when they're trying to purchase property. Outreach - not just in hurricane season... but year-round. We have to be more far reaching as far as the possible effects of sea rise in this area. What happens if all of the sudden everything is a meter higher? What's the impact?

To encourage business owners and homeowners to harden their own homes and businesses to the extent that they can economically. To educate, I think education is an important component in an element.

Table 35: Select responses to Question 8

Question 9: How does your department coordinate with other departments and other governments to create a quality hazard mitigation element?

Hazards and disasters go beyond the functions of any one department and cross political boundaries. This question provided interviewees an opportunity to discuss how they coordinate across functions and boundaries to create the highest quality hazard mitigation elements. Some interviewees reported using new and creative methods of communication including Facebook and Twitter, and Sharepoint ${ }^{\mathrm{TM}}$ to share draft documents. Other reported more traditional methods such as keeping a list of stakeholders and coordinating with them; participating in councils bringing together regional planning departments and other affected agencies from multiple local governments; sending drafts through other departments and municipalities; and involvement with the Local Mitigation Strategy Committee.

Well, the main feature that we use right now is the Local Mitigation Strategy Committee. That committee meets quarterly, at least, usually. We have representatives from cities on that, as well as some of the constitutional officers, some of the groups that are involved. We'll have full meetings on an as needed basis if we have something we need to coordinate with. 
We strive to communicate with as much people as possible. We engage in online networking programs - Facebook and Twitter - we are just starting very timidly to use them. We have an extensive list of stakeholders and contacts.

It's primarily with the Department of Emergency Management... we attend their meetings, which are ongoing.

It's just really kind of keeping in touch. If we have meetings, they definitely are invited. If we have drafts, we run them by various people that may have an interest. We try to inform them [municipalities] as best we can, particularly through websites and SharePoint.

Table 36: Select responses to Question 9

Question 10: Is your county represented on the water management district? Is your department represented at all or nearly all of its meetings? Does the person responsible for the hazard mitigation element attend its meetings? How does the water management district affect your hazard mitigation element?

Water Management Districts (WMDs) in Florida manage watersheds that go beyond the political boundary of any one county. They provide important methods of regional coordination to align water policies and address water issues. When asked about their coordination with WMDs, interviewees said that, typically, one county official represents the county to the WMD in an administrative capacity (not as a voting board member), and this person is part of the county executive office and not the Planning department. If an issue relevant to the $\mathrm{CP}$ will be taken up at the WMD board, a representative from the Planning Department may attend a given meeting, but the Planning Department typically does not routinely send a representative to every meeting (one county did report sending a representative to every meeting).

In terms of coordination in the planning process, planning departments may send drafts of relevant items to the local WMD for review, but coordination is typically not any higher than that level. One county did report a much higher level of communication, 
however, and said that its staff was in constant communication with the local WMD. As an indirect form of coordination, the WMD has authority to review certain projects and issue permits for them. This drives a level of communication between planning departments and the WMD. 
Question 11: Please describe coordination between your department and the Emergency Management Department and how you share information.

This question provided interviewees the opportunity to discuss their department's relationship with their county's Emergency Management Department. This part of the conversation explored how counties connect the Mitigation and Response functions of the Disaster Management Cycle. According to interviewees, planning departments tend to seek out the input and review of emergency management departments in making policies related to hazard mitigation. Conversely, emergency management departments tend to be consumers of Planning Department information, such as zoning densities, which are used to facilitate response planning. Planners also said that coordination tends to be ad hoc and focused on specific issues rather than ongoing and constant. Finally, two interviewees noted that their department is represented at the county Emergency Operations Center when it is activated.

That [coordination between the Planning and Emergency Management Department] is primarily done above my department.

We are pretty close. Most recently, for instance, we have been working with them in updating the Coastal High Hazard Area.

We coordinate with them on the policies we add to the Comprehensive Plan. If there is any other general policy with regards to hazard mitigation, we seek their input. Is there anything that needs to be updated? Is there anything here that we need to include that we've overlooked in the past? Are there new issues in hazard mitigation that need to be addressed that haven't been addressed in the past? Basically on an as-needed basis.

We review their Comprehensive Emergency Management Plan when it's updated."

Table 37: Select responses to Question 11

Question 12: How interested is the public in providing input related to the hazard mitigation element? What public groups take a strong interest in this? When are public meetings regarding the hazard mitigation element typically held? How does your 
department work to educate the public about hazard mitigation to foster quality participation?

This series of questions was aimed at assessing the level of public involvement in the hazard mitigation element and how planning departments elicit public involvement. Overall, respondents reported that the public is not very interested in providing input about hazard mitigation, unless there recently has been a hazard strike or disaster that captures public attention. While individuals tend to show little interest in hazard mitigation in comprehensive planning, civic organizations such as environmental, watchdog, health care, building, and disaster response groups tend to be the groups most interested in giving input regarding hazard mitigation.

Respondents reported that the value of public input is that it brings people's personal experiences and perceptions to the table. People participating in the process can help the Planning Department to know how people mitigate against hazards. Despite this value of public participation, half the respondents said that they hold public meetings on the Hazard Mitigation Element in the daytime, and the other two respondents reported holding these meetings in the evenings. Respondents also reported that activities to educate the public are typically left to the Emergency Management Department, although two respondents reported working with this department on outreach (but the Emergency Management Department had primary responsibility).

Overall, while there was recognition of the value of public input, planning departments do not seem to fully embrace this input. With meetings held in the evenings, the public may not be able to attend (or only certain groups that can make time in the day may be represented). Furthermore, by leaving public interaction to response oriented 
emergency management departments, planning departments may be losing prime

opportunities to engage with the public about mitigation.

\begin{abstract}
We do the outreach regarding focus groups. Our public participation has been through the focus groups, like our environmental group and also though, we tried to do some other outreach with other associations, other agencies, municipalities. We have our Intergovernmental Coordination Element which is what we follow to try to provide information, to solicit information from the outside.
\end{abstract}

When we were doing out Local Mitigation Strategy, we held focus groups and invited non-profit groups, civic groups to these meetings. We held them mid-county, north-county, south county. Our participation was disappointing in a way. We do a whole lot of other outreach and solicit comments. I can't say we get a whole lot of comments. Sometimes I question the amount of money we put into outreach compared to the benefit we get from it. Unless it happens to hit somebody in their own pocketbook at that particular point in time, getting participation is tough, no matter who you try to solicit it from, particularly from the public at large, and they won't come busting the door down unless the floodwaters are up to the doors of their house, then they come.

We've held, as far as our, we held the meetings in the evening. For the Local Mitigation Strategy itself it was during the day. But when we have public focus groups, they are in the evening.

If we didn't have that [public] input, we'd never at least have tried to address that particular situation.

They are very interested. There are certain groups that are more interested than others. One of those is called 1,000 Friends of Florida, they are not really an environmental group, but more a watchdog. There are also groups of private property owners interested in hazard mitigation.

Those meetings [public meetings] only happen when we are doing amendments, for changes to the elements there are no meetings. Depending on the situation and the topic, we hold those meetings during the day. We very rarely hold meetings in the evening.

"We seek input from the public either via the internet or workshops in which we go through every element of plans including this one, or at least topical areas. Probably the Department of Emergency Management is out there more than we are. Sometimes this element [Hazard Mitigation] gets lost among...

I don't think we do much personally, this department. In preparing the element there was that public input either directly or indirectly by this department, there hasn't been so much the last 15 years because it's already been in place. We probably should do more than what we do in the EAR...

When we go to the workshops and meet with the public in general on these issues, we do not get much of a response."

"We normally, when we adjust our Comprehensive Plan, will hold a public hearing at the Planning Board, their job is to review it and take input from the public and they send it off to the County Commission. The County Commission then takes input and votes on it at a public hearing... The other things is that our Local Mitigation Strategy Committee is a public meeting and we advertise that.

Table 38: Select responses to Question 12 


\section{Conclusion: No One Way to Plan for Hazard Mitigation}

Overall, interviewees expressed similar opinions on many issues, but also showed some variety in their responses. Certainly, because there were only four interviewees, broad trends should not be inferred from this, but the interviews do shed light into the inner-workings of planning departments.

Consistently, interviewees indicated that the $\mathrm{CP}$ is a way of translating policies into actionable items, and that the hazard mitigation element needs to be built in this perspective. They said that the purpose of the hazard mitigation element of a land use plan is to identify hazards and then develop policies in response that translate into development controls and/or regulations. Several interviewees also noted the importance of expressing these policies in plans through maps that can bring policies, features, and hazards to life. This indicates an important focus on framing planning as a policymaking and implementation tool - one which can involve the public intimately, which can be very useful to bring local knowledge to hazard mitigation.

Based on the interviews, there is a fairly low level of coordination between Comprehensive planning departments and Water Management Districts, the public, other governments, and departments within their own government. Given the potential for better addressing disasters through the Disaster Management Cycle (Mitigation $\rightarrow$ Preparedness $\rightarrow$ Response $\rightarrow$ Recovery) and regional coordination, this is an area for potential improvement.

In terms of relationships with the public, it appears that planning departments and the public are missing opportunities by not holding meetings at times accessible to the 
working public. Holding hearings in the daytime makes it hard for working-class members of the public, to come and contribute to the process of planning for hazard mitigation. Conversely, interviewees may not have much reason to take time in the evenings to hold these hearings, because they also report that the public, overall, has little interest in the Hazard Mitigation Element, unless there has been a recent hazard or disaster. What stood out the most in the interviews was that planning departments generally are not involved with communicating with the public about hazards and disasters, rather, this is often left to emergency management departments. This is likely a lost opportunity for increased public education about hazard mitigation, and for attracting public participation in building Hazard Mitigation elements. Given that the public may have a great deal of knowledge about local problems that arise during natural hazards, and may have creative mitigation strategies, this is a valuable interaction that both sides are missing out on.

Overall, routine coordination with other departments and governments was lacking. Given that natural disasters tend to involve multiple government functions, and occur across political boundaries, this is a telling finding. In one case, however, a county reported that the area has a regional coordinating body focusing on environmental issues, which brings multiple governments together on a regular basis, and includes multiple departments from each participant. This model of a regional coordinating body could be a solution to improve intergovernmental coordination for hazard mitigation.

Finally, coordination with Water Management Districts (WMDs) was varied, but typically reported at low levels, despite the fact that these organizations provide direct 
potential to address the multi-jurisdictional nature of flooding. Typically, interviewees reported that their departments attend WMD meetings on an ad hoc basis.

There was general confusion over mitigation-related terms. At least one interviewee intermingled the concepts of response and mitigation, as he noted that hazard mitigation elements in land use plans should address plans for evacuating people before a storm, moving them back after, and resuming normal operations. Another confused the concepts of recovery and mitigation, and spoke extensively about his county's flood assistance program to help people recover from floods when I asked him about plan features exceeding county requirements, instead of discussing hazard mitigation. Yet another peppered his information about mitigation with comments about recovery programs being run by the sheriff's office.

Overall, the interviews reflect that there are certain normative values involved with comprehensive planning for hazard mitigation that are not being met in the actual planning process. In particular eliciting public input, working with other government agencies, and working with other governments and inter-governmental agencies, seemed to be lacking, while planners reported that these were important features. 


\section{Survey Questions and Sources for Each}

The survey questions and topics covered are listed Table 39, below. Each question or topic may have several sources indicated, as each source checked provides significant support for asking a particular question. Those marked "Interviews" come from interviews of planners, those marked "Literature" are drawn from the literature reviewed, and those marked "Practice" were selected based on their value in practice for planning for hazard-mitigation in comprehensive plans.

\begin{tabular}{|l|c|c|c|}
\hline \multicolumn{1}{|c|}{ Question } & Interviews & Literature & Practice \\
\hline Planners interview key hazard mitigation stakeholders & & $\mathrm{X}$ & $\mathrm{X}$ \\
\hline $\begin{array}{l}\text { The plan uses Sea, Lake and Overland Surges from } \\
\text { Hurricanes (SLOSH) or an alternative formal model }\end{array}$ & $\mathrm{X}$ & $\mathrm{X}$ & \\
\hline Development limited in hazard zones & $\mathrm{X}$ & $\mathrm{X}$ & \\
\hline Development prohibited in hazard zones & & $\mathrm{X}$ & \\
\hline $\begin{array}{l}\text { No additions or improvements to public infrastructure in } \\
\text { hazard zones }\end{array}$ & & $\mathrm{X}$ & $\mathrm{X}$ \\
\hline $\begin{array}{l}\text { Mitigation required from developments that increase } \\
\text { evacuation times }\end{array}$ & & $\mathrm{X}$ & $\mathrm{X}$ \\
\hline $\begin{array}{l}\text { Nature used as a barrier against natural hazards (e.g. } \\
\text { mangrove protection to maintain coastline) }\end{array}$ & & $\mathrm{X}$ & \\
\hline $\begin{array}{l}\text { The planning department is mandated to hold public } \\
\text { meetings throughout the planning process }\end{array}$ & & $\mathrm{X}$ \\
\hline $\begin{array}{l}\text { Required consultation with special districts and local } \\
\text { governments in county (e.g. school boards, municipalities, } \\
\text { etcetera) }\end{array}$ & & $\mathrm{X}$ & $\mathrm{X}$ \\
\hline Building codes employed in hazard zones & $\mathrm{X}$ & $\mathrm{X}$ \\
\hline $\begin{array}{l}\text { Generally speaking, Comprehensive Plans should } \\
\text { incorporate the concept of vulnerability }\end{array}$ & & $\mathrm{X}$ \\
\hline Planners need education in... Environmental Sciences & & $\mathrm{X}$ \\
\hline Planners need education in... Natural Sciences & & \\
\hline $\begin{array}{l}\text { Importance of planners having experience in... } \\
\text { Environmental Conservation and Resources }\end{array}$ & & & \\
\hline $\begin{array}{l}\text { Importance of planners having experience in... Natural } \\
\text { Sciences }\end{array}$ & & & \\
\hline $\begin{array}{l}\text { Importance of planners having experience in... Experienced } \\
\text { a disaster firsthand }\end{array}$ & & & \\
\hline $\begin{array}{l}\text { Planner attendance of at least one conference annually, } \\
\text { focusing on hazards/disasters, the environment, planning, } \\
\text { public administration, or a related topic }\end{array}$ & $\begin{array}{l}\text { Xordination between planning departments and local water } \\
\text { management districts }\end{array}$ & & \\
\hline
\end{tabular}




\begin{tabular}{|l|c|c|c|}
\hline \multicolumn{1}{|c|}{ Question } & Interviews & Literature & Practice \\
\hline $\begin{array}{l}\text { Coordination between planning departments and local } \\
\text { emergency management departments }\end{array}$ & $\mathrm{X}$ & \\
\hline $\begin{array}{l}\text { Communities with a wealthier population base are more } \\
\text { likely to have higher quality hazard mitigation elements in } \\
\text { Comprehensive Plans }\end{array}$ & & & \\
\hline $\begin{array}{l}\text { Communities with a higher percentage of minority residents } \\
\text { are more likely to have lower quality of hazard mitigation } \\
\text { elements in Comprehensive Plans }\end{array}$ & & & \\
\hline $\begin{array}{l}\text { Communities that have experienced disasters are more likely } \\
\text { to have higher quality hazard mitigation elements in } \\
\text { Comprehensive Plans }\end{array}$ & & & \\
\hline $\begin{array}{l}\text { Hazard mitigation elements in Comprehensive Plans will be } \\
\text { improved if elected officials are actively involved with } \\
\text { writing these elements }\end{array}$ & & & \\
\hline $\begin{array}{l}\text { Hazard mitigation elements in Comprehensive Plans will be } \\
\text { improved if elected officials are engaged in oversight of } \\
\text { implementing new hazard mitigation measures }\end{array}$ & & $\mathrm{X}$ \\
\hline $\begin{array}{l}\text { Communities should benchmark their hazard mitigation } \\
\text { elements in Comprehensive Plans against communities of } \\
\text { similar size and/or hazard exposure }\end{array}$ & & & \\
\hline $\begin{array}{l}\text { Communities should benchmark their hazard mitigation } \\
\text { elements in Comprehensive Plans against a model hazard } \\
\text { mitigation element }\end{array}$ & & & $\mathrm{X}$ \\
\hline $\begin{array}{l}\text { County planning departments have the time and resources to } \\
\text { benchmark their plans }\end{array}$ & & & $\mathrm{X}$ \\
\hline $\begin{array}{l}\text { Community participation throughout the planning process } \\
\text { If the state windstorm insurer, Citizens, charged market rates } \\
\text { Plans would be improved }\end{array}$ & $\mathrm{X}$ & $\mathrm{X}$ & $\mathrm{X}$ \\
\hline
\end{tabular}

Table 39: Survey questions and topics and sources 


\section{Regression of Demographic and Hazard History Variables}

\section{Against Hazard Mitigation Element Quality}

To better understand how the demographic and hazard history related variables involved may correlate with plan quality, I conducted regression analysis. Instead of using only the variables found to be significant in the correlation analysis, I included all variables in the first regression model to see how well regression models comport with the findings from the analysis of correlation using Spearman's Rho. Recall that Storm Exposure is a measure of exposure to hurricanes for each county, factoring in number of storms, strength, and years elapsed since each, over the last 30 years. Notably, with only 35 cases, regression testing is a dubious exercise, and results should not be extrapolated. 


\section{Model Including All Variables}

The first regression test included all variables. It had moderate predictive power for plan quality, with an $r^{2}$ of 0.612 . Table 40 , below, presents these results.

\begin{tabular}{|c|c|c|c|c|c|c|}
\hline & \multicolumn{2}{|c|}{$\begin{array}{c}\text { Unstandardized } \\
\text { Coefficients }\end{array}$} & \multirow[b]{2}{*}{$\mathrm{t}$} & \multirow[b]{2}{*}{ Sig. } & \multicolumn{2}{|c|}{$\begin{array}{c}95.0 \% \\
\text { Confidence } \\
\text { Interval for B } \\
\end{array}$} \\
\hline & $\mathrm{B}$ & $\begin{array}{l}\text { Std. } \\
\text { Error }\end{array}$ & & & $\begin{array}{l}\text { Lower } \\
\text { Bound }\end{array}$ & $\begin{array}{l}\text { Upper } \\
\text { Bound }\end{array}$ \\
\hline $\begin{array}{l}\text { Percent of Population over } 25 \text { with a High } \\
\text { School Diploma }\end{array}$ & .099 & .281 & .352 & .728 & -.482 & .680 \\
\hline $\begin{array}{l}\text { Percent of Population over } 25 \text { with a } \\
\text { Bachelor's Degree or Higher }\end{array}$ & .115 & .206 & .558 & .582 & -.312 & .542 \\
\hline Median Household Income & $-8.458 \mathrm{E}-5$ & .000 & -.436 & .667 & .000 & .000 \\
\hline Population Density per Square Mile & .004 & .002 & 2.142 & .043 & .000 & .007 \\
\hline $\begin{array}{l}\text { Population Density Change from } 2000 \text { to } \\
2010\end{array}$ & -1.241 & 4.225 & -.294 & .772 & -9.982 & 7.499 \\
\hline Percent of Population Age 62 and Up & 28.722 & 14.652 & 1.960 & .062 & -1.588 & 59.031 \\
\hline Percent of Population Non-White & -3.009 & 10.341 & -.291 & .774 & $\begin{array}{r}- \\
24.402 \\
\end{array}$ & 18.383 \\
\hline Percent of Population Hispanic or Latino & -1.276 & 16.525 & -.077 & .939 & - & 32.908 \\
\hline $\begin{array}{l}\text { Percent of Population in Renter Occupied } \\
\text { Housing Units }\end{array}$ & 13.664 & 18.945 & .721 & .478 & $\begin{array}{r}- \\
25.526\end{array}$ & 52.854 \\
\hline Storm Exposure & -.090 & 1.647 & -.054 & .957 & -3.497 & 3.318 \\
\hline
\end{tabular}

Table 40: Regression on plan quality - full model

The regression indicates that the only variable having a statistically significant correlation with hazard mitigation element quality is Population Density per Square Mile. While this initially appears to be discordant with findings above that other demographic variables correlate with hazard mitigation element quality, this is likely the result of using the non-parametric Spearman's Rho test for the main analysis. Spearman's Rho was used because it is better suited for analysis with a small number of cases than is regression 
testing. Because only Population Density per Square Mile was found to be a statistically significant predictor of hazard mitigation element quality, analysis was stopped at this point. 


\section{REFERENCES}

Alexander, D. (1997). The study of natural disasters, 1977-1997: some reflections on a changing field of knowledge. Disasters, 21(4), 284-304.

Alexander, E. R. (2005). Institutional transformation and planning: from institutionalization theory to institutional design. Planning Theory, 4(3), 209-223.

Allmendinger, P. (2002). Planning Theory. Hampshire, United Kingdom: Palgrave.

Association of State Floodplain Managers. (2007). National Flood Programs and Policies in Review. Madison: Association of State Floodplain Managers.

Austin, D. E. (2006). Coastal exploitation, land loss, and hurricanes: a recipe for disaster. American Anthropologist, 108(4), 671-691.

Baer, W. C. (1997). General plan evaluation criteria: An approach to making better plans. Journal of the American Planning Association, 63(3), 329-344.

Berke, P. R., \& Campanella, T. J. (2006). Planning for postdisaster resiliency. The ANNALS of the American Academy of Political and Social Science, 604, 192-207.

Berke, P. R., \& French, S. P. (1994). The Influence of State Planning Mandates on Local Plan Quality. Journal of Planning Education and Research, 13(4), 237-250.

Brody, S. D. (2003). Are we learning to make better plans? A longitudinal analysis of plan quality associated with natural hazards. Journal of Planning Education and Research, 23, 191-201.

Brody, S. D., Highfield, W. E., Ryu, H.-C., \& Spanel-Weber, L. (2007). Examining the relationship between wetland alteration and watershed flooding in Texas and Florida. Natural Hazards, 40, 413-428.

Brody, S. D., Zahran, S., Highfield, W. E., Grover, H., \& Vedlitz, A. (2008). Identifying the impact of the built environment on flood damage in Texas. Disasters, 32(1), $1-18$.

Brody, S. D., Zahran, S., Maghelal, P., Grover, H., \& Highfield, W. H. (2007). The rising costs of floods. Journal of the American Planning Association, 73(3), 330-345.

Brookings Institution. (2005). New Orleans after the storm: Lessons from the past, a plan for the future. Metropolitan Policy Program. Washington, D.C.: The Brookings Institution. 
Burby, R. J. (2005). Have state comprehensive planning mandates reduced insured losses from natural disasters? Natural Hazards Review, 6(2), 67-81.

Burby, R. J. (2006). Hurricane Katrina and the paradoxes of government disaster policy: bringing about wise governmental decisions for hazardous areas. The ANNALS of the American Academy of Political and Social Science, 604, 171-191.

Burby, R. J., \& Dalton, L. C. (1994). Plans can matter! The role of land use plans and state planning mandates in limiting the development of hazardous areas. Public Administration Review, 54(3), 229-238.

Burby, R. J., Beatley, T., Berke, P. R., Deyle, R. E., French, S. P., Godschalk, D. R., et al. (1999). Unleashing the Power of Planning to Create Disaster Resistant

Communities. Journal of the American Planning Association, 65(3), 247-258.

Burby, R. J., French, S. P., \& Nelson, A. C. (1998). Plans, Code Enforcement, and Damage Reduction: Evidence from the Northridge Earthquake. Earthquake Spectra, 14(1), 59-74.

Burningham, K., Fielding, J., \& Thrush, D. (2008). "It'll never happen to me": understanding public awareness of local flood risk. Disasters(32), 216-238.

Comfort, L. (2006). Cities at risk: Hurricane Katrina and the drowning of New Orleans. Urban Affairs Review, 41(4), 501-516.

Cutter, S. L., \& Emrich, C. T. (2006). Moral hazard, social catastrophe; the changing face of vulnerability along the hurricane coasts. ANNALS of the American Academy of Political Science, 604, 102-112.

Cutter, S. L., Boruff, B. J., \& Shirley, W. L. (2003). Social vulnerability to environmental hazards. Social Science Quarterly, 84(2), 242-262.

Davis, I. (2004). Progress in Analysis of Social Vulnerability and Capacity. In G. Bankoff, G. Frerks, \& D. Hilhorst (Eds.), Mapping vulnerability: disasters, development, and people (pp. 128-144). Sterling, VA: Earthscan Publications.

Deyle, R. E., \& Smith, R. A. (1998). Local government compliance with state planning mandates: The effects of state implementation in Florida. Journal of the American Planning Association, 64(4), 457-469.

Deyle, R. E., French, S. P., Olshansky, R. B., \& Paterson, R. G. (1998). Hazard Assesment: The Factual Basis for Planning and Mitigation. In R. J. Burby, Cooperating with Nature: confronting natural hazards with land use planning for sustainable communities (pp. 119-166). Washington, D.C.: Joseph Henry Press. 
Donner, W. R. (2007). The political ecology of disaster: and anaysis of factors influencing U.S. tornado fatalities and injuries, 1998-2000. Demography, 44(3), 669-685.

Ferris, J. M., \& Tang, S.-Y. (1993). The new institutionalism and public administration: An overview. Journal of Public Administration Research and Theory, 3(1), 4-10.

Flyvbjerg, B., \& Richardson, T. (2002). Planning and Foucalt: In Search of the Dark Side of Planning Theory. In P. Allmendinger, \& M. Tewdw-Jonesr, Planning Futures: New Directions for Planning Theory (pp. 45-62). London, England: Routledge.

Follett, M. P. (1925). The Giving of Orders. Dyanmic Administration. England: Pittman.

Follett, M. P. (1926, May 6). The Influence of Employee Representation in a Remoulding of the Accepted Type of Business Managers. Dynamic Administration. England: Pittman.

Follett, M. P. (1927). The Psychology of Consent and Participation. Dyanmic Administration. England: Pittman.

Fothergill, A., Maestas, E. G., \& Darlington, J. D. (1999). Race, Ethnicity and Disasters in the United States: A Review of the Literature. Disasters, 23(2), 156-173.

Frederickson, H. G., \& Smith, K. B. (2003). The Public Administration Theory Primer. Boulder, Colorado: Westview Press.

Furedi, F. (2007). From the narrative of the blitz to the rhetoric of vulnerability. Cultural Sociology, 1(2), 235-254.

Galea, S., Ahern, J., \& Karpati, A. (2005). A model of underlying socioeconomic vulnerability in human populations: evidence from variability in population health and implications for public health. Social Science \& Medicine, 60, 2417-2430.

Gerber, B. J. (2007). Disaster management in the United States: Examaning Key Political and Policy Changes. The Policy Studies Journal, 35(2), 227-238.

Glavovic, B. C., Saunders, W. A., \& Becker, J. S. (2010). Land-use planning for natural hazards in New Zealand: the settling barriers, the 'burning issues' and priority actions. Natural Hazards, 54, 679-706.

Godschalk, D. R., Brody, S., \& Burby, R. (2003). Public participation in natural hazard mitigation policy formation: challenges for comprehensive planning. Journal of Environmental Planning and Management, 46(5), 733-754. 
Gopalakrishnan, C., \& Okada, N. (2007). Designing new institutions for implementing disaster risk management: key elements and future directions. Disasters, 31(4), 353-372.

Greenberg, M. R., Lahr, M., \& Mantell, N. (2007). Understanding economic costs and benefits of catastrophes and their aftermath: a review and suggestions for the U.S. federal government. Risk Analysis, 27(1), 83-96.

Greif, A. (1998). Cultural beliefs and the organization of society: a historical and theoretical reflection on collectivist and individual societies. In M. C. Brinton, \& V. Nee (Eds.), The New Institutionalism in Sociology (pp. 77-104). New York, NY: Russel Sage Foundation.

Grunwald, M., \& Glasser, S. B. (2005, October 9). The slow drowning of New Orleans. Washington Post, The, p. A01.

Hamza, M., \& Zetter, R. (1998). Structural adjustment, urban systems, and disaster vulnerability in developing countries. Cities, 15(4), 291-299.

Harrison, P. (2002). A pragmatic attitude to planning. In P. Allmendinger, \& P. TewdwrJones, Planning Futures: New Directions for Planning Theory (pp. 157-170). London, England: Routledge.

Healey, P. (1999). Institutionalist analysis, communicative planning, and shaping places. Journal of Planning Education and Research, 19, 111-121.

Heijmans, A. (2004). From vulnerability to empowerment. In G. Bankoff, G. Frerks, \& D. Hillhorst, Mapping vulnerability: disasters, development, and people (pp. 115127). Sterling, VA: Earthscan Publications.

Henstra, D., \& McBean, G. (2005). Canadian disaster management policy: moving toward a paradigm shift? Canadian Public Policy, 31(3), 303-318.

Hewitt, K. (1995). Excluded perspectives in the social construction of disaster. International Journal of Mass Emergencies and Disasters, 13(3), 317-339.

Highfield, W. E., \& Brody, S. D. (2006). Price of Permits: Measuring the Economic Impacts of Wetland Development on Flood Damages in Florida. Natural Hazards Review, 7(3), 123-130.

Hung, H.-C., \& Chen, L.-C. (2007). The application of seismic risk-benefit analysis to land use planning in Taipei City. Disasters, 31(3), 256-276. 
Hutton, D., \& Haque, C. E. (2004). Human vulnerability, dislocation, and resettlement: Adaptation processes of river-bank erosion-induced displacees in Bangladesh. Disasters, 28(1), 41-62.

Inam, A. (1999). Institutions, routines, and crises. Cities, 16(6), 391-407.

Jennings, S. (2005). Back to Work: how people are recovering their livelihoods 12 months after the tsunami. Oxford, England: Oxfam International.

Kapucu, N. (2008). Collaborative emergency management: better community organizing, better public preparedness and response. Disasters, 32(2), 239-262.

King, D. (2008). Reducing hazard vulnerability through local government engagement and action. Natural Hazards, 47, 497-508.

Knabb, R. D., Rhome, J. R., \& Brown, D. P. (2006). Tropical Cylcone Report: Hurricane Katrina. Miami: National Hurricane Center.

Kreps, G. A. (1984). Sociological inquiry and disaster research. Annual Review of Sociology, 10, 309-330.

Kusenbach, M., Simms, J. L., \& Tobin, G. A. (2010). Disaster vulnerability and evacuation readiness: coastal mobile home residents in Florida. Natural Hazards, $52,79-95$.

Lewis Mumford Center. (2001). Ethnic Diversity Grows, Neighborhood Integration Lags Behind. Albany, New York: State University of New York at Albany.

Louisiana Department of Health and Hospitals. (2006, August 2). Deceased Reports. Retrieved April 26, 2010, from Reports of Missing and Deceased Persons: http://www.dhh.louisiana.gov/offices/page.asp?ID=192\&Detail=5248

Manyena, S. B. (2006). The concept of resilience revisted. 30(4), 433-450.

Muprhy, R. (2001). Nature's temporalities and the manufacture of vulnerability. Time and Society, 10(2/3), 329-348.

Nee, V., \& Ingram, P. (1998). Embeddedness and beyond: institutions, exchange, and social structure. In M. C. Brinton, \& V. Nee (Eds.), The New Institutionalism in Sociology (pp. 19-45). New York, NY: Russel Sage Foundation.

Nelson, A. C., \& French, S. P. (2002). Plan quality and mitigating damage from natural disasters. APA Journal, 68(2), 194-207. 
Neumayer, E., \& Plumper, T. (2007). The gendered nature of natural disasters: the impact of catstrophic events on the gender gap in life expectancy, 1981-2002. Annals of the Association of American Geographers, 97(3), 551-566.

O'Hare, G., \& Rivas, S. (2005). The landslide hazard and human vulnerability in La Paz City, Bolivia. The Geography Journal, 171(3), 239-258.

Oliver-Smith, A. (1996). Anthropological Research on Hazards and Disasters. Annual Review of Anthropology, 303-328.

Olshansky, R. B. (2001). Land use planning for seismic safety: the Los Angeles County Experience, 1971-1994. APA Journal, 67(2), 173-185.

Ostrom, E. (1990). Governing the Commons. Cambridge, MA: Cambridge University Press.

Parasuraman, S., \& Acharya, N. (2000). Analysing forms of vulnerability in a disaster. The Indian Journal of Social Work, 61(4), 53-63.

Patterson, J. M. (2002). Integrating Family Resilience and Family Stress Theory. Journal of Marriage and Family, 64, 349-360.

Peacock, W. G., Brody, S. D., \& Highfield, W. (2004). Hurricane risk perceptions among Florida's single family homeowners (in press). Landscape and Urban Planning.

Peguero, A. A. (2006). Latino disaster vulnerability: the dissemination of hurricane mitigation information among Florida's homeowners. Hispanic Journal of Behavioral Sciences, 28(5), 5-22.

Pelling, M. (2003). The Vulnerability of Cities: Natural Disasters and Social Resilience. London, England: Earthscan Publications.

Perry, R. W., \& Green, M. R. (1982). The role of ethnicity in the emergency decisionmaking process. Sociological Inquiry, 52(4), 306-334.

Pielke Jr., R. A., Gratz, J., Landsea, C. W., Collins, D., Saunders, M. A., \& Musulin, R. (2008). Normalized hurricane damage in the United States: 1900-2005. Natural Hazards Review, 9(1), 29-42.

Pittman, C. (2011, May 22). Powerful Interests Checkmated Growth Agency. St. Petersburg Times (FL).

Pittman, C. (2011, March 8). Scott wants Department of Community Affairs dismantled Gov. Rick Scott wants to gut the Department of Community Affairs, saying the 
agency in charge of managing Florida's growth is a red-tape-crazy job-killer standing in the way of economic recovery. Miami Herald.

Puszkin-Chevlin, A., \& Esnard, A.-M. (2009). Incremental evolution and devolution of Florida's coastal high hazard area policy. Journal of Environmental Planning and Management, 52(3), 297-313.

Quarantelli, E. L. (2003). Urban Vulnerability to Disasters in Developing Countries: Managing Risks. In A. Kreimir, M. Arnold, \& A. Carlin, Building Safer Cities: the Future of Disaster Risk (pp. 211-231). Washington, D.C.: World Bank.

Rocha, J. L., \& Christoplos, I. (2001). Disaster mitigation and preparedness on the Nicaraguan post-Mitch agenda. Disasters, 25(3), 240-250.

Selznick, P. (1996). Institutionalism "Old" and "New". Administrative Science Quarterly, 41(2), 270-277.

Senge, P. M. (1990). The Fifth Discipline. New York, USA: Doubleday.

Sengezer, B., \& Koc, E. (2005). A critical analysis of earthquakes and urban planning in Turkey. Disasters, 29(2), 171-194.

Skertchly, A., \& Skertchley, K. (2001). Catastrophe management: coping with totally unexpected extreme disasters. Australian Journal of Emergency Management, 16(1), 23-33.

St. Bernard, G. (2004). Toward the construction of a social vulnerability index theoretical and methodological considerations. Social and Economic Studies, 53(2), 1-29.

Steinberg, M., \& Burby, R. J. (2002, April). Growing safe: Is your comprehensive plan hazardous to your community's health? Planning Magazine, pp. 22-23.

Tewdwr-Jones, M. (2002). Personal dynamics and planning. In P. Allmendinger, \& M. Tewdwr-Jones, Planning Futures: New Directions for Planning Theory (pp. 6592). London, England: Routledge.

Tierney, K. (1999). Toward a critical sociology of risk. Sociological Forum, 14(2), $215-$ 242.

Turner, B. A. (1979). The social aetiology of disasters. Disasters, 3(1), 53-59.

U.S. National Committee for the Decade for Natural Disaster Reduction. (1991). A Safer Future: Reducing the Impacts of Natural Disasters. Washington: National Academy Press. 
Université Catholique de Louvain. (2010, February). EM-DAT. Retrieved April 24, 2010, from The OFDA/CRED International Disaster Database: http://www.emdat.be/

Université Catholique de Louvain. (2011). EM-DAT: The OFDA/CRED International Disaster Database. Retrieved from http://www.emdat.be/natural-disasters-trends

Vatsa, K. S. (2004). Risk, vulnerability, and asset-based approaches to disaster risk management. The International Journal of Sociology and Social Policy, 10/11, 148.

Wahlstrom, M. (2007). Before the next disaster strikes: the humanitatrian impact of climate change. UN Chronicle, 2, 30-32.

White, G. F. (1936). Notes on flood protection ans land-use planning. Planners' Journal, The, 3(3), 57-61.

Winchester, P. (2000). Cyclone mitigation, resource allocation and post-disaster reconstruction in south India: Lessons from two decades of research. Disasters, 24(1), 18-37.

Wisner, B., Blaikie, P., Cannon, T., \& Davis, I. (2004). At Risk (Second ed.). New York, New York, USA: Routledge.

Yahmed, S. B. (1994). Population growth and disasters. World Health, 47(3), 26.

Zahran, S., Brody, S. D., Peacock, W. G., Vedlitz, A., \& Grover, H. (2008). Social vulnerability and the natural and built environment: a model of flood casualies in Texas. Disasters, 32(4), 537-560. 
VITA

\title{
EVELIO ENRIQUE ASTRAY-CANEDA III
}

\author{
Born, Miami, Florida
}

$1997-2000$

A.A., Political Science and International Relations Miami-Dade Community College

Miami, Florida

2000-2002

B.A., Political Science and Business

Florida International University

Miami, Florida

2002-2003

Florida Department of Children and Families Miami, Florida

2003-2005

M.P.A, Public Administration

Florida International University

Miami, Florida

2003-2004

2004-2005

2006-2008

2006-2013

2008-2011

Silver Palm United Methodist Church Homestead, Florida

Florida Department of Children and Families Miami, Florida

Miami-Dade County Public Schools

Miami, Florida

Doctoral Candidate

Florida International University

Miami, Florida

MAXIMUS

Reston, Virginia, and Austin, Texas

2011-2013

Deloitte Consulting LLP

Austin, Texas 


\section{PUBLICATIONS AND PRESENTATIONS}

Astray-Caneda III, E., (October, 2006). Same-Sex Domestic Partner Benefits for Government Employees: Reasons, Examples, and Methods. Paper presented at the International Conference on Public Administration, Coventry, England.

Astray-Caneda III, E., (March, 2007). Same-Sex Domestic Partner Benefits for Government Employees: Reasons, Examples, and Methods. Paper presented at the annual meeting of the American Society for Public Administration, Washington, DC.

Astray-Caneda III, E., Azad, M., (September, 2007). Demography of a Disaster: Demographic Changes Along the Path of Hurricane Andrew in Miami-Dade County. Paper presented at the Southeastern Conference on Public Administration, Nashville, Tennessee.

Astray-Caneda III, E., (July, 2008). Determinants of Quality of County Participation in the Community Rating System of the National Flood Insurance Program. Poster presented at the annual Natural Hazards Workshop, Broomfield, Colorado.

Astray-Caneda III, E. (July, 2011). Variation of Quality of Hazard Mitigation Elements in Florida Coastal County Comprehensive Plans and Correlation with Social and Environmental Vulnerability Factors. Poster presented at the annual Natural Hazards Workshop, Broomfield, Colorado.

Astray-Caneda III, E. (2011). Offering Same-Sex Domestic Partner Benefits for Government Employees: Reasons, Examples, and Methods. Public Personnel Management, 40(2): 89-100.

Astray-Caneda III, E., (July, 2012). Local Mitigation Planning: Better Plans, More Resilient Communities? Presentation and panel presentation at the annual Natural Hazards Workshop, Broomfield, Colorado. 